San Jose State University

SJSU ScholarWorks

Master's Theses

Master's Theses and Graduate Research

1996

\title{
Dissociation rate constant measurement for double stranded DNA and protamine P1
}

Paul A. Poenisch

San Jose State University

Follow this and additional works at: https://scholarworks.sjsu.edu/etd_theses

\section{Recommended Citation}

Poenisch, Paul A., "Dissociation rate constant measurement for double stranded DNA and protamine P1" (1996). Master's Theses. 1332.

DOI: https://doi.org/10.31979/etd.75qp-33e8

https://scholarworks.sjsu.edu/etd_theses/1332

This Thesis is brought to you for free and open access by the Master's Theses and Graduate Research at SJSU ScholarWorks. It has been accepted for inclusion in Master's Theses by an authorized administrator of SJSU ScholarWorks. For more information, please contact scholarworks@sjsu.edu. 


\section{INFORMATION TO USERS}

This manuscript has been reproduced from the microfilm master. UMI films the text directly from the original or copy submitted. Thus, some thesis and dissertation copies are in typewriter face, while others may be from any type of computer printer.

The quality of this reproduction is dependent upon the quality of the copy submitted. Broken or indistinct print, colored or poor quality illustrations and photographs, print bleedthrough, substandard margins, and improper alignment can adversely affect reproduction.

In the unlikely event that the author did not send UMI a complete manuscript and there are missing pages, these will be noted. Also, if unauthorized copyright material had to be removed, a note will indicate the deletion.

Oversize materials (e.g., maps, drawings, charts) are reproduced by sectioning the original, beginning at the upper left-hand corner and continuing from left to right in equal sections with small overlaps. Each original is also photographed in one exposure and is included in reduced form at the back of the book.

Photographs included in the original manuscript have been reproduced xerographically in this copy. Higher quality $6^{n} \times 9^{n}$ black and white photographic prints are available for any photographs or illustrations appearing in this copy for an additional charge. Contact UMI directly to order.

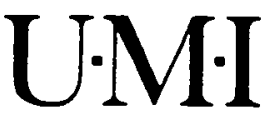





\title{
Dissociation Rate Constant Measurement for Double Stranded DNA and Protamine P1
}

\author{
A Thesis \\ Presented to \\ The Faculty of the Department of Chemistry \\ San José State University \\ In Partial Fulfillment \\ of the Requirements for the Degree \\ Master of Science
}

by

Paul A. Poenisch

August, 1996 
UMI Number: 1381443

Copyright 1996 by

Poenisch, Paul Arthur

All rights reserved.

UMI Microform 1381443

Copyright 1996, by UMI Company. All rights reserved.

This microform edition is protected against unauthorized copying under Title 17, United States Code.

\section{UMI \\ 300 North Zeeb Road \\ Ann Arbor, MI 48103}


(C) 1996

by Paul A. Poenisch

ALL RIGHTS RESERVED 
APPROVED FOR THE DEPARTMENT OF CHEMISTRY

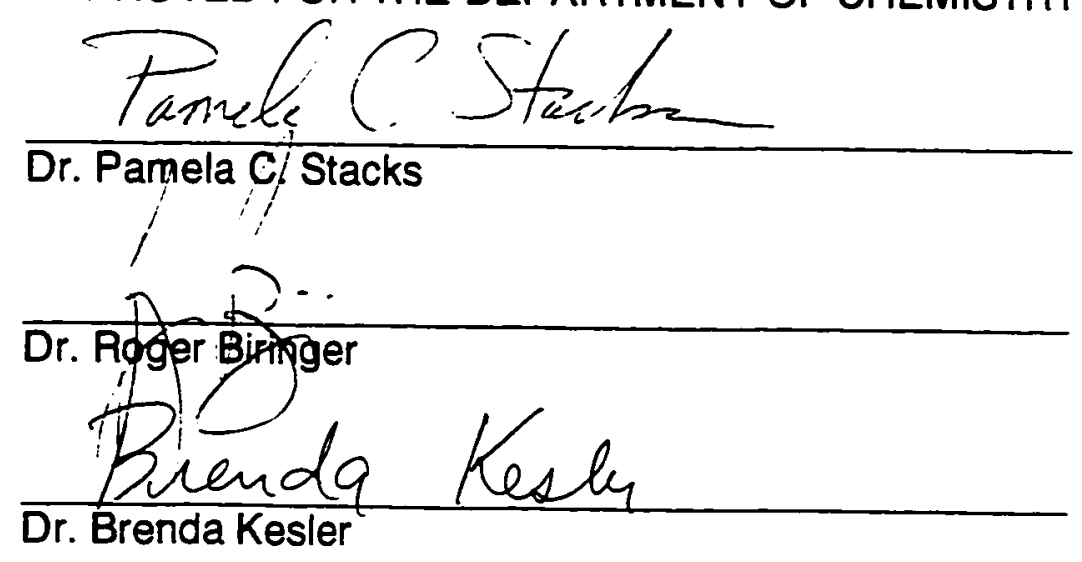

APPROVED FOR THE UNIVERSITY

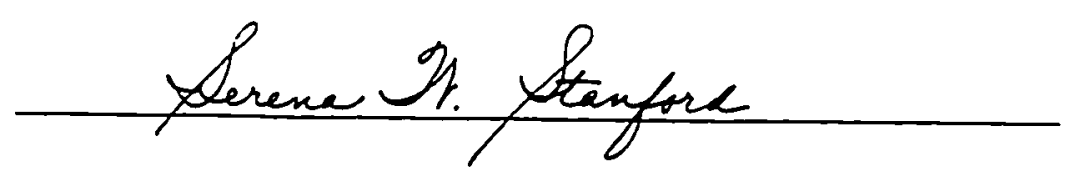




\title{
ABSTRACT \\ Dissociation Rate Constant Measurement for Double Stranded DNA and Protamine P1 \\ by Paul A. Poenisch
}

\begin{abstract}
Protamines are general DNA binding proteins utilized to form the very compact packages of genetic material in sperm cells. They are produced by a wide range of animals including trout, squid, echidna, opossum, rooster, boar and man.
\end{abstract}

Studies have shown that protamines bind extremely tightly but non-sequence specifically to double stranded DNA. Studies of free protamine interactions with free DNA are hampered by aggregation of the complexes. Work on protamines at San Jose State University has focused on the use of a solid substrate to immobilize the protein, thereby preventing aggregation.

This report describes measurement of the dissociation rate constant for bull protamine $\mathrm{P1}$ and DNA oligomers using a substrate resin with a carbamate linkage. The results indicate that the carbamate-linked substrate yields reproducible results for the dissociation rate constant and can be useful in future studies. Problems and limitations with the method are identified. 


\section{Acknowledgments}

This work has been supported by grant AREA grant \#1R15HD31689-01 from NIH. The experiments reported here would not have been possible without the help of Dr. Rod Balhorn and his research group at Lawrence Livermore National Laboratory, who kindly supplied both purified bull protamine $\mathrm{P} 1$ and the $12 \mathrm{bp}$ oligomers for the work.

I would also like to acknowledge the guidance and encouragement that I received from my research advisor, Dr. Pamela Stacks and the helpful suggestions and inputs I received from the other members of my research committee, Dr. Roger Biringer and Dr. Brenda Kesler. Additionally Dr. Stephen Branz provided me with several useful insights into support linkage reactions.

Finally this work, and indeed my whole chemistry education, would not have been possible without the enthusiastic and whole hearted support of my wife, Joan. 


\section{Table of Contents}

Page

Abstract . . . . . . . . . . . . . . . . . . . iv

Acknowledgments . . . . . . . . . . . . . . . . v

List of Tables . . . . . . . . . . . . . . . . . viii

List of Figures . . . . . . . . . . . . . . . . . . . ix

List of Abbreviations . . . . . . . . . . . . . . . . . . . xi

INTRODUCTION . . . . . . . . . . . . . . . . . . 1

Protamines . . . . . . . . . . . . . . . . . 1

Structure of Protamines . . . . . . . . . . . . . . . . 4

Biological Function of Protamines . . . . . . . . . . . . . 6

Protamine Studies . . . . . . . . . . . . . . . 11

Current Research Objectives . . . . . . . . . . . . . 14

MATERIALS AND METHODS . . . . . . . . . . . . . . . . . 19

Equipment . . . . . . . . . . . . . . . . . 19

Protamine . . . . . . . . . . . . . . . . . . . . 19

Buffers . . . . . . . . . . . . . . . . . . . . . . . . . . .

CDI Activated Resin . . . . . . . . . . . . . . . . . . . . 22

Thiol Activated Resin . . . . . . . . . . . . . . . . . . . . 23

Binding of Protamine to the CDI Activated Resin . . . . . . 23

DNA . . . . . . . . . . . . . . . . . . . 26

Labeling of the DNA Oligomers . . . . . . . . . . . . . . 27

Dissociation and Assay Procedure . . . . . . . . . . . . . . . 29

Data Analysis . . . . . . . . . . . . . . . . . . . . . . . 32 
Table of Contents (continued)

Page

Mullipie Binding Miodes . . . . . . . . . . . . . . . 37

RESULTS . . . . . . . . . . . . . . . . . . 40

Assays for Binding of Protamine P1 to the Support . . . . 40

Resin Leaching . . . . . . . . . . . . . . . 44

Dissociation Rate Constant Determination at $25^{\circ} \mathrm{C}$. . . . . .47

Slow Rate Constant . . . . . . . . . . . . . . . . . . 66

DISCUSSION . . . . . . . . . . . . . . . . . . . . . . . . 44

Utility of 1-1'-carbonyldiimidazole Activated Resins for Protamine Studies . . . . . . . . . . . . . . . . . 74

Protamine-DNA Complex Dissociation Rate . . . . . . . . $\quad .77$

Origin of the Slow Rate Constant . . . . . . . . . . . . 80

Context of this Experimental System. . . . . . . . . . 81

CONCLUSIONS . . . . . . . . . . . . . . . . . . . 84

Protamine Substitution on Imidazolyl Carbamate Activated

Resin. . . . . . . . . . . . . . . . . 84

Dissociation of DNA and Bull Protamine P1 . . . . . . . . .85

Future Directions . . . . . . . . . . . . . . . 86

REFERENCES . . . . . . . . . . . . . . . . . . . . . 88

APPENDIX A: Calculation of Allowable Molar Surface Concentration for

Modified Affinity Resins . . . . . . . . . . . . . . 91

APPENDIX B: Calculation of Specific Activity for Labeled DNA . . . .94 


\title{
List of Tables
}

\begin{abstract}
Page
Table 1: Protamine Concentration Eifects on DNA Binding . . . . . 42

Table 2: Resin and DNA Preparation . . . . . . . . . . . . . 48

Table 3: Radioactivity Determination for Experiments 15 and 22. . . . 52

Table 4: Slow Rate Constant Determinations, $25^{\circ} \mathrm{C}$. . . . . . . .58

Table 5: Fast Rate Constant Determinations, $25^{\circ} \mathrm{C}$. . . . . . . .64

Table 6: Slow Rate Constant Experiment Labeling Mixtures . . . . . 71

Table 7: Dilution Schedule for Slow Rate Constant Experiment . . . 71
\end{abstract}




\section{List of Figures}

Page

Figure 1: Structure of histone/DNA complex . . . . . . . . . . . 2

Figure 2: Protamine P1 across species . . . . . . . . . . 5

Figure 3: Proposed protamine disulfide structure . . . . . . . . 7

Figure 4: Intermolecular protamine disulfide cross-linking models . . 8

Figure 5: Progression of DNA binding proteins in the maturation of sperm cell . . . . . . . . . . . . . . . 10

Figure 6: Multiple binding site model for protamine-DNA complex aggregation . . . . . . . . . . . . . . . 12

Figure 7: Disulfide bond aggregation mechanism . . . . . . . 13

Figure 8: 1,1'-Carbonyldiimidazole activation reaction . . . . . . . 16

Figure 9: Imidazolyl carbamate reactions . . . . . . . . . . . . 17

Figure 10: Dissociation experiment protocol . . . . . . . . . 30

Figure 11: Combination of two rate constants . . . . . . . . . 38

Figure 12: DNA binding assay results . . . . . . . . . . . . . 41

Figure 13: Resin leakage data from experiment 19a . . . . . . 46

Figure 14: Ratio of filter bound label to total label for experiment 15. . . 49

Figure 15: Ratio of filter bound label to total label for experiment $22 . \quad 50$

Figure 16: Log-linear plot of blank and unmodified resin data and models for experiment 22 . . . . . . . . . . . . . . 55

Figure 17: Log-linear plot of modified resin data and slow rate constant model for experiment 22. . . . . . . . . . . . . . . 56 


\section{List of Figures (continued)}

Page

Figure 18: Data from experiment is with siow rate constant siripped out . . . . . . . . . . . . . . . . . 59

Figure 19: Data from experiment 22 with slow rate constant stripped out . . . . . . . . . . . . . . . . . 60

Figure 20: Stripped data for modified resin from experiment 15 and fast rate model . . . . . . . . . . . . . . . 62

Figure 21: Stripped data for modified resin from experiment 22 and fast rate model . . . . . . . . . . . . . . . . 63

Figure 22: Combined normalized data for the fast rate constant at $25^{\circ} \mathrm{C}$. . . . . . . . . . . . . . . . 65

Figure 23: Ratio of filter bound label to total label for $\mathrm{P} 1$-thiol linked resin . . . . . . . . . . . . . . . . . 67

Figure 24: Slow rate constant model for thiol linked resin and observed data . . . . . . . . . . . . . . . . .68

Figure 25: Stripped data for modified thiol linked resin and fast rate model . . . . . . . . . . . . . . . .69

Figure 26: Test to determine the source of the slow rate constant. .73

Figure 27: Surface area model for affinity resins . . . . . . . . .92 


\section{Table of Abbreviations}

Amino Acids:
A alanine
M methionine
C cysteine
$P$ proline
F phenylalanine
Q glutamine
G glycine
$\mathrm{R}$ arginine
H histidine
$S$ serine
1 isoleucine
$T$ threonine
$K$ lysine
$\checkmark$ valine
L leucine
$Y \quad$ tyrosine

Reagents:
ATP
Adenosine-5'-triphosphate
CDI
1,1'-carbonyldiimidazole

DNA

Deoxyribose nucleic acid (double stranded, unless

otherwise noted)

DTT Dithiothreitol

EDTA Ethylenediaminetetraacetic acid

HEPES 4-(2-hydroxyethyl)-1-piperazineethanesulfonic acid

TAPS 3-[tris(hydroxymethyl)-methylamino]-1-propanesulfonic acid

TRIS Tri(hydroxymethyl)aminomethane

TRIS-HCl Tri(hydroxymethyl)aminomethane hydrochloride salt

Other:

bp base pair(s) 


\section{Introduction}

Protamines. Somatic cells of eukaryotes confine most of their genetic material to the interior of their nuciei. The DNA that encodes the genetic information for these cells is organized and packed in the nucleus by complexing with a group of basic proteins known as histones. These proteins (of which there are five subtypes) form spindle shaped cores (containing two copies of each of four protein subtypes) around which the DNA is wrapped. The fifth protein subtype locks the DNA in place as shown in Figure $1 .{ }^{1}$

It has been known since at least 1874 that during the maturation of sperm cells of some fish, notably trout and salmon, a group of basic non-histone proteins is produced. ${ }^{2}$ in the salmon sperm cells, these proteins appeared to substitute for the histone proteins that normally package DNA in the nucleus of cells.2,3,4 The proteins were given the name protamines. There are two distinguishing characteristics of these proteins; a large proportion of their amino acid residues are arginines and when combined with DNA the volume of the nucleus is greatly reduced compared with other types of cells.

Later studies by many researchers found proteins in the sperm of a wide range of animals that are closely related to the protamines found in salmon sperm. These species included trout ${ }^{5}$, chicken 6 , boar ${ }^{7}$, bulli, opossum ${ }^{9}$, echidna ${ }^{10}$, cuttlefish ${ }^{11}$, mouse ${ }^{12}$, rat $^{13}$, man $^{14}$ and many other species of animal.

Further studies showed that there were distinct differences between the protamines of some of these species. In the fish species, the proteins contained only a single functional domain, an arginine rich area. The amino and carboxyl termini did not appear to be functionally differentiated. Also, the fish protamine did not contain any cysteine or histidine residues. For the fowl 


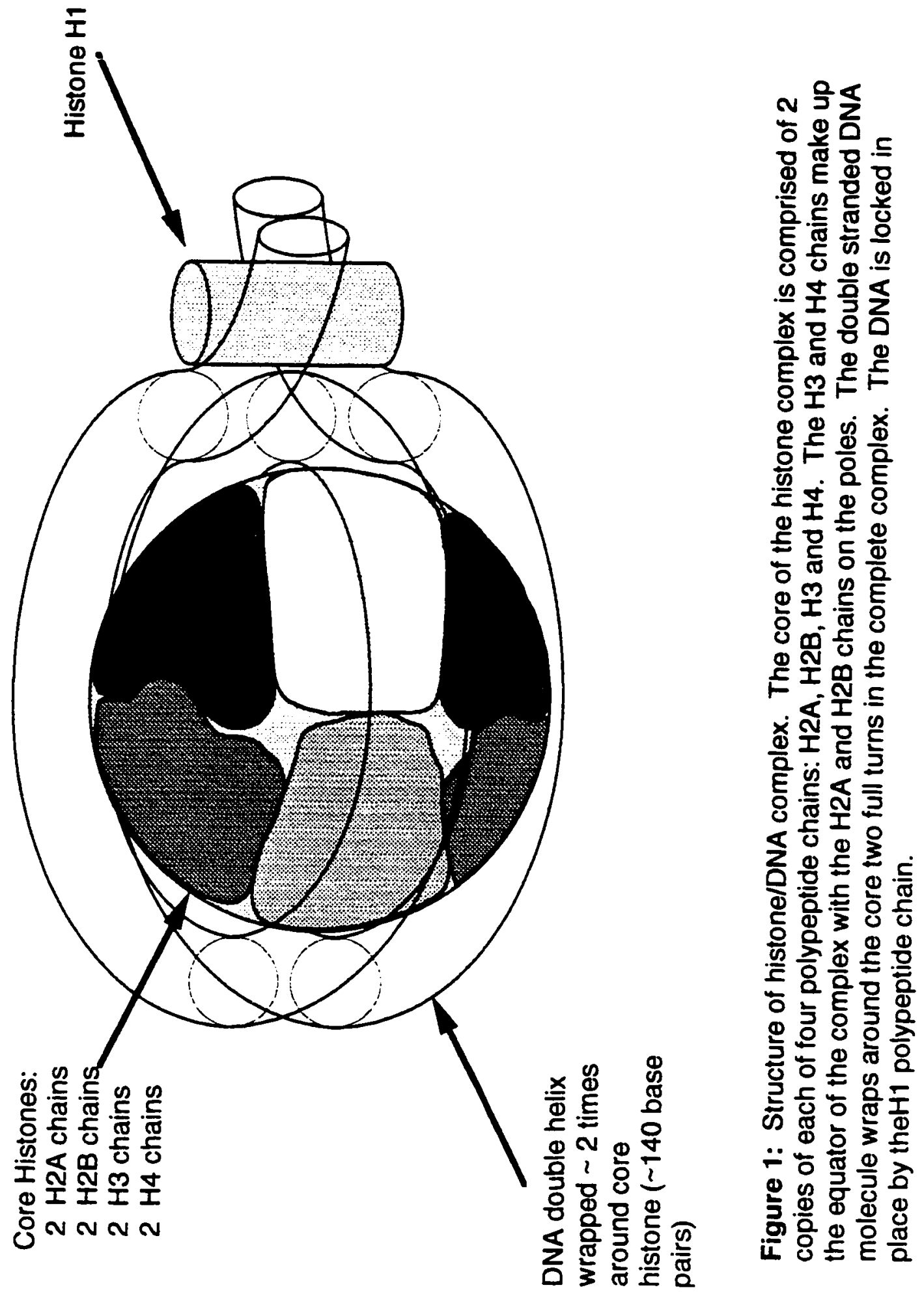


species, the proteins had three distinct domains; an amino terminus, a carboxyl terminus and the arginine rich region, but again, no cysteine or histidine residues.

It was found that there were two types of arginine rich protamine-like proteins in mammals. These two types of proteins have been given the designations P1 (the protein most like the fish and fowl proteins) and P2 (the protein type that appears to be unique to mammals). The mammalian P1 has a high arginine content; similar to that found in birds. In addition, there is a higher proportion of cysteine residues in the mammalian P1 as compared to the avian form of the protein. As a general convention, all of these proteins, no matter what species they come from, are now called protamines.

P2, which is found in some (but not all) mammals, is usually represented by a small family of related proteins all of which are minor variations on a single primary structure. These proteins, in addition to the usual arginine, have a relatively high percentage of histidine.

Also, the P2 proteins are generally somewhat larger with a different regional structure than the P1 proteins (there is some indication that a zinc finger structure may be present). ${ }^{15}$ The distribution of this second family of proteins across mammalian species is still somewhat puzzling; while mice, horses and humans possess these protamines, rats, bulls and rams lack them. There is some indication that the gene for P2 type proteins may be present in many mammals that do not express the protein. ${ }^{16}$ Therefore, the lack of P2 in the sperm of certain mammals may be an indicator or a change in the expression of the genes involved in spermatogenesis rather than a change in the genetic content. 
The binding between double stranded DNA (DNA) and the protamine proteins is known to be quite strong, with values of $K_{c}$ reported as $3.4 \times 10^{6}$ $M^{-1}$ for boar, $1.8 \times 10^{7} \mathrm{M}^{-1}$ for herring ${ }^{17}$ and $3.3 \times 10^{7} \mathrm{~N}^{-1}$ for chicken. Separation of DNA from protamines in sperm cell nuclei requires conditions significantly more extreme than the conditions needed to separate histones from DNA. Histone/DNA complexes from the nuclei of somatic cells can generally be separated by $\mathrm{CsCl}$ gradient centrifugation. ${ }^{18}$ Mammalian protamine/DNA complexes usually require a reducing environment (such as that provided by the addition of dithiothreitol 12 or mercaptoethanol and iodoacetate ${ }^{7}$ ) in addition to a high ionic concentration to separate the protein from the DNA.

This tight binding of DNA is one of the most biologically important features of protamines. One of the main purposes of the protamines is to produce a dense, compact, stable sperm head in which to carry the DNA. For this reason, characterization of the thermodynamics and kinetics of the DNA/protamine system, for both natural and modified protamines, has been a key goal of protamine studies from the beginning.

The study described here is designed to examine one of the kinetic parameters, the dissociation rate constant $k_{2}$, for the P1/DNA system (bull P1 in this case).

Structure of Protamines. Protamine P1 is a highly conserved protein. Figure 2 shows a comparison of $P 1$ found in several species. As can be seen in the Figure, all of the proteins have a central motif of repeated sections of four to seven arginines $(R)$ separated by one or two other uncharged residues. In addition to this section of arginine repeats, the fowl and mammalian $\mathrm{P} 1$ proteins have specialized amino and carboxyl terminal regions 


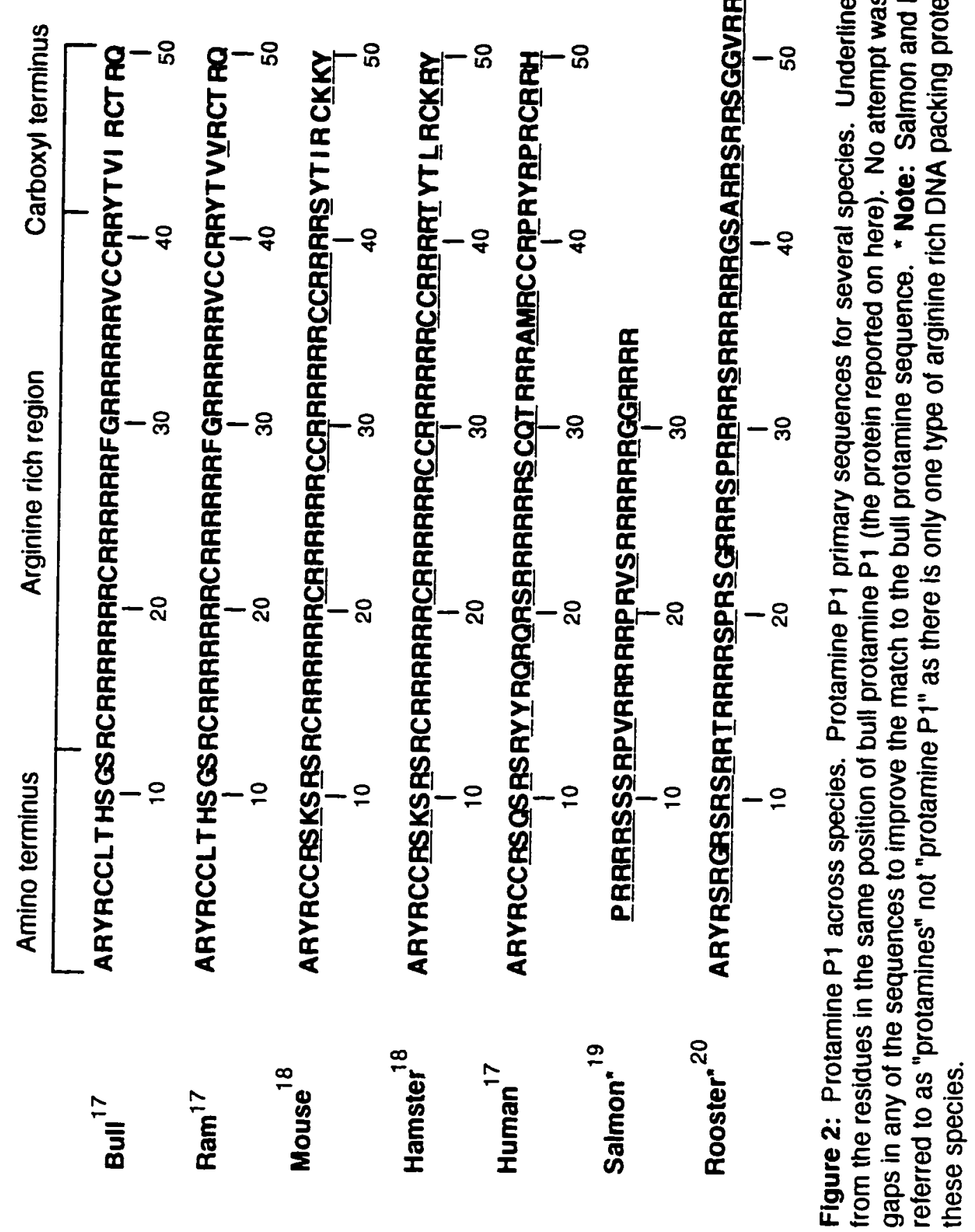


to the molecules. The mammalian proteins also have several cysteine (C) residues (scattered throughout the sequence) which the fowl proteins lack.

Work by Bathorn at al. ${ }^{19}$ has identified both intia- and intermolecular disulfide bonds formed by these cysteine residues in bull protamine P1. The intramolecular disulfide bonds identified by Balhorn makes a structure containing two "hair-pin" turns for bull P1 likely, as shown in Figure 3. This type of structure may have some relevance to the work reported here in that it may effect the mode in which bull protamine $\mathrm{P} 1$ (and other $\mathrm{P} 1$ proteins) binds to the solid substrates used.

In addition to the intramolecular disulfide bonds proposed by Balhorn, intermolecular disulfide bonds were also expected. It has been known for some time that it is necessary to use conditions sufficient to reduce disulfide bonds to separate condensed sperm chromatin from protamines.7,12 Figure 4 shows the model proposed by Balhorn that is consistent with the intermolecular bonds that his group has identified for bull protamine P1.

One other feature that can be seen in Figure 2 that is significant to this study is that bull $P 1$ (and human $P 1$ ) lacks any lysine $(K)$ residues. This means that the only primary amine group possessed by these proteins is at their amino terminus.

Biological Function of Protamines. Species that produce protamines, produce them only in sperm cells. Protamines have been reported in mammals, birds, some of the bony fish and a few invertebrates. ${ }^{11}$ There appears to be very few reports of protamine in the sperm cells of reptiles or amphibians. However, this may be due to a paucity of studies of these species, not due to a lack of the proteins. One of the main functions of protamines, apparently, is the compacting of the genetic material to be 


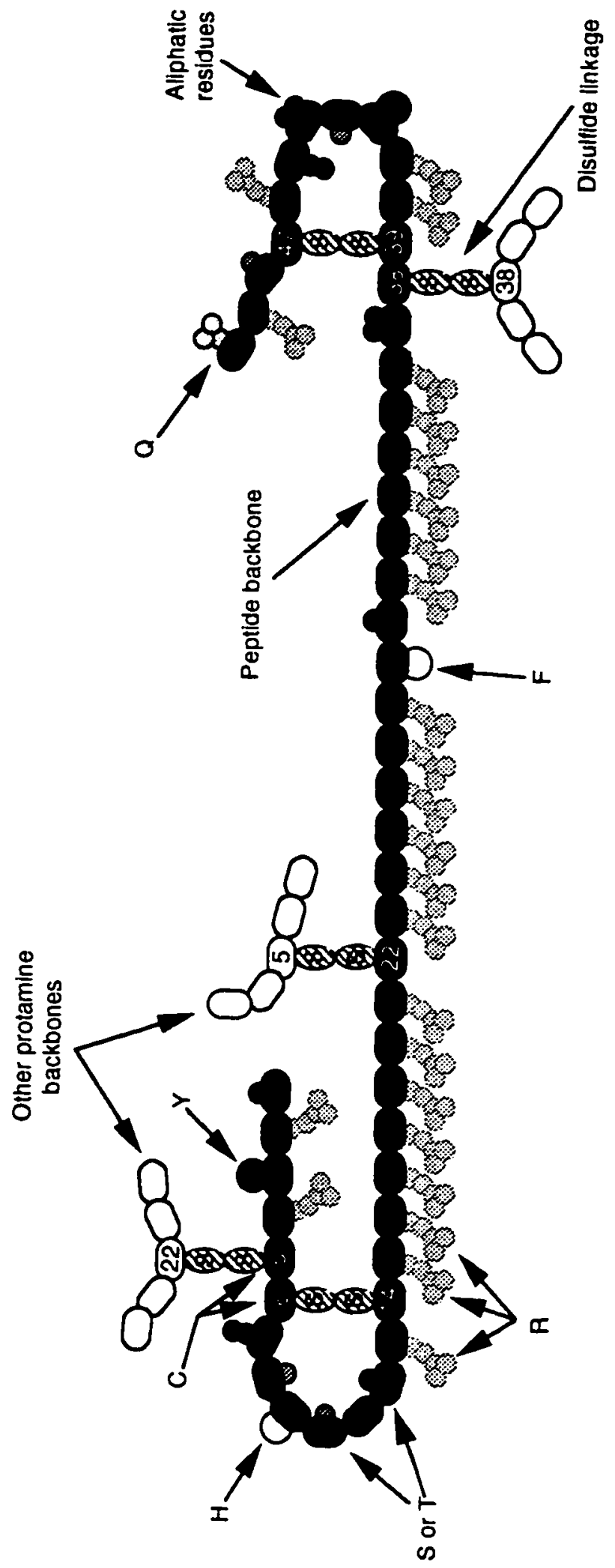

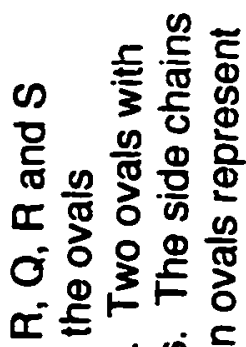

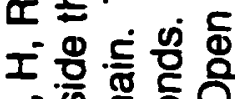
एँ ن

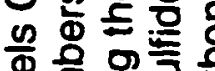
을 옥용 뜨 든 음 음

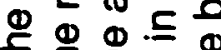
Еฐ

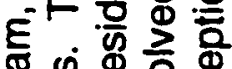
ㅎ⿺ㄴ

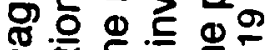
के

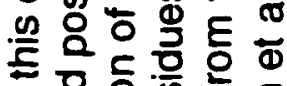

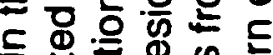
夏 Ф음 용. 음

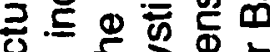

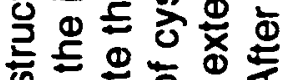
क 은 男흥 응

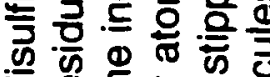
政

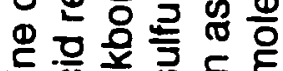
든 흥 的

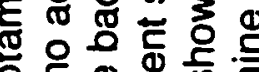
흐웡

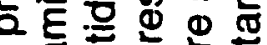
宁 훙ㅎㅀ

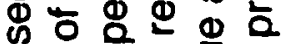
요웡

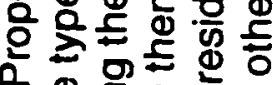

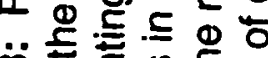
in ญ 怘

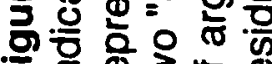
屰.돈ㅎㅀ 
A

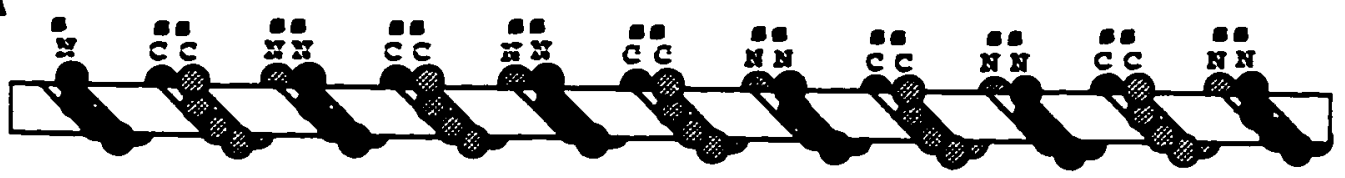

B

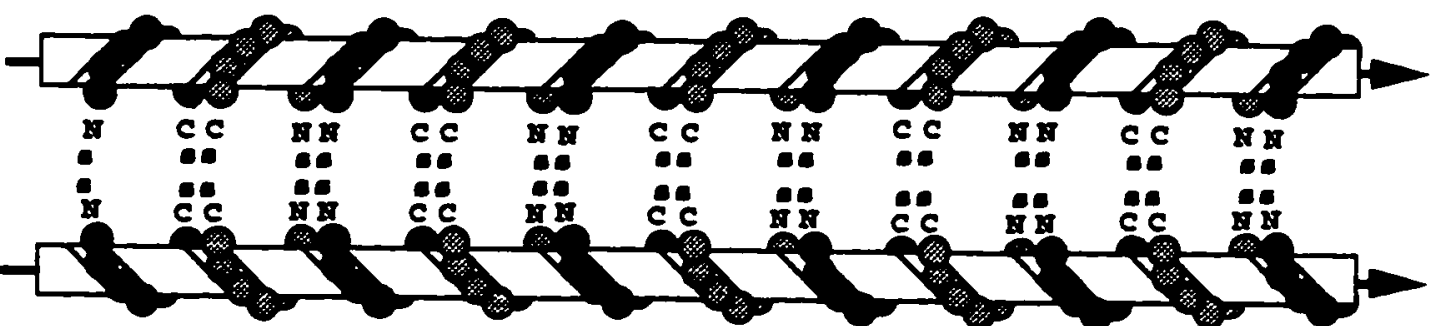

C
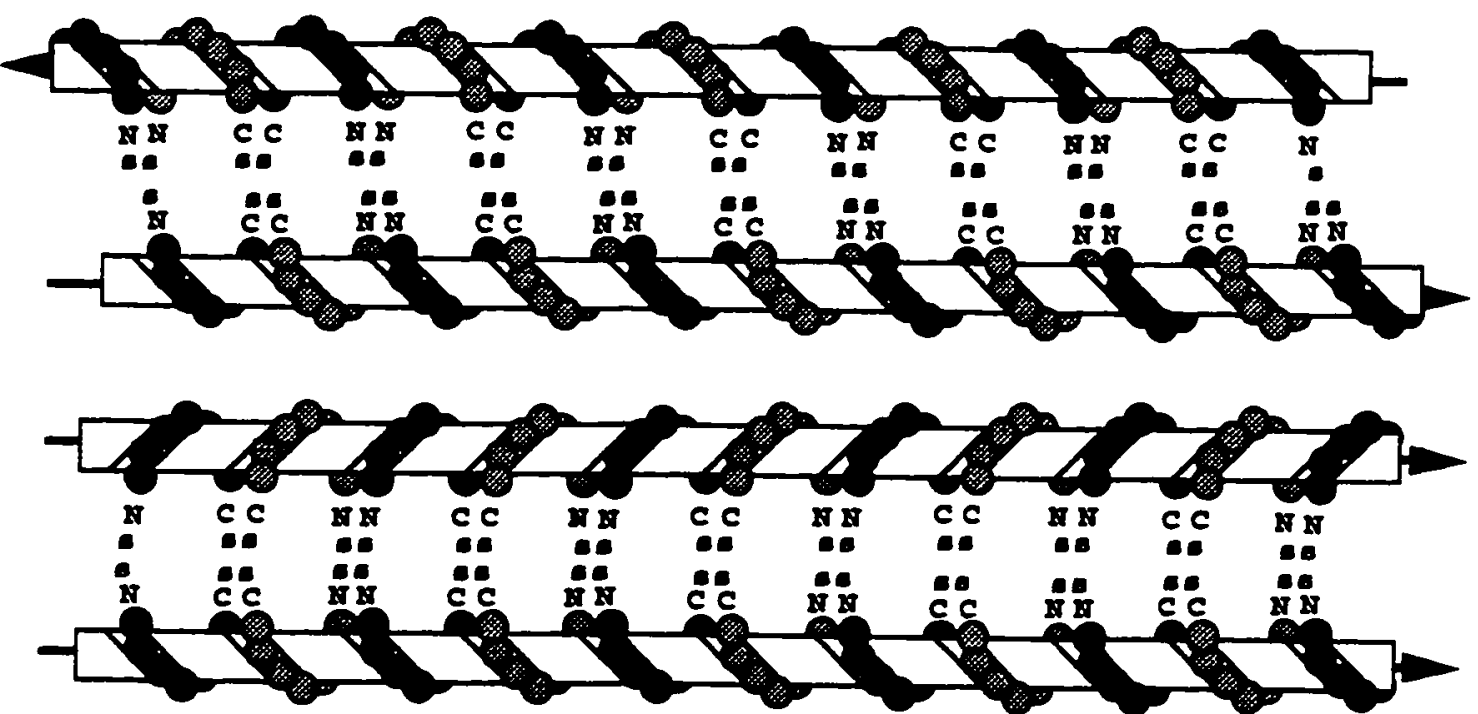

Figure 4: Intermolecular protamine disulfide cross-linking models. (A) The orientation of each protamine molecule alternates along the same DNA strand. Cross-links are formed between neighbors along the entire length of the DNA. (B) Each protamine is oriented in the same direction along the DNA strand, and the intermolecular disulfides are formed between protamines on two different strands running in the same direction. (C) The orientation of each protamine molecule alternates along the same DNA strand. Correct intermolecular cross-links can form between protamines on neighboring DNA strands running in either direction. Individual protamine molecules are schematically represented with only the carboxy- $(C)$ or amino-terminal $(\mathrm{N})$ intermolecular disulfides. 19 
transmitted by the sperm cell into an easily transported package. Because the stem cells that form sperm have their DNA packaged with histones, at some point in the development of the sperm, the histones must be replaced by protamines.

Studies have shown that this transition from histones to protamines proceeds in stages as illustrated in Figure 5.3,4,5,13,20 Initially, some of the histones are replaced by transition proteins. Transition proteins are similar to mammalian protamines in that they contain substantial amounts of arginine and cysteine, are basic, and have similar electrophoretic mobilities. ${ }^{20}$ These in turn are replaced by modified protamines which also replace the remaining histones. These protamines are modified by the phosphorylation of serine and/or threonine residues. The purpose of this phosphorylation is yet to be determined but may have the function of lowering the DNA binding equilibrium constant 21 or in forming salt bridges that serve to orient the protamines (Balhorn, personal communication). Either of these effects may be important for ensuring the binding of protamine to DNA in the proper orientation, but further work is needed to determine the role of phosphorylation in this process.

Gradually, as maturation of the sperm cell proceeds, there is an increase in the proportion of protamine to histone on the DNA; at the same time the phosphorylation of the protamine is modulated by the cell. In the final stage of sperm maturation, most of the histone has been replaced with protamine and most, if not all, of the phosphate groups are removed from the protamines. The amount of histones remaining in the sperm head is species dependent but generally not more than $15 \% .{ }^{14}$ 

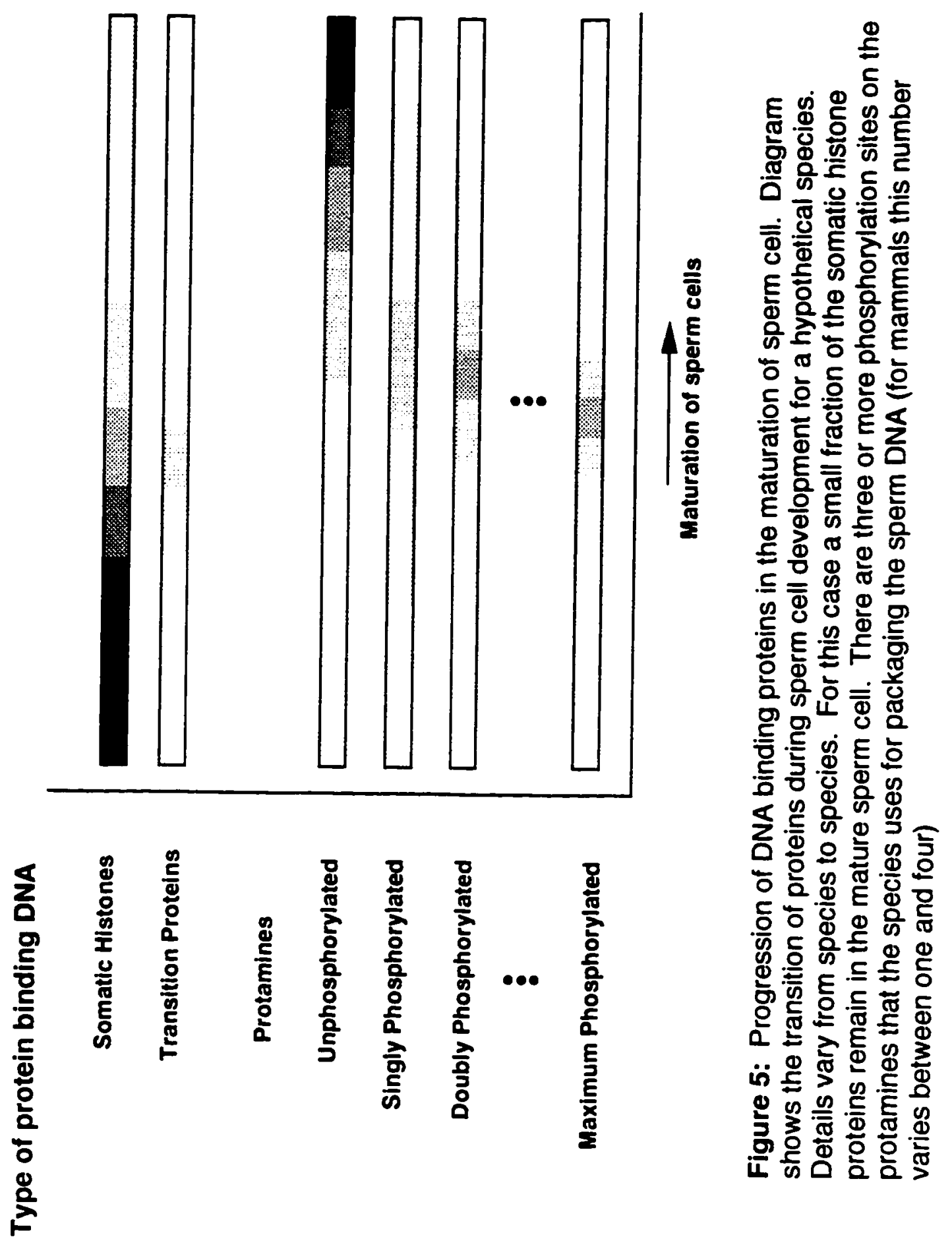
After fertilization of an egg by the sperm cell, this procedure of packing the DNA with protamine must be reversed to release the genetic material in the sperm for the development of the embryo. At this point, very little is known about the biochemistry of this process. There has been some speculation that protamine $\mathrm{P} 2$ is used by some mammals to tag particular parts of the genetic material for early release from protamine binding, 15,21 but this has yet to be tested, much less proved.

Protamine Studies. Most studies of protamine interactions with DNA have been done in free solutions. One of the main difficulties in studying protamine in this fashion is that the complexes formed tend to aggregate and then precipitate. There are at least two possible mechanisms for this aggregation. The first mechanism involves the binding of both the individual DNA and protamine molecules to more than one substrate as illustrated in Figure 6. This results in chains of alternating DNA and protamine molecules. A second mechanism, illustrated in Figure 7 is polymerization of the protamine through disulfide bridges (for the mammalian protamine P1's).

There is evidence that both of these mechanisms occur. Protamines from all species tend to aggregate in the presence of double stranded DNA, indicating that disulfide bridges are not required for the process. For the second mechanism, it has been shown that segments of DNA that are too short to bind to more than one protamine binding site also cause the protein to aggregate and fall out of solution.

A two phase system can be used to avoid the aggregation problems. By attaching the DNA or protamine to a solid substrate and allowing the other molecule to move freely in a liquid phase, aggregation of the material is prevented. In methods developed at San José State University, protamine 


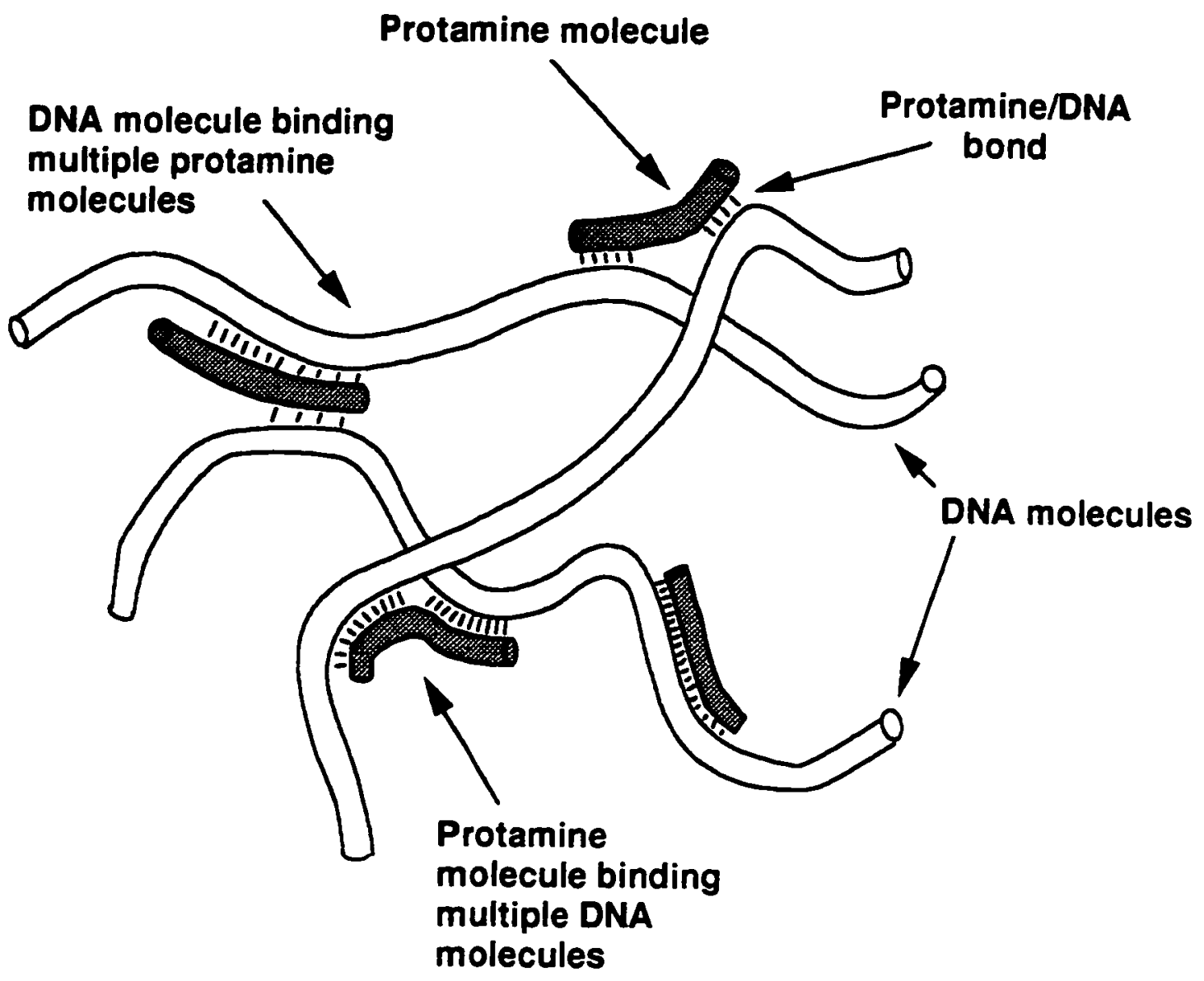

Figure 6: Multiple binding site model for protamine/DNA complex aggregation. Each protamine molecule binds to two or more DNA molecules, each DNA molecule binds two or more protamine molecules. If each molecule binds exactly two other molecules a chain is formed. If the average molecule binds over two molecules, a cross linked network of molecules is formed which will drop out of solution as an aggregate. 


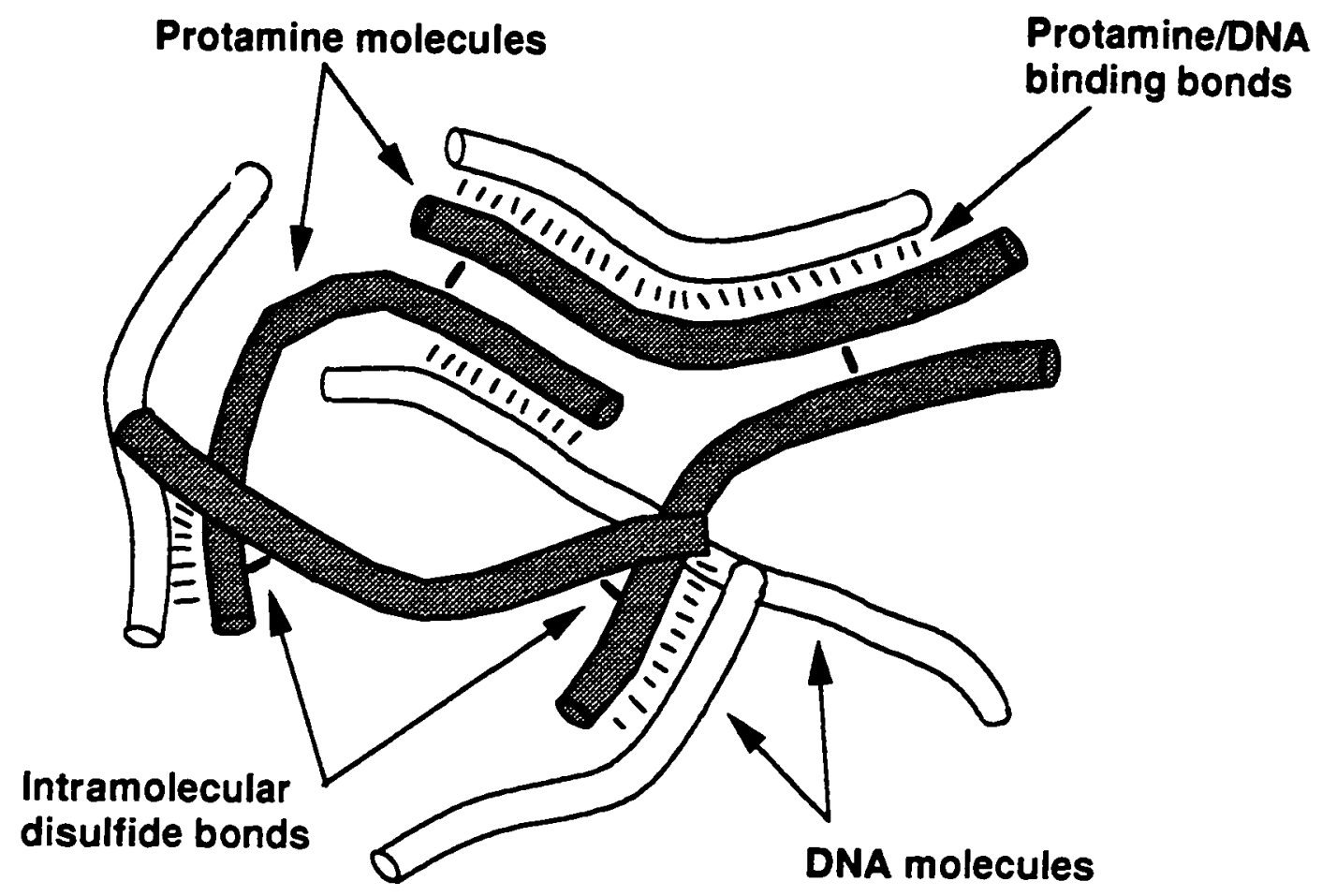

Figure 7: Disulfide bond aggregation mechanism. Protamine/DNA complex aggregation due to intermolecular disulfide bonds between protamine molecules. Each protamine molecule binds one or more DNA molecules, each DNA molecule binds one or more protamine molecule. Protamine molecules bind each other through disulfide linkages. Because there are three sulfhydride groups available on each protamine molecule for intermolecular bonding (Balhorn model) a network of molecules can form. 
molecules are attached to a resin bead substrate that is then used in binding experiments with ${ }^{32} \mathrm{P}-5^{\prime}$ or ${ }^{33 \mathrm{P}-5^{\prime}}$ labeled DNA oligomers. ${ }^{22}$ Attachment of the protamine to a substiate at a low surface density and the use of reiativeiy short oligomers ensures that even if a protamine molecule binds with more than one DNA molecule there are no other protamine molecules close enough to bind to the same molecule of DNA. This methodology allows for the characterization of the protamine DNA interaction for isolated molecules, something that is very difficult to accomplish in free solution.

Calculations in Appendix A show that the amount of protein that can be bound to the surface of resin beads and still allow independent binding of DNA molecules by each protein molecule is quite small. This implies that the detection method that is required in this protocol must be very sensitive. The one chosen for this work is the use of radiolabeled DNA. Use of 32P or 33p for the radiolabel allows quantities of DNA as small as $8.8 \times 10^{-18}$ moles to be reliably detected (33P, 50\% detection efficiency, background of $25 \mathrm{cpm}$, detection limit of twice background, 100\% labeling, DNA labeled on one end only and 5 minute count time).

Current Research Objectives. Previous studies have found that the binding of DNA to protamine P1 immobilized on resin beads is very fast. ${ }^{22}$ The methods described below in the methods and materials section are probably not suitable for accurate measurement of the association constant, $k_{1}$, for DNA and protamine P1. For that reason, this study has concentrated on evaluation of the dissociation constant for the system, $\mathrm{k}_{2}$.

Previous work at SJSU used a resin that was activated with a thiol group. This group forms a strong bond to the various cysteine residues of mammalian protamines. Because there are several different cysteines that 
could in theory bind to the resin thiol group, there should be some distribution of configurations of protamine binding to the resin. This distribution of configurations may contribute to variability in the results of experiments that use the thiol resin. This work is an attempt to address that issue.

As mentioned earlier, bull protamine P1 completely lacks lysine residues. This is not a characteristic that is common to all mammalian protamine P1's, as can be seen in Figure 2. Fortunately, this lack in bull P1 allows for an alternate, unique binding group to be used to attach the protein to an activated resin. The only primary amine group on bull $\mathrm{P} 1$ is the amino terminus of the molecule. A resin that is activated with a group that binds exclusively, or even predominately, to primary amines would bind bull P1 at only a single site. By using an attachment method that predominantly produces a single binding site on the protein, the number of possible configurations that the protein can take while attached to the resin is greatly reduced from the number that could result from multiple binding sites. Additionally, this binding site involves attachment of the protein to the resin well away from the arginine rich central region of the protein that is believed to be directly involved in the binding of DNA (at least in the sense of the primary structure).

In 1979 Bethell et al.23 reported an activation method for agarose gels used for affinity columns that reacted mainly with primary amines. The activation method relied on the reaction of 1,1'-carbonyldiimidazole (CDI) with the free hydroxyl groups of the agarose backbone. This reaction, resulting in an imidazolyl carbamate-agarose matrix, is shown in Figure 8.

When the imidazolyl carbamate group is exposed to primary amino groups under alkali conditions, the two reactions shown in Figure 9 take place. The 


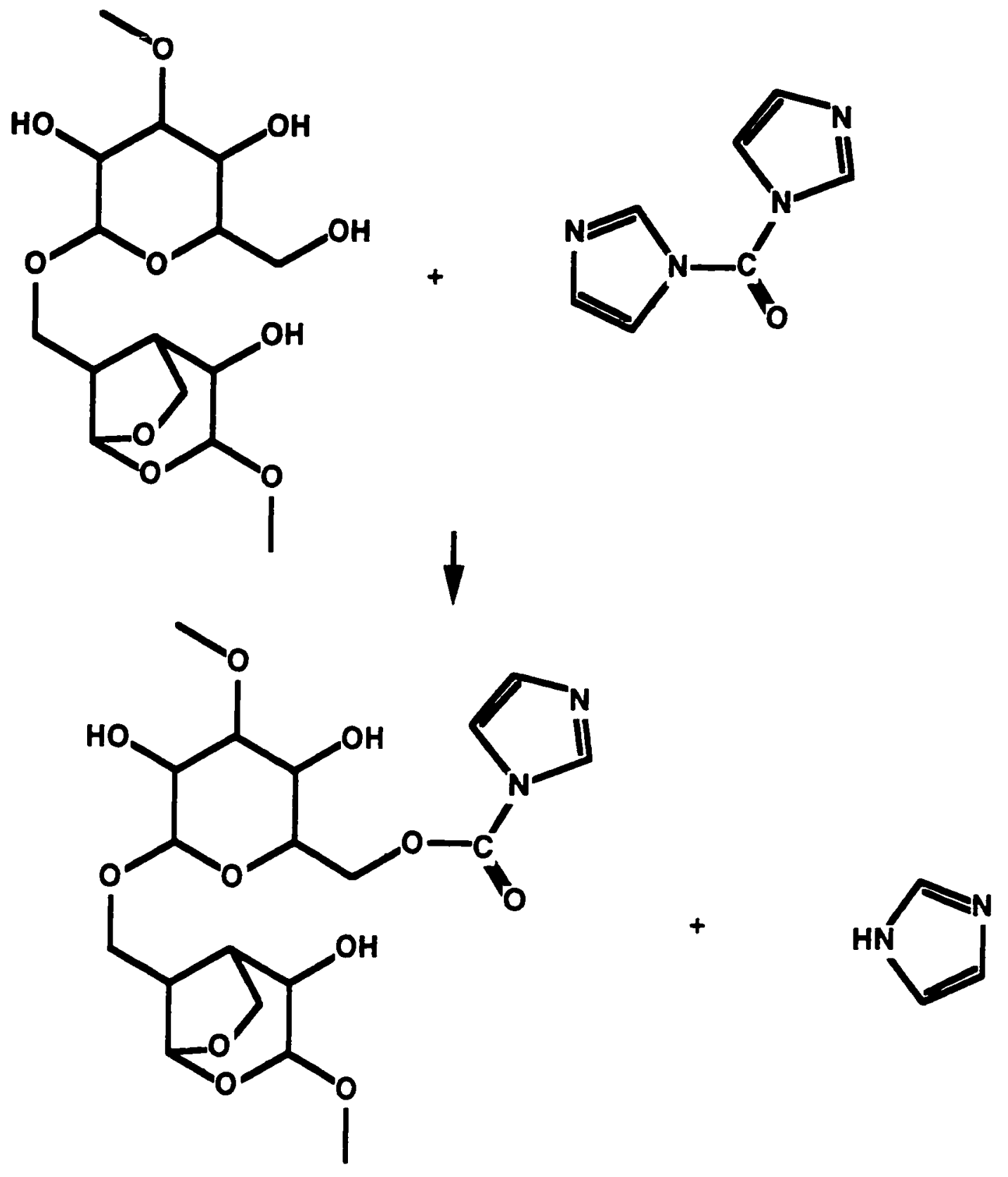

Figure 8: 1,1'- Carbonyldiimidazole activation reaction. 


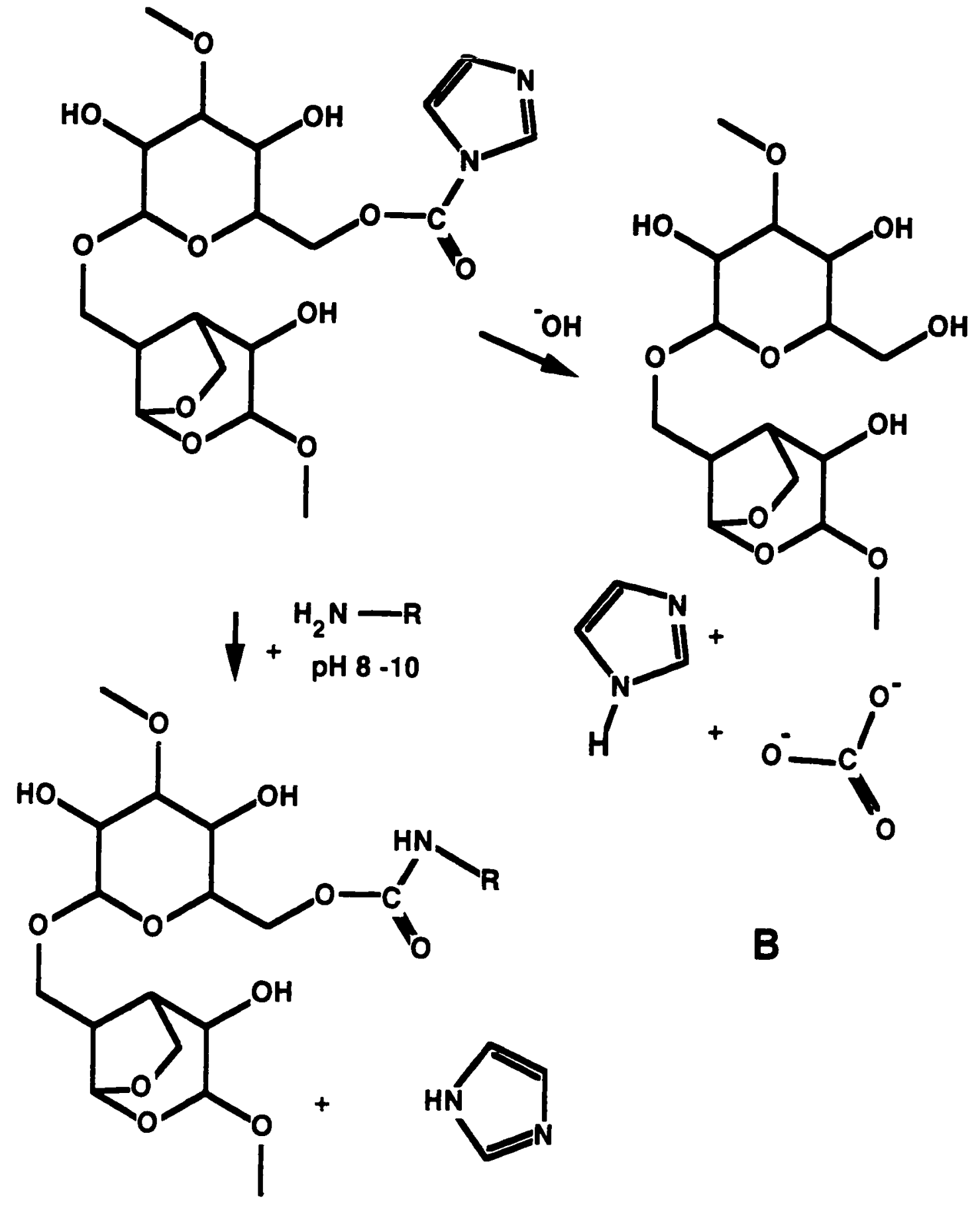

A

Figure 9: Imidazolyl carbamate reactions. 
desired reaction, $A$, is actually the minor reaction. Because the reaction takes place under alkaline conditions, a large number of the activated sites are likely to react with the free hydroxyl ions of the solution, which will result in most of the activated sites being unavailable for reaction with available primary amine groups. Therefore, it can be expected that the efficiency of the coupling reaction will be less than 1 .

While the efficiency of this coupling reaction is not likely to be high, the fact that the imidazolyl carbamate group is unreactive toward $O$ - and $S$ nucleophiles means that it will have a high selectivity to amino groups over hydroxyl and thiol groups. 24,25

In the late 1980's agarose resin gels that had been activated with CDI became commercially available. The recommended reaction conditions for these resins are $\mathrm{pH}$ between 8.0 and 10.0 at $4^{\circ} \mathrm{C}$ for 8 to 48 hours (the duration is $\mathrm{pH}$ dependent). To ensure that all of the activation sites have been either coupled or neutralized, it is recommended that the resin be reacted with a concentrated amine after the coupling reaction. The usual amine used is $2 \mathrm{M}$ TRIS with a pH between 8 and 10 . 


\section{Materials and Methods}

Equipment. Spectrophotometric measurements for these experiments were made on a Hewlett Packard Diode Array Spectrophotometer, model number 8452A. Absorption values were determined at 230, 280 and $320 \mathrm{~nm}$. The spectral bandwidth of this spectrophotometer is $2 \mathrm{~nm}$ for each measurement.

Radioactive decay measurements were made by scintillation counting in a Packard Tri-carb Liquid Scintillation Analyzer, model 1900CA. Total counts were used for evaluation of decay measurements with an averaging time of 5 minutes for each scintillation vial.

In the dissociation experiments, control of the temperature of the samples was accomplished with a Lauda Instruments Tisch-Kryomat temperature bath, model KT-30, with an external circulation loop that passed through a secondary water bath containing the sample tubes.

Protamine. The protamine used in these experiments was HPLC reverse phase-purified bull protamine P1. This material was generously supplied by Dr. Rod Balhorn and his colleagues at the Lawrence Livermore National Laboratories. It was originally obtained from mature bull sperm and therefore represents the protamine that is in its fully matured state; in the case of bull protamine $\mathrm{P} 1$, this means that it is completely unphosphorylated.26 The protamine was supplied to us in a lyophilized form.

Solutions of the protamine were prepared by dissolving a small amount of the protein in $1 \mathrm{~mL}$ of $10 \mathrm{mM} \mathrm{HCl}$. The absorption of the solution was then measured at $230 \mathrm{~nm}$. An absorbtion coefficient of $5.8 \mathrm{~cm}^{2} / \mathrm{mg}$ at $230 \mathrm{~nm}$ was used to quantify the bull protamine P1 concentration (equivallent to a molar extinction coefficient of $38.5 \times 10^{4} \mathrm{M}^{-1} \mathrm{~cm}^{-1}$ ). Once the initial concentration of 
the protein solution was determined, a series of dilutions (maximum dilution of $1 / 10$ for any single step) was performed to reach the desired concentration(s).

Buffers. Solubility of protamine $P 1$ is quite limited in the common buffers used for the suspension of other proteins. In particular, phosphate and borate buffers are poor choices for use with protamines due to the formation of aggregates, possibly due to the multi-valent nature of both the anions and the protein. Additionally, the high positive charge on the proteins, resulting from the high proportion of arginine residues, makes the use of basic buffers desirable. For this work, two buffers were primarily used; HEPES (with a usable pH range of 6.8 to 8.3) and TAPS (with a pH range of 7.7 to 9.1), both of which are "Good" buffers. The acids and salts for these buffers were obtained from Sigma Chemicals.

Buffers used were: HEPES ( 50 mM HEPES, pH $7.40 \pm 0.02$ ); HEPES$\mathrm{NaCl}$ (HEPES buffer with $100 \mathrm{mM} \mathrm{NaCl}$ added); HEPES-guanidine $\mathrm{HCl}$ (HEPES buffer with $6 \mathrm{M}$ guanidine $\mathrm{HCl}$, obtained from Schwarz/Mann Biotech); TAPS (50 mM TAPS, pH 8.10 to $8.60 \pm 0.02$, depending on experiment) and TAPS- $\mathrm{NaCl}$ (TAPS buffer with $50 \mathrm{mM} \mathrm{NaCl}$ added). Note that in each experiment, the $\mathrm{PH}$ of the TAPS buffer and TAPS-NaCl buffer were the same, although that $\mathrm{pH}$ was varied from experiment to experiment.

It was found that repeated resuspension and lyophilization of the protamine promoted aggregation. Aggregation was evaluated by comparing the absorption of protamine solutions at $280 \mathrm{~nm}$ and $320 \mathrm{~nm}$. The absorption of the solution at $280 \mathrm{~nm}$ results from the tyrosine residues (positions three and forty-two) in bull protamine P1. Absorption measured at $320 \mathrm{~nm}$ is caused by scattering of the light beam by particles suspended in the solution that are roughly $200 \mathrm{~nm}$ in size (based on the light scattering properties of 
small particles, light wavelength and index of refraction of dilute aqueous solutions).

Solutions with littie aggregation generaily nad $\dot{A}_{280} / \hat{A}_{320}$ values of between 5 and 10; solutions with high aggregation had values of approximately 1 . There are at least two possibie mechanisms for the aggregation of protamines in solution.

The first is simple contact aggregation due to Van der Waals forces, dipole-dipole interactions, induced dipole moments and other non bonding mechanisms. I believe that this mechanism is unlikely for protamines. This is due to the high positive charge density present on the molecules and the lack of hydrophobic regions. The high positive charges would require substantial numbers of counter ions between the molecules to prevent unfavorable electric field interactions. These counter ions would in turn "lubricate" the interface between the molecules allowing them to slide past each other. It does not seem that this kind of structure is likely to lead to stable aggregate formation.

A second possible mechanism for the aggregation is the formation of disulfide or other types of bridges between molecules of protein during the lyophilization process. However, while reduction of the bridges lowered the scattering of the protein in suspension, it quickly rose again (sometimes in as little as a single day, while the solution was frozen). This may indicate that other protein-protein interactions are taking place, possibly ester formation between either the tyrosine, threonine or serine residues and the carboxyl terminus (Balhorn, personal communications). For this reason fresh samples (less than one month after HPLC purification) of protamine were used in the preparation of materials for experimentation whenever possible. The UV 
spectrum of the protamine was checked each time new resin preparations were made. An $A_{280} / A_{320}$ ratio below 5 usually indicated that binding of the protamine to the resin would be problematic.

CDI Activated Resin. The primary solid substrate used in these experiments was REACTI-GEL ( $6 \mathrm{X}) \otimes$, supplied by Pierce. This material is a $6 \%$ cross-linked agarose bead that has been activated with CDI $\left(1,1^{\prime}\right.$ carbonyldiimidazole). The reaction for the activation is shown in Figure 9.23 Particles range in size from 45 to $165 \mu \mathrm{m}$ and the activation level is at least 50 $\mu \mathrm{mol}$ per $\mathrm{mL}$ of gel.

The imidazolyl carbamate activating group on the resin is an electrophile. As such, it tends to react with nucleophiles in $S_{n 1}$ or $S_{n 2}$ type reactions. There are three different nucleophiles present on the bull protamine P1 molecule: the nucleophilic primary amino group on the N-terminus, the nucleophilic alcohol groups of the tyrosine, threonine and serine residues, and the S-nucleophiles of the cysteine residues.

CDI activated support resins preferentially react with $\mathrm{N}$-nucleophiles over O-nucleophiles. ${ }^{24}$ There appears to be little information available on how CDI activated resins react with $\mathrm{S}$-nucleophiles relative to $\mathrm{N}$-nucleophiles. If, by extension from O-nucleophiles, $\mathrm{N}$-nucleophiles react with the resin preferentially over S-nucleophiles when used in the vendor recommended $\mathrm{pH}$ range, bull protamine $\mathrm{P} 1$ should bind to the resin by the only primary amine in the protein, the amino terminus.

For the simplest case where the imidazolyl carbamate reacts only with the primary amine group on the protein, all protein molecules that bind to the substrate will be bound with the same linkage, thereby ensuring that DNA binding to the protein will always occur in the same environment. 
In the case where the imidazolyl carbamate group has minor reactions with either the O- or S-nucleophiles or the protein, there will be a (hopefully small) population of proteins bound to the resin in some configuration different than that produced by the carbamate reaction with the primary amine. If this second population is small enough compared to the population of amine bound proteins (less than about $10 \%$ ) it will not make a significant contribution to experimental results.

Thiol Activated Resin. Previous studies 22 used a thiol activated resin rather than the carbonyldiimidazole activated resin used in most of the studies reported here. For the purpose of comparison, one experiment was carried out using bull protamine $\mathrm{P} 1$ linked to the thiol activated resin. The resin used was Thiol Activated SEPHAROSE $\otimes$ (4G) supplied by Pharmacia. This resin has a glutathione group attached to the substrate at a level of $1 \mu \mathrm{mol} / \mathrm{mL}$ of gel. The resin was in a dry form and was weighed, then swelled in HEPES buffer before use.

This resin will bind to any free thiol group, of which bull protamine $\mathrm{P} 1$ has between three (two intramolecular disulfide bonds as proposed by Balhorn) and seven (completely reduced), depending on the protein's overall oxidation state. The large number of available thiol groups on the protamine molecule allows for a corresponding number of configurations in which the protamine can bind to the thiol activated resin.

\section{Binding of Protamine to the CDI Activated Resin. The REACTI-GEL} resin is supplied suspended in acetone. For most experiments reported here, $200 \mu \mathrm{L}$ aliquots of the resin suspension were used for each preparation.

Centrifuging $200 \mu \mathrm{L}$ of the resin suspension yields a cake of resin of between 75 and $100 \mu \mathrm{L}$ volume. The acetone was removed by either vacuum 
desiccation (approximately 1 hour) or by decanting the excess fluid and then allowing evaporation at room temperature (about 20 minutes). In accordance with the manufacturer's recommended procedure for this material, the resin was dried to a paste-like consistency.

Once most of the acetone was removed by evaporation, $1 \mathrm{~mL}$ of TAPS$\mathrm{NaCl}$ buffer was added. The resultant suspension was centrifuged at 13,600 $g$ for approximately 15 seconds and the supernatant removed by pipette. This procedure was repeated a total of three times. The salt content of the buffer was recommended by the resin vendor for the initial washing procedure.

The protamine binding protocol developed in our lab for use with the thiol activated resin was carried out without the presence of salt in the buffer, so a second series of rinses (a total of three centrifugations) with TAPS buffer was performed. The last addition of TAPS buffer was adjusted to bring the total volume to $800 \mu \mathrm{L}$. The volume occupied by the resin was usually between 80 and $100 \mu \mathrm{L}$ by the end of the washing procedure.

Protamine solutions were prepared while the acetone was evaporating from the resin. Due to the uncertainty of the efficiency of attachment of protamine to this resin, several different concentrations of protein solutions were generally prepared to allow for a range of substitution levels on the resin. The range used in these experiments was from $0.125 \mu \mathrm{g} / \mathrm{mL}$ to 15.0 $\mu \mathrm{g} / \mathrm{mL}$ (or $16.8 \mathrm{nM}$ to $2.02 \mu \mathrm{M}$ ).

Once both the protein solutions and the samples of resin were prepared, $200 \mu \mathrm{L}$ of each of the protamine solutions was mixed with separate samples of the resin. This brought the total volume of each sample to $1 \mathrm{~mL}$. For 
control purposes, one of the samples was always prepared with $200 \mu \mathrm{L}$ of 10 $\mathrm{mM} \mathrm{HCl}$, providing a sample with no protamine substitution.

Addition of $200 \mu \mathrm{L}$ of $10 \mathrm{mM} \mathrm{HCl}$ results in a lowering of the $\mathrm{pH}$ of the resin suspension of about 0.25 units (i.e., $\mathrm{pH} 8.10$ was reduced to 7.85 ). Initial work with the REACTI-GEL resin was done with a TAPS buffer set at a $\mathrm{pH}$ of 8.1. The lowering of the $\mathrm{pH}$ resulting from the addition of the protamine solution to the buffer took the $\mathrm{pH}$ outside the recommended range for substitution for the resin. For this reason, in later resin preparations a TAPS buffer with a pH of 8.6 was used.

This procedure resulted in between 0 to $675 \mathrm{pmol}$ of protamine being mixed with an approximately $90 \mu \mathrm{L}$ volume of resin.

The samples were then incubated for 48 to 72 hours at $4^{\circ} \mathrm{C}$. The resin supplier states that the reaction is complete in 42 hours when the least basic $\mathrm{pH}(8.0)$ recommended conditions (slowest) are used.

After the incubation time had elapsed, the samples were centrifuged and the supernatant removed by pipette. In most experiments, any remaining carbonyldiimidazole groups were inactivated (reacted with the TRIS base) by decanting the protamine solution and adding $1 \mathrm{~mL}$ of $2 \mathrm{M}$ TRIS buffer $(\mathrm{pH}$ $8.00 \pm 0.02$, acid and base forms supplied by Sigma) and allowing the reaction to proceed for 1 hour at $4^{\circ} \mathrm{C}$.

After the capping reaction had been completed, any residual protein (either in solution or adhering to the surface of the resin beads) was removed by centrifuging the samples, pipetting off the supernatant and adding $1 \mathrm{~mL}$ of HEPES-guanidine $\mathrm{HCl}$. This mixture was allowed to incubate for 5 minutes at room temperature. The HEPES-guanidine $\mathrm{HCl}$ solution was then centrifuged and removed by pipette, and $1 \mathrm{~mL}$ of HEPES buffer was added. This was 
repeated once more, and finally the sample was then centrifuged, the supernatant removed and the total volume brought to $500 \mu \mathrm{L}$ with HEPES buffer. At the end of this procedure, the resin voiume was usually between 75 and $90 \mu \mathrm{L}$.

The prepared resin was stored at $4^{\circ} \mathrm{C}$ until needed. In most cases, the material was used within 14 days of the time it was prepared. The maximum length of time any sample was stored was 32 days for the resin leakage experiment (19a).

DNA. The DNA used in all of these experiments was a synthetic double stranded oligomer with a length of 12 nucleotide base pairs (bp). It was produced by Clonetech and delivered in a blocked form. Our collaborators at Lawrence Livermore National Laboratories annealed the two single strands and purified the double stranded oligomer from the unannealed single strands by HPLC. They also unblocked the $5^{\prime}$ ends of the oligomers. The double stranded character of the 12 bp oligomer was verified by a melting profile and absorbence measurements at $260 \mathrm{~nm} .22$

It is believed that there is some "breathing" of the ends of the double stranded DNA but that the structure is stable (Stacks and Balhorn, personal communications). The actual structure of the molecule is likely fairly flexible, transitioning between the different DNA forms.

The DNA sequence used was: 5' TCG AAT GTA CAA 3'. As can be seen, the sequence is not a palindrome. This was done purposely, since the oligomer is intended to represent a typical stretch of DNA to which protamine might bind. The length of the oligomer was chosen because tests by other researchers have indicated that the DNA binding site on typical protamine $P_{1}$ molecule is about 12 bp long. ${ }^{27}$ Additionally, there have been indications that 
shorter oligomers (10 bp) may not be stable in a double stranded form (Balhorn and Stacks, personal communications). The oligomer lacked a phosphate group on the 5 ' ends.

Labeling of the DNA Oligomers. Labeling was carried out by a modification of the T4 Polynuceotide Kinase method.28 [33P- $\gamma$ ] ATP was used in the labeling, supplied by NEN Research Products (DuPont). The ATP had a specific activity in the range of $2000 \mathrm{mCi} / \mathrm{mmol}$ on a specified date. On the specified date, the activity of the material was specified as $10.0 \mathrm{mCi} / \mathrm{mL}$, giving an ATP concentration of $5 \mathrm{M}$. Fresh supplies of ATP were acquired on a monthly basis (33P has a half-life of 24.5 days).

The T4 kinase used in the procedure was derived from $E$. coli cultures and supplied by Stratagene. It has an activity level of $10 \mathrm{U} / \mu \mathrm{L}$. One unit of activity is defined as the amount of enzyme needed to incorporate $1 \mathrm{nmol}$ of 32P from [32P- $\gamma$ ]-dATP into micrococcal nuclease-treated calf thymus DNA in 30 minutes at $37^{\circ} \mathrm{C}$. The enzyme was suspended in a mixture of $50 \mathrm{mM}$ TRIS- $\mathrm{HCl}$ (pH 7.6), $25 \mathrm{mM} \mathrm{KCl}, 0.1 \mathrm{mM}$ EDTA, $1 \mathrm{mM}$ DTT, $0.1 \mu \mathrm{M}$ ATP and $50 \%$ glycerol $(\mathrm{V} / \mathrm{V})$.

For this procedure the following mixture was made:

$\begin{array}{ll}\text { water } & 11 \mu \mathrm{L} \\ \text { DNA oligomer } & 1 \mu \mathrm{L} \\ \text { Solution V } & 2 \mu \mathrm{L} \\ \text { [33P- } \gamma \text { ] ATP } & 5 \mu \mathrm{L} \\ \text { T4 Polynucleotide Kinase } & 1.3 \mu \mathrm{L}\end{array}$

Solution $V$ is composed of $500 \mathrm{mM}$ TRIS- $\mathrm{HCl}, 100 \mathrm{mM} \mathrm{MgCl}_{2}, 10 \mathrm{mM}$ EDTA, $1 \mathrm{mM}$ spermidine and $50 \mathrm{mM}$ DTT. It was mixed in our lab and stored in a frozen state. 
After the mixture was made, it was incubated in a water bath at a nominal temperature of $37^{\circ} \mathrm{C}\left(36\right.$ to $\left.39^{\circ} \mathrm{C}\right)$ for 45 minutes. The mixture was then quenched in an ice water bath for 30 minutes to stop the reaction. HEPES buffer was then added to bring the total volume to $50 \mu \mathrm{L}$.

To monitor the efficiency of labeling of the oligomers, a $1 \mu \mathrm{L}$ aliquot was removed from the mixture at this point and placed in a scintillation vial. All scintillation vials used in the procedures described here were $20 \mathrm{~mL}$ total volume vials and were prepared with $7 \mathrm{~mL}$ of CYOSCINT $^{\circledR}$ (ICN Biomedicals, Inc.) scintillation cocktail.

The DNA mixture was then placed on a prepared QUICKSPIN ${ }^{\circledR}$ separation column (obtained from VWR and manufactured by Kodak under the name NuClean D25 Disposable spun Columns) and centrifuged at $1000 \mathrm{~g}$ for 2 to 5 minutes. Prepared columns were shipped containing a TRIS buffer solution. This was replaced by four washes of HEPES buffer and then centrifuged at $1000 \mathrm{~g}$ to remove excess fluid immediately before use. The resulting solution had another $1 \mu \mathrm{L}$ aliquot removed for scintillation counting and was then stored at $4{ }^{\circ} \mathrm{C}$ until needed. Over $95 \%$ of the solution, by volume, was routinely recovered from the columns.

The specific activity of the DNA preparation is not used directly in the calculations of dissociation rate constants for this study. However, validity of the results depends on sufficient activity of the DNA to produce a count rate of protamine bound DNA that is easily distinguishable from the background count rate.

In the experiments reported here, specific activities in the 1500 to 2500 $\mathrm{Ci} / \mathrm{mol}$ range were used. (Calculation of the specific activity of some of the experiments produced count rates that were significantly lower, so the specific 
activities for those experiments are somewhat suspect, however the count rate was in the same range as the count rates for other experiments). Specific activities in the 1500 to $2500 \mathrm{Ci} / \mathrm{mol}$ range, for 33P label, indicate that roughly 3 in 10000 DNA molecules are labeled. Details of the specific activity calculation and related information is given in Appendix $B$.

Due to the relatively short half life of ${ }^{33} \mathrm{P}$, new DNA preparations were made every three to four weeks.

Dissociation and Assay Procedure. The dissociation and assay experiments reported here had two stages. The procedure is diagrammed in Figure 10.

The first stage of dissociation experiments involved the binding of labeled DNA to the modified resin. Samples of the resin preparations were measured out by volume into centrifuge tubes. The amount used for each incubation sample had a volume of resin suspension equal to $10 \mu \mathrm{L}$ per data point to be taken plus $10 \mu \mathrm{L}$ to account for losses. For assays, the incubation sample volume was $50 \mu \mathrm{L}$ (2 time data points, in duplicate plus the $10 \mu \mathrm{L}$ for losses). For dissociation experiments, the incubation sample volume was usually 190 $\mu \mathrm{L}$ (9 time data points, in duplicate plus $10 \mu \mathrm{L}$ for losses). One of the resin samples was always unmodified with protamine. Additionally, there was always one blank sample of the same quantity of HEPES buffer with no resin as a control.

The DNA used for each experiment was prepared from the stock labeled DNA by diluting it with unlabeled DNA. The unlabeled DNA used for the dilution was the same stock supply used to prepare the labeled DNA, so the concentrations were proportional to each other (the unlabeled DNA had no phosphate group on the $5^{\prime}$ end). The dilution ratio was generally $1: 1$ by 


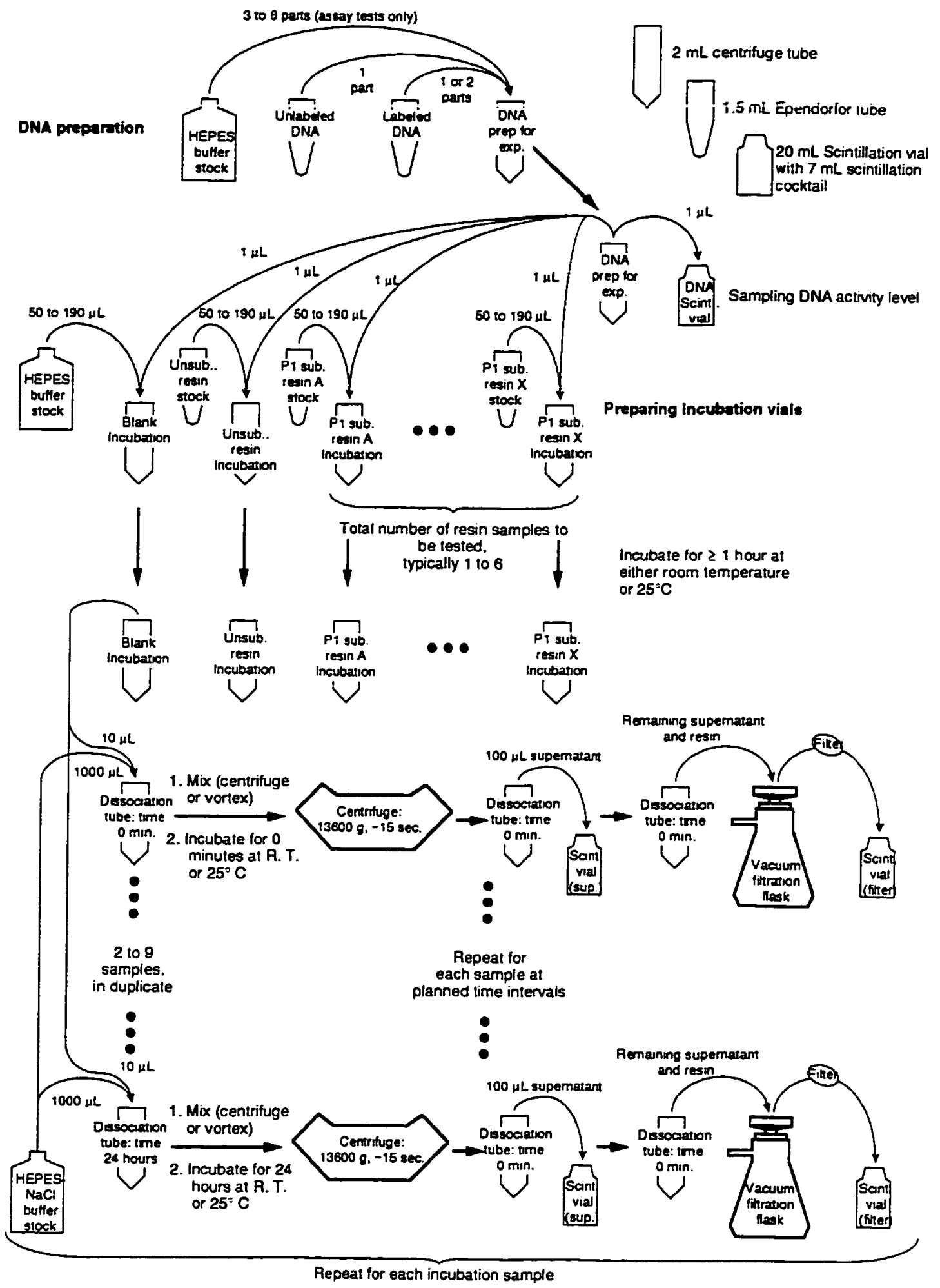

Figure 10: Dissociation experiment protocol. 
volume. Specific activity of the DNA is not crucial to the experimental procedure as long as it is in a range where the binding of the DNA to the protamine on the resin can be distinguished from the background. The specific activity of the DNA used in the experiments was estimated and is included in the data for each experiment. In cases where the activity of the labeled DNA was decreasing due to decay of the 33P, (generally 20 to 30 days after the DNA was labeled) the labeled DNA dilution ratio was changed to $2: 1$, to keep the scintillator count rate in a usable range.

One $\mu \mathrm{L}$ of labeled DNA solution was then added to each of the incubation tubes. The total amount of DNA in each incubation tube was about $25 \mathrm{pmol}$ $(-130 n M)$.

The second step of the experimental procedure was the dissociation step. Ten $\mu \mathrm{L}$ aliquots of the resin and DNA mixtures were placed into centrifuge tubes with $1 \mathrm{~mL}$ HEPES-NaCl buffer to initiate dissociation of the DNA from the resin. Most of the dissociation experiments used 9 dissociation tubes, each of which was run in duplicate. For dissociation rate determination experiments, the sample tubes were placed in the $25^{\circ} \mathrm{C}$ controlled temperature bath. At predetermined times, these sample tubes were centrifuged $(13,600 \mathrm{~g})$ for 5 to 10 seconds and $100 \mu \mathrm{L}$ of the supernatant was removed and place in a scintillation vial. The remaining material was then remixed and vacuum filtered (Millipore $0.45 \mu \mathrm{m}$ pore size nitrocellulose filter papers). The filter paper was placed in a separate scintillation vial.

Initial mixing of the DNA/resin aliquots and the HEPES- $\mathrm{NaCl}$ dissociation buffer was done by placing the aliquot on the side of the dissociation tube and centrifuging (experiments 19 and earlier) or by vortex mixer (experiments 19a and later). 
The purpose of the assays was to determine which of several resin preparations (each of which used a different protamine concentration) would bind sufficient DNA to provide a decay count rate above the background and had a protamine surface concentration low enough to allow dissociation of the DNA from the protein when the mixture was diluted with buffer.

There are several distinctions between the dissociation procedure and the assay procedure. Dissociation experiments are done in a temperature controlled bath while assay experiments are conducted at room temperature (between 26 and $35^{\circ} \mathrm{C}$ for the assay experiments reported here).

The second difference is the number of data points taken over time in the two types of experiment. Assays have data taken at 0 hours of dissociation and at approximately 24 hours of dissociation. Dissociation experiments have many data points taken over a 24 hour period (usually 9).

Also for assay experiments, the DNA preparation was diluted again after the labeled DNA was mixed with the unlabeled DNA by addition of HEPES buffer to adjust the amount of DNA in $1 \mu \mathrm{L}$ to give approximately the same concentration of DNA in the incubation tubes as produced in the incubation tubes for the dissociation. Because the assay experiments started with only $50 \mu \mathrm{L}$ of resin preparation, while the dissociation experiments started with 190 $\mu \mathrm{L}$, the DNA was diluted 3:1 with HEPES buffer. For the assay experiments, addition of $1 \mu \mathrm{L}$ of this diluted DNA resulted in about $6.4 \mathrm{pmol}(-125 \mathrm{nM})$ of DNA in each incubation tube.

Data Analysis. Appropriate mathematical treatment of the scintillation counts for the two scintillation vials containing the $100 \mu \mathrm{L}$ aliquot of supernatant and the filter, allowed for the ratio of bound to unbound label to 
be determined for each of the dissociation tubes. The equation used for determining the ratio of bound to unbound label was:

$$
R=\left(C_{f}-B\right) /\left\{\left(C_{f}-B\right)+\left[\left(C_{s}-B\right) * 10.1\right\}\right\}
$$

Where $C_{F}$ is the count rate for the scintillation vial with the filter paper, $C_{s}$ is the count rate for the scintillation vial with the supernatant aliquot and $B$ is the background count for the scintillation counter. In this equation, the factor of 10.1 is derived from the total volume of the dissociation tube $(1000 \mu \mathrm{L}$ of HEPES- $\mathrm{NaCl}$ plus $10 \mu \mathrm{L}$ of the resin and DNA mixture) divided by the volume of the supernatant aliquot $(100 \mu \mathrm{L})$.

Plotting the ratio of bound label to unbound label versus the dissociation time allows for the calculation of the dissociation rate constant. Because the dissociation reaction being studied with these experiments is of the "A -> B + $C$ "type, we expect that the dissociation of DNA from protamine will be a first order process. This will be the case as long as the reaction is not catalyzed in any way (for instance by collisions with molecules, other than water, in solution). Equation 2 shows the rate determining equation for first order reactions.

$$
\partial[C] / \partial t=-k_{2} *[C]
$$

In this equation, $[C]$ is the concentration of the species of interest at any given time (the DNA-protamine complex in this case) and $k_{2}$ is the dissociation rate constant.

Integration of this equation gives the equation of the curve expected for the plot of a first order process:

$$
[C]=\left[C_{0}\right]^{*} \exp \left(-k_{2}^{*} t\right)
$$

In equation $3,\left[C_{0}\right]$ is the concentration of the DNA-protamine complex at time 0 . 
Taking the log of equation 3 results in an equation that describes the straight line that should result from plotting the log of concentration of the complex versus time:

$$
\ln ([C])=-k_{2} * t+\ln \left[C_{0}\right]
$$

To determine the rate constant involved in the dissociation of DNA and protamine, straight line curve fitting to the log-linear plots should be usable. However, a serious complication in this method for this application is that the scintillation counts tend to be noisy (on the order of $10 \mathrm{cpm}$, about $2 \%$ of the count rate for a typical filter from the end of a dissociation experiment). Additionally, variations in the individual dissociation samples add error to the measurements, such as the number of resin beads transferred from the initial binding sample to the dissociation tube and in the quantity of protamine bound to individual resin beads. The result of this is that many data points are needed to produce a statistically significant measurement of the dissociation rate constant for DNA and protamine.

One way of minimizing the various sources of error and noise in the experimental procedure is to increase the number of data points taken over time for each experiment. Unfortunately, multiple time measurements provide the most information when they are taken during the period of highest rate of change in the binding ratio. This period for the protocol outlined above is the first 15 minutes to 1 hour of dissociation. For logistical and mechanical reasons it was found to be impractical to take more than about 6 data points during the first hour of dissociation. Also, if there is a slow dissociation rate (see "Multiple Binding Modes", below) in addition to a fast rate, data points must be taken for an extended period of time to ensure accurate determination of both rate constants. 
A second source of data points is running duplicate samples simultaneously. For the protocol that has been used here, two parallel dissociation series were run for each starting sample in each experiment. Additionally, in some cases, there was sufficient resin prepared at the start of an experiment for the dissociation protocol to be run twice. As a result, for each resin preparation, between two and four data points were determined for each dissociation time.

Finally, experiments using different resin preparations can be used to increase the number of data points in the rate constant extractions by combining data sets. However, care must be taken when data from multiple resin preparations are combined. In particular, one of the model parameters for a straight line fit to a log-linear dissociation plot is the 0 time intercept (In[ $\left.\mathrm{C}_{0}\right]$ in equation 4), which is likely to differ for each resin preparation.

Because it is known that the equilibrium constant for DNA and protamines combining into complexes is very large $\left(-10^{6} \mathrm{M}^{-1}\right)$, and assuming for the moment that the DNA is not the limiting factor in the amount of DNA bound to the protamine sites on the resin, all of the protamine that can bind DNA has done so at the beginning of the dissociation phase of the experiments. In the experiments reported here, the ratio of bound label to total label never exceeded $25 \%$, this means that the DNA was always in large excess (4 to 20 times) of the protamine sites that bind it. This means the 0 time intercept is a measure of the amount of protamine on the resin available for DNA binding. In the course of this work, it became clear that this value was quite difficult to control for the resin system used. Therefore, for each resin preparation, the 0 time intercept must be independently derived. Once the 0 time intercept (the total number of available binding sites for each resin preparation) was known, 
the data for each experiment can be normalized, which allows it to be combined with other experiments to provide a better estimation of the dissociation rate constant.

During the determination of the 0 time intercept, a dissociation rate constant was also determined for each experiment. Once the data from several experiments were combined, the rate constant for the whole set of data can be compared to the constants derived for each individual resin preparation. If one or more of the rate constants significantly (greater than about 2 sigma) disagree with the constant for the whole set it, indicates that at least one of the resins behaved differently than the rest.

There were several equations used in the curve fitting for this work. All of them were obtained from Statistical Treatment of Experimental Data by Hugh D. Young. ${ }^{29}$ The slope of the best fit line for a set of data points is given by equation 5 (equation $5 b$ gives the formula for the common denominator found in all of the equations for this fit method). In this equation, $m$ is the slope of the line, corresponding to $-k_{2}$ in equation $3 ; r_{i}$ is the ratio of bound to total label for the $i^{\text {th }}$ data point; $t_{i}$ is the dissociation time of the th data point; and $N$ is the total number of data points.

$$
\begin{aligned}
& m=\left[N * \Sigma\left(r_{i}^{*} t_{i}\right)-\Sigma\left(r_{i}\right)^{*} \Sigma\left(t_{i}\right)\right] / \Delta \\
& \Delta=N^{*} \Sigma\left(t_{i}^{2}\right)-\Sigma\left(t_{i}\right)^{2}
\end{aligned}
$$

The 0 time intercept is given by equation 6 , where $b$ corresponds to $\ln \left[C_{0}\right]$ in equation 4.

$$
b=\left[\Sigma\left(r_{i}\right) * \Sigma\left(t_{i}^{2}\right)-\Sigma\left(r_{i}^{*} t_{i}\right) * \Sigma\left(t_{i}\right)\right] / \Delta
$$

One significant advantage of using this data extraction method to derive the rate constant for a reaction is that the variance of both the rate constant and the 0 time intercept can also be extracted. Additionally, examination of 
the fit coefficient, $r$, can indicate if the extracted parameters can be trusted. Equations for these quality parameters are given in equations 7 through 10. The total variance of the model from the data, $\sigma$, is given by equation 7 . The portion of that variance that is due to the slope of the model, $\sigma_{\mathrm{m}}$, is given in equation 8 and the portion of it due to the 0 time intercept of the model, $\sigma_{b}$, is given in equation 9 . Finally the coefficient of fit, $r$, is given by equation 10 .

$$
\begin{array}{cr}
\sigma^{2}=\Sigma\left[\left(m * t_{i}+b-r_{i}\right)^{2}\right] / N & 7 \\
\sigma_{m}=N * \sigma^{2} / \Delta & 8 \\
\sigma_{b}=\sigma^{2} * \Sigma\left(t_{i}\right) / \Delta & 9 \\
r=\left[N * \Sigma\left(r_{i} * t_{i}\right)-\Sigma\left(r_{i}\right) * \Sigma\left(t_{i}\right)\right] /\left\{\Delta^{1 / 2 *}\left[N * \Sigma\left(r_{i}^{2}\right)-\Sigma\left(r_{i}\right)^{2}\right]^{1 / 2}\right\} & 10
\end{array}
$$

Multiple Binding Modes. If there is more than one rate constant involved, for instance if there are two different binding modes of DNA to protamine, then there should be two straight segments to the curve that blend into each other, as shown in Figure 11.

When cases of this type are encountered, the two (or more) rate constants can be extracted from the data providing that two conditions are met. ${ }^{30}$ The first is that the difference in the magnitude of the rate constants be large enough to be statistically separable given all the variations and errors in the data (for good quality data rate constants with a ratio of 2 or 3 can be separable). Second, sufficient data must be taken during the period that each of the rate constants dominates the reaction for statistically valid determination of the constants to be made.

Given that the conditions stated above are met, extracting rate constants from data with multiple constants can be accomplished with the following procedure: 


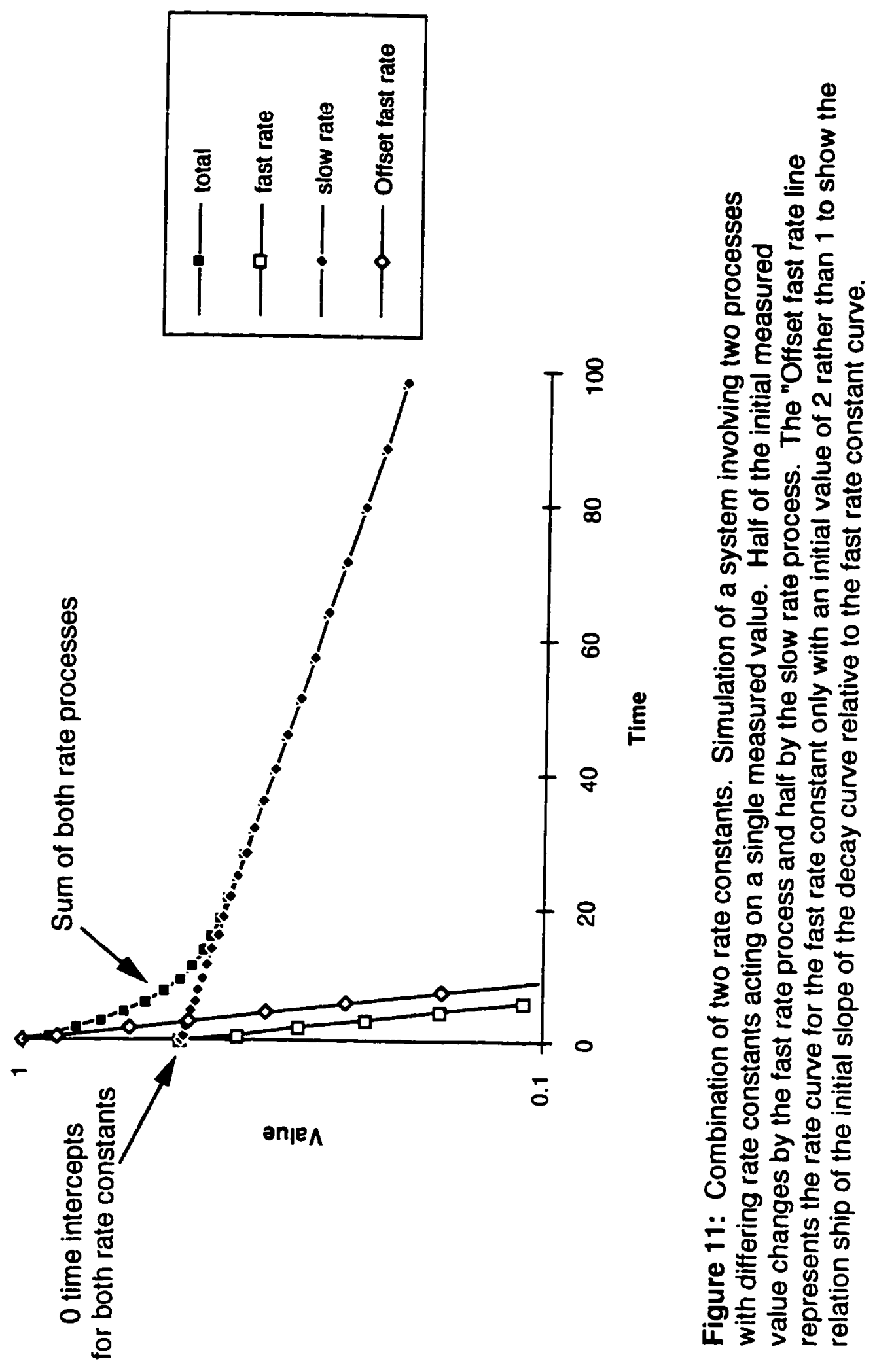


1. The slowest rate constant, $m_{1}$, and the amount of starting material that follows this rate, $b_{1}$, is extracted as described in the section above using the data points at the end of the experimental run which plot out on a log-linear graph as a straight line.

2. The values of $m_{1}$ and $b_{1}$ are used in a model to determine the amount of measured parameter (bound to total label ratio in this case) that is involved with the slowest rate at the time of each data point. This value is then subtracted from the measured data at each data point, yielding a "stripped" data set.

3. Replotting the stripped data from step 2 should now result in a new straight line section representing the section of data that was dominated by the second slowest rate constant. Step 1 is repeated to determine $m_{2}$ and $b_{2}$.

4. If there are more (faster) rate constants involved, steps 2 and 3 are repeated with the new constants being used to strip progressively more of the reactions out of the data. 


\section{Results}

Assays for Binding of Protamine P1 to the Support. Initial experiments with the imidazolyl carbamate resin were aimed at determining the conditions needed to bind a reproducible amount of the protamine to the resin. In previous work (Wren and Stacks, personal communications) it was found that the presence of a reporter group on the thiol activated resin was not useful due to the very low substitution level needed to ensure reversible binding of DNA with the protein. Further work showed that the substitution level on the thiol activated resin could be reliably controlled by adjusting the concentration of protamine in the solution mixed with the resin (a fixed volume of protamine solution was always mixed with a fixed weight of swelled resin). ${ }^{22}$ Evaluation of the imidazolyl carbamate resin started with the same procedure.

The extent of modification of the resin with protamine was evaluated with a DNA binding assay test. This involved the binding experiment procedure using only two time points, zero and approximately 24 hours. The criteria for evaluating the results of the test were that a significant amount of DNA should be bound to the resin at the zero time point and an insignificant amount should be bound at the 24 hour point. In this case, significant means that the DNA is easily distinguishable from the background binding determined by a blank sample with no resin and a control sample with unsubstituted resin (both usually around $3 \%$ of the total label). Figure 12 shows a typical experiment of this type with a series of different protamine concentrations. Only resin preparations that both bind DNA initially and have released that DNA after 24 hours can be used in the dissociation protocol. Table 1 summarizes a series of experiments evaluating the effect of protamine concentration on the binding assay. 


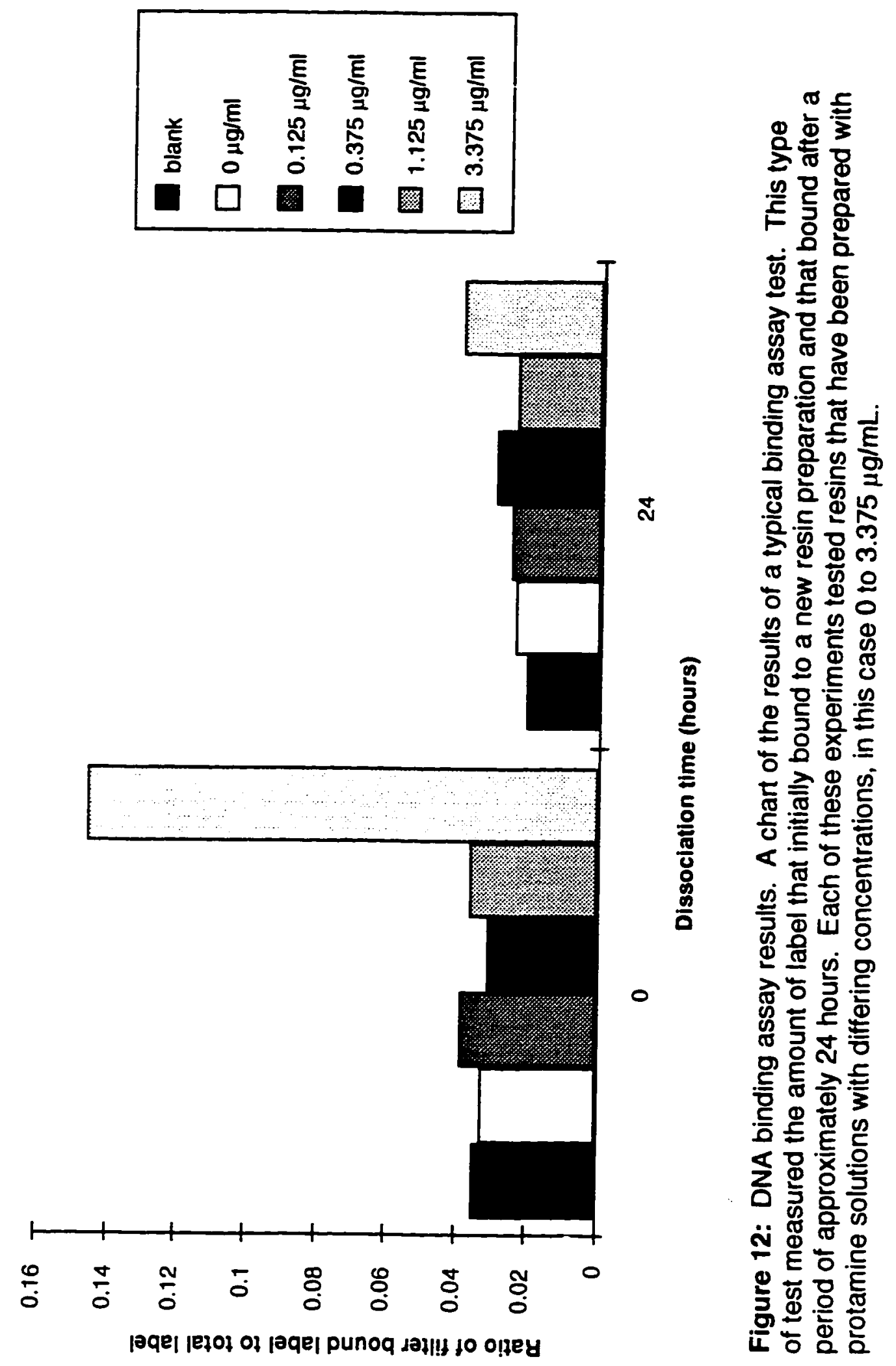




\section{Table 1: Protamine Concentration Effects on DNA Binding}

\begin{tabular}{|c|c|c|c|c|c|c|c|c|c|c|}
\hline \multirow[b]{2}{*}{ Exper. } & \multirow[b]{2}{*}{$A_{280} / A_{320}$} & \multirow[b]{2}{*}{$\mathrm{pH}$} & \multirow[b]{2}{*}{ Time } & \multirow[b]{2}{*}{$\mathbb{P} 1]_{\mu \mathrm{g} / \mathrm{mL}}$} & \multicolumn{3}{|c|}{ Q Hours } & \multicolumn{3}{|c|}{-24 Hours } \\
\hline & & & & & L Sug & Fills & Ratio' $^{\dagger}$ & Sup & Filf & Ratio $^{\dagger}$ \\
\hline \multirow[t]{10}{*}{14} & $-1.11^{* *}$ & 8.4 & 49 & 0 & 1447.8 & 510.4 & & 1634.0 & 466.0 & \\
\hline & & & & & 1088.6 & 391.8 & 0.033 & 1541.8 & 363.2 & 0.024 \\
\hline & & & & 0.125 & 1188.8 & 495.0 & & 1663.4 & 404.4 & \\
\hline & & & & & 1090.0 & 464.2 & 0.039 & 1670.4 & 496.6 & 0.025 \\
\hline & & & & 0.375 & 1172.4 & 359.4 & & 1239.8 & 423.0 & \\
\hline & & & & & 1106.8 & 402.8 & 0.031 & 1435.8 & 439.6 & 0.030 \\
\hline & & & & 1.125 & 1267.8 & 410.4 & & 1610.0 & 364.8 & \\
\hline & & & & & 1112.8 & 512.6 & 0.036 & 1454.8 & 430.6 & 0.024 \\
\hline & & & & 3.375 & 1183.2 & 1709.4 & & 1608.6 & 743.8 & 0.039 \\
\hline & & & & & 1004.6 & 1983.0 & 0.146 & 1478.8 & 558.8 & 0.039 \\
\hline \multirow[t]{10}{*}{17} & & 8.1 & 48 & 0 & 876.2 & 628.6 & & 1028.6 & 273.2 & \\
\hline & & & & & 859.0 & 330.0 & 0.050 & 1071.4 & 286.4 & 0.024 \\
\hline & & & & 0.125 & 934.0 & 487.6 & & 1027.2 & 335.6 & \\
\hline & & & & & 906.6 & 305.4 & 0.039 & 400.4 & 346.8 & 0.054 \\
\hline & & & & 0.375 & 980.0 & 411.4 & & 1113.8 & 265.2 & \\
\hline & & & & & 831.8 & 317.0 & 0.057 & 1080.0 & 212.8 & 0.019 \\
\hline & & & & 1.125 & 901.0 & 791.4 & & 1068.2 & 287.6 & \\
\hline & & & & & 807.6 & 903.4 & 0.090 & 1098.2 & 286.0 & 0.024 \\
\hline & & & & 3.375 & 932.2 & 2599.0 & & 1065.4 & 1448.0 & \\
\hline & & & & & 840.8 & 2898.4 & 0.240 & 1095.6 & 1497.2 & 0.120 \\
\hline \multirow[t]{6}{*}{$24 a$} & 1.13 & 7.4 & 71 & $0^{*}$ & 370.4 & 259.8 & & 432.2 & 152.0 & \\
\hline & & & & & 415.8 & 204.6 & 0.053 & 460.2 & 191.0 & 0.033 \\
\hline & & & & $0.188^{*}$ & 275.0 & 110.6 & & 285.0 & 106.6 & \\
\hline & & & & & 282.0 & 122.8 & 0.032 & 305.8 & 92.6 & 0.026 \\
\hline & & & & $0.375^{*}$ & 390.2 & 162.4 & & 436.4 & 96.4 & \\
\hline & & & & & 357.4 & 171.4 & 0.039 & 435.8 & 126.6 & 0.020 \\
\hline $24 b$ & 1.44 & 8.6 & 71 & 0 & 558.4 & 395.2 & & 642.8 & 190.8 & \\
\hline
\end{tabular}




\section{Table 1: Protamine Concentration Effects on DNA Binding (continued)}

\begin{tabular}{|c|c|c|c|c|c|c|c|c|}
\hline \multirow[b]{2}{*}{$A_{28} / A_{220}$} & \multirow[b]{2}{*}{$\underline{\text { Time }}$} & \multirow[b]{2}{*}[P_{1}]{$_{u} \mathrm{o} / \mathrm{mL}$} & \multicolumn{3}{|c|}{0 Hours } & \multicolumn{3}{|c|}{-24 Hours } \\
\hline & & & $=$ Sup & Filt & Ratio $^{\dagger}$ & Sup & Fift & Aatict $^{\dagger}$ \\
\hline \multirow[t]{5}{*}{$24 b$ (cont.) } & & & 552.4 & 613.4 & 0.082 & 632.0 & 302.2 & 0.034 \\
\hline & & 3.375 & 563.4 & 289.4 & & 676.2 & 204.2 & \\
\hline & & & 614.6 & 254.4 & 0.042 & 682.8 & 166.4 & 0.024 \\
\hline & & 6.750 & 546.2 & 281.0 & & 680.2 & 181.8 & \\
\hline & & & 535.2 & 237.8 & 0.043 & 649.8 & 177.2 & 0.023 \\
\hline \multirow[t]{6}{*}{1.13} & $7.4 \quad 49$ & $0^{*}$ & 502.2 & 141.2 & & 602.2 & 171.0 & \\
\hline & & & 522.8 & 119.8 & 0.021 & 608.8 & 177.4 & 0.025 \\
\hline & & $0.75^{\circ}$ & 548.8 & 227.8 & & 682.6 & 181.4 & \\
\hline & & & 568.4 & 232.2 & 0.036 & 640.6 & 200.0 & 0.025 \\
\hline & & $1.50^{\circ}$ & 365.2 & 879.4 & & 477.0 & 708.0 & \\
\hline & & & 367.6 & 831.0 & 0.194 & 511.8 & 565.4 & 0.115 \\
\hline \multirow[t]{6}{*}{27} & $\begin{array}{ll}8.6 \quad 47\end{array}$ & 3.75 & 396.0 & 125.0 & & 459.4 & 113.2 & \\
\hline & & & 374.6 & 156.6 & 0.031 & 415.4 & 148.2 & 0.025 \\
\hline & & 7.50 & 399.4 & 184.4 & & 421.0 & 106.6 & \\
\hline & & & 392.4 & 123.6 & 0.033 & 416.8 & 137.8 & 0.023 \\
\hline & & 15.0 & 347.0 & 159.6 & & 475.2 & 116.6 & \\
\hline & & & 363.2 & 170.6 & 0.040 & 416.4 & 131.0 & 0.022 \\
\hline
\end{tabular}

Notes: $\quad A_{280} / A_{320}$ column is the ratio of absorbence at the two wavelengths that was measured when the protamine solutions were prepared.

pH column is the $\mathrm{pH}$ of the TAPS solution (CDI resin) or HEPES solution (Thiol resin) used in the resin substitution reaction.

Time column is the reaction time for the resin substitution in hours.

0 Hours columns refer to the data obtained from resin/DNA samples that had zero dissociation time.

-24 Hours columns refer to data obtained from resin/DNA samples that had approximately 24 hours of dissociation time.

Sup. columns are the counts (cpm) obtained from supernatant aliquots.

Filt. columns are the counts (cpm) obtained from scintillation vials containing resin filters.

$\dagger$ average of the bound label to total label ratio for two data points "Thiol linkage resin

"* For this experiment the A320 value was negative indicating very little scattering. 
By comparing the data in the "O hours Ratio" column (ratio of the label found on the filters to the total label in the sample at 0 dissociation time) for unmodified resin ([P1] values of 0 ) with the same values for various concentrations of protamine $\mathrm{P} 1$, the minimum concentration of the protein needed to give a measurable binding of DNA (above the background) can be determined. Because this ratio for unmodified resins varies between about 3 and $8 \%$ binding, a minimum ratio of around $10 \%$ binding is needed for protamine modified resins to distinguish them from unmodified resins.

In the event that the surface of the resin has been over modified (that is, the modification of the resin has reached the point that the protamine molecules are close enough that they start to interact) the value in the " -24 hour ratio" column will show higher than background binding of 3 to $8 \%$. This assumes that the dissociation rate for DNA binding to protamine under the conditions used here is sufficiently high to ensure that all the DNA bound to a single protamine molecule will dissociate within 24 hours This will be discussed further later.

Resin Leaching. Once a protein has been attached to a solid substrate, there is usually some finite rate at which that bond will spontaneously hydrolyze. To explore this issue in the protamine P1 substituted REACTIGEL system, a series of zero time DNA binding assays were performed on a single gel preparation over a period of about a month. Because this type of test measures the DNA binding capacity of the substituted resin, only the protamine that can actively bind DNA is monitored. Therefore, any population of protamine that is attached to the resin but unable to bind DNA (for environmental, configuration or steric reasons) will not be measured by this 
test. On the other hand, any protamine molecule that can not bind DNA is not of great interest for this particular study.

This part of the study is a compilation of zero dissociation times from a group of experiments that all used the same resin preparation and were spread over a period of approximately one month. Only the zero time data points from the assay and dissociation experiments were used in this analysis. In addition to using the same substituted resin for this experiment, the same batch of labeled DNA and diluted DNA was used to minimize variables.

In this experiment, the specific activity of the labeled DNA decreased over time. Due to this decay of the label, the dilution factor used in each of the tests that made up this experiment was varied over the course of the tests to ensure that the signal-to-noise ratio was high enough to yield usable data. This had the effect of changing the DNA concentration for each of the tests. Most experiments were run with a DNA concentration of about $125 \mathrm{pM}$, but this went as high as about $175 \mathrm{pM}$ in some experiments. The combination of these two effects means that normalization factors must be used to relate the data from each of the tests to each other.

Figure 13 shows the results of this control experiment for a control unsubstituted resin batch and a P1 substituted resin batch. The data for the unsubstituted resin shows a fairly random variation in the amount of DNA bound with a slight increase in binding over time. The model (first order) for this data gives a negative dissociation constant (negative of the slope of the linear fit model) but the variation in the value of that rate constant (variance of the slope) is twice its value. Therefore, within the variance of the value for the rate constant there is no change over the period of the experiment. 


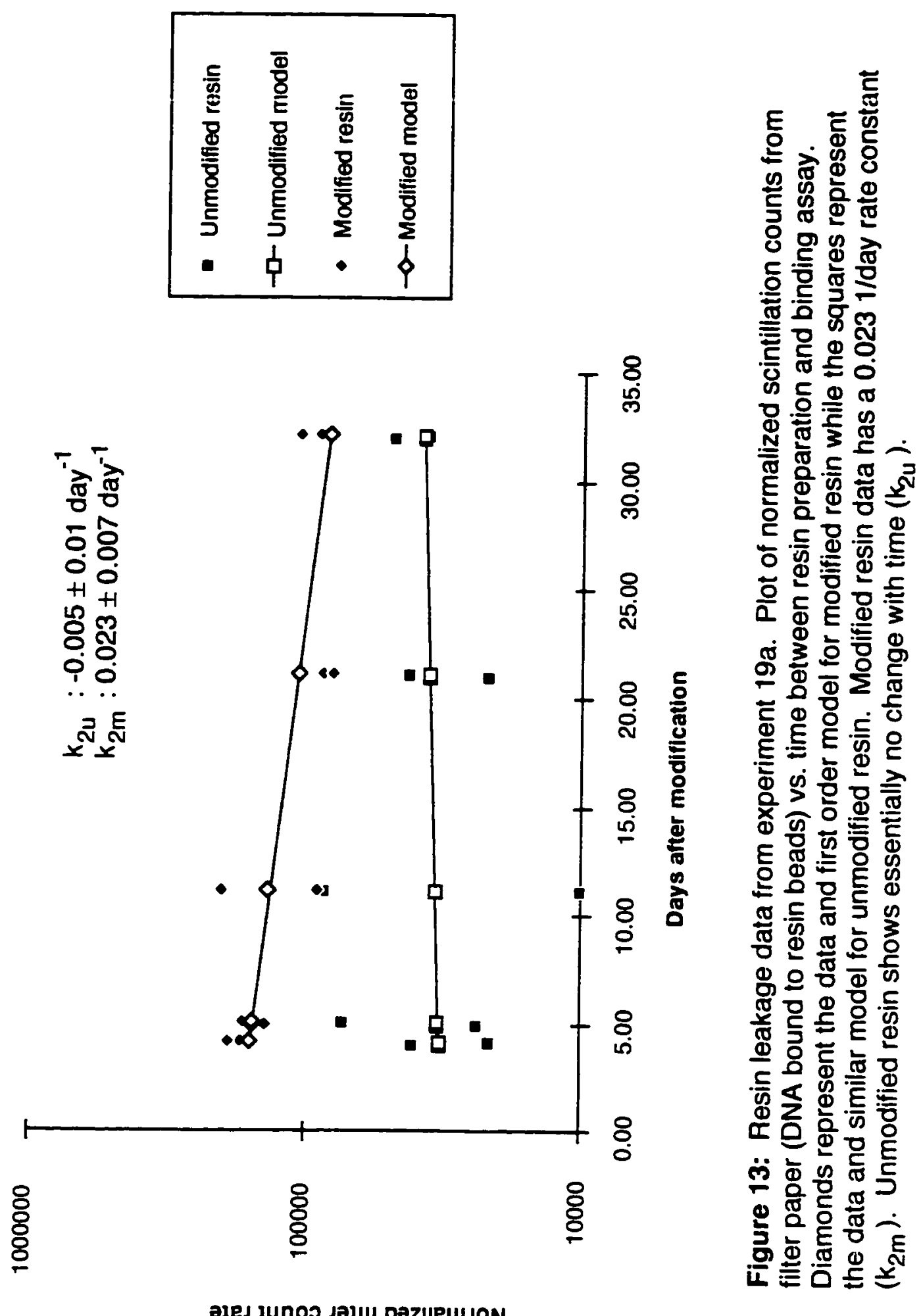


The data for the P1 substituted REACTI-GEL shows a marked decrease in the amount of DNA bound over the period of the experiment. When this data is modeled, assuming a first order rate equation, a rate constant of $0.023 \pm$ 0.007 day $^{-1}\left(2.66 \times 10^{-7} \pm 8.10 \times 10^{-8} \mathrm{~s}^{-1}\right)$ results. This translates into a loss of $10 \%$ of the protein off the substituted resin in 4.6 days.

Most of the results in this report were taken with resin that was substituted within 14 days of use. In no case was the resin more than 21 days old. The rate constant reported above would indicate that even at 21 days after the resin was prepared at least $62 \%$ of the protein that was placed on the resin to begin with was present and able to bind DNA at the time of the experiments.

Dissociation Rate Constant Determination at $25^{\circ} \mathrm{C}$. The resin used in these tests was usually modified in batches that yielded enough material for one or two assay tests and two dissociation experiments. Occasionally, batches twice this size were processed. Table 2 lists the material information for the resin and DNA used in the dissociation experiments reported here.

Figures 14 and 15 depict the results from two of the dissociation experiments carried out at $25^{\circ} \mathrm{C}$. These experiments used different resin preparations. There were three samples used in each of the experiments; each is shown as a separate data set in the figures. One of the data sets is for a sample of DNA mixed with HEPES buffer and no resin; a second sample is for DNA mixed with unmodified (TRIS capped only) resin; and the final set is for a sample of DNA and P1 substituted resin.

Clearly, in both of the figures, the blank and unmodified resins show a slow drop in the ratio of bound to total label over the period of approximately one day, as shown by the clustering of the data for these samples along a straight line. The modified resin, on the other hand, shows a bi-phasic 
Table 2: Resin and DNA Preparation

Exper. Resin Prep. DNA Prep. S.A. (1) DNA(2) fDNA $^{(3)} \underline{N}_{\text {ATP }}{ }^{(4)}$

15 Exp. 14:3.375 $\mu \mathrm{g} / \mathrm{mL} \quad$ Exp. $14 \quad 1506 \quad 127 \quad 2.83 \times 10^{-4} \quad 22.0$

19a(5) Exp. 17: $3.375 \mu \mathrm{g} / \mathrm{mL} \quad$ Exp. $17 \quad 2497 \quad 127 \quad 4.70 \times 10^{-4} \quad 46.2$

$\begin{array}{lllll}\text { Exp. } 17 \quad 2427 \quad 127 & 4.57 \times 10^{-4} & 44.9\end{array}$

$\begin{array}{llll}\text { Exp. } 17 \quad 2108 & 127 & 3.97 \times 10^{-4} & 39.0\end{array}$

Exp. $17 \quad 2384 \quad 173 \quad 4.97 \times 10^{-4} 44.1$

Exp. $17 \quad 2330 \quad 173 \quad 4.38 \times 10^{-4} \quad 43.2$

$21 \quad$ Exp. 20: $1.125 \mu \mathrm{g} / \mathrm{mL} \quad$ Exp. 20(6) $372.6 \quad 127 \quad 7.01 \times 10^{-5} \quad 225$

$\begin{array}{lllll}\text { Exp. 20: } 3.375 \mu \mathrm{g} / \mathrm{mL} \quad \text { Exp. 20(6) } & 372.6 & 127 & 7.01 \times 10^{-5} & 225\end{array}$

$22 \quad$ Exp. 20: $3.375 \mu \mathrm{g} / \mathrm{mL} \quad$ Exp. 20(6) $332.8 \quad 127 \quad 6.26 \times 10^{-5} 201$

$25 \quad$ Exp. 24b: $1.50 \mu \mathrm{g} / \mathrm{mL}(7)$ Exp. 20(6) $200.2 \quad 127 \quad 3.77 \times 10^{-5} \quad 121$

1 Specific activity in $\mathrm{Ci} / \mathrm{mol}$.

2 Amount of DNA in the incubation tubes (in pmol).

3 Fraction of DNA labeled with ${ }^{33 p}$.

4 Number of fmol of [ $\gamma$-33P]ATP added to the incubation tubes.

5 Experiment 19a consisted of a series of experiments run over a period of about a month, the specific activity at each of the experiments is listed due to the decay of 33p over the experimental period.

6 The proportion of ATP that passed through the separation column was set to 0.05 rather than 0.147 due to a negative value that results for the NDNA value when the larger value was used, see Appendix B. S. A., fDNA ${ }^{*}$ and NATP" values for these experiments are suspect.

7 Thiol linked resin. 


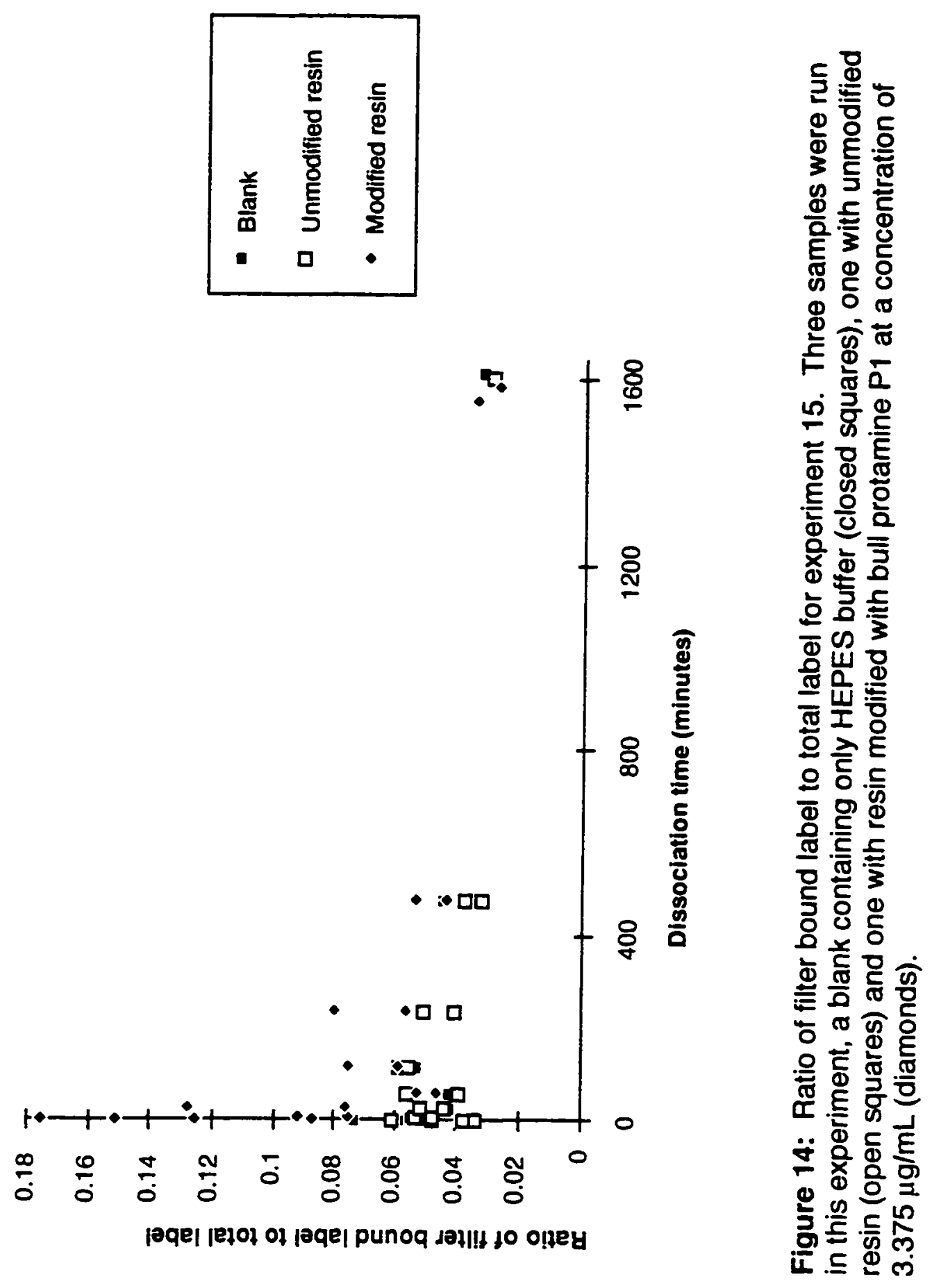




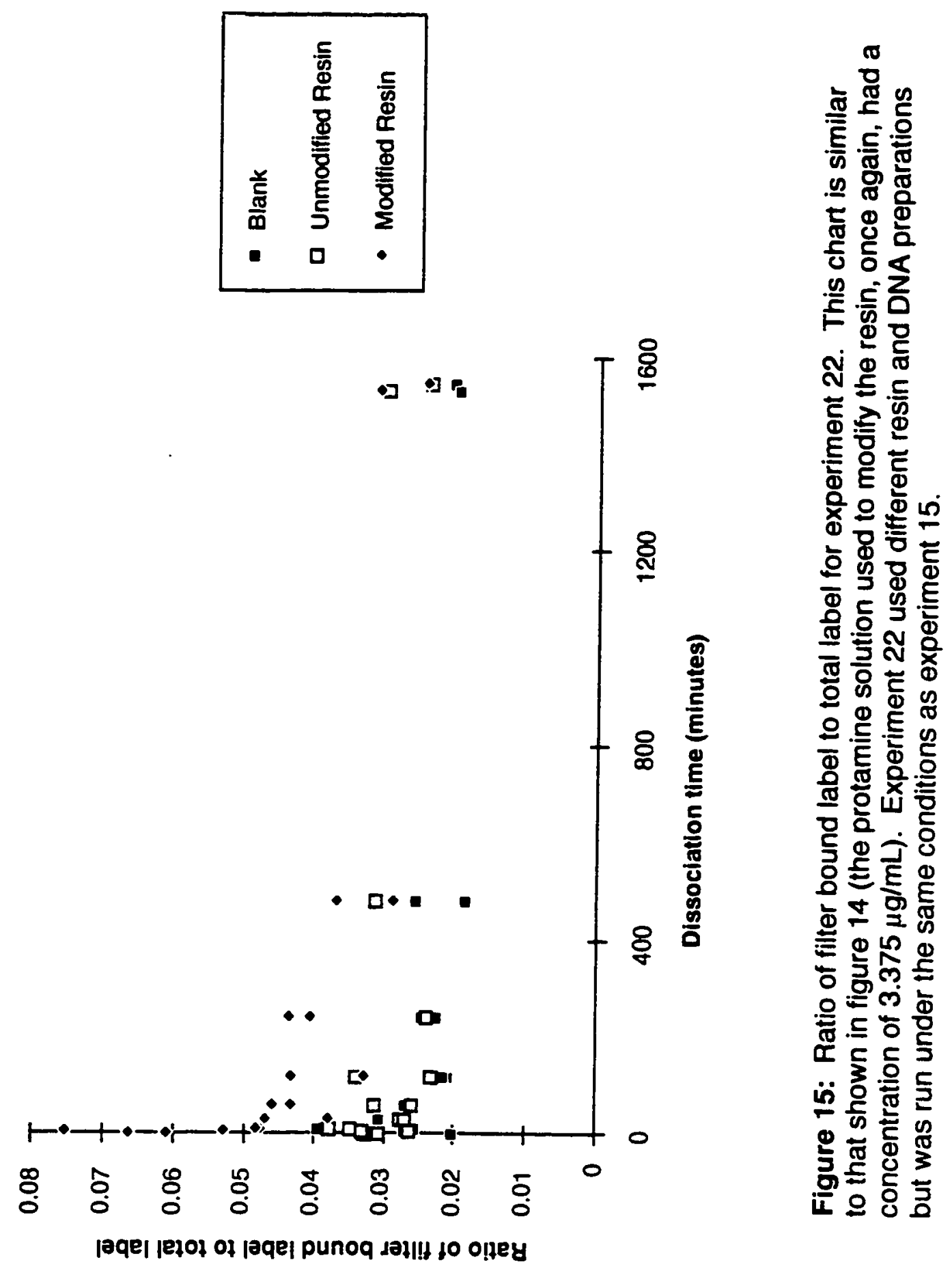


dissociation curve with an initial rapid drop (from 0 to $\sim 100$ minutes) followed by a slower fall that roughly parallels the drop seen for the blank and unmodified resin curves.

Another feature that can be seen is that the zero time ratios for the modified resins in Figures 14 and 15 are different. The actual amount of label bound to the modified resins at the zero dissociation time in these two experiments was also different, as can be seen in Table 3, which shows the raw data for these experiments. There are several factors that contribute to this variability. The actual substitution density on the resin likely varies from resin batch to resin batch. The amount of resin used in each of the initial association samples will vary from experiment to experiment. There is some variation in the amount of resin transferred in the $10 \mu \mathrm{L}$ aliquots from the association tubes to the dissociation tubes. Finally, the total amount of DNA placed in the association tubes will vary from experiment to experiment. In Table 2, it is shown that these two experiments used different resin and DNA preparations.

Variation in the specific activity can not account for the variation seen here. While variations in specific activity will result in variations in the scintillation counts found for label bound to resin samples deposited on filter papers in different experiments, specific activity variations are nulled out when the ratio of bound to total label is calculated. Figures 14 and 15 show that the ratios as well as the filter counts (Table 3 ) are varying. There are at least three possible sources for this variation; differing $\mathrm{P} 1$ substitution levels on the resin preparations, differing amounts of resin in each incubation sample, and differing concentrations of DNA in the incubations. 
Table 3: Radioactivity Determination for Experiments 15 and 22

\begin{tabular}{|c|c|c|c|c|c|c|c|}
\hline \multicolumn{5}{|c|}{ Experiment $1^{\dagger}$} & \multicolumn{3}{|c|}{ Experiment $22^{* *}$} \\
\hline Sample & $\frac{\text { Time }}{(\min )}$ & $\frac{\text { Supernat }}{\text { (cpm) }}$ & $\underset{\text { ant }}{\frac{\text { Filter }}{(\mathrm{com})}}$ & Sample & $\frac{\text { Time }}{(\min )}$ & $\frac{\text { Supernatan }}{\text { (cpm) }}$ & nt Filter \\
\hline Blank & $\begin{array}{c}0 \\
0 \\
5 \\
5 \\
10 \\
10 \\
30 \\
30 \\
60 \\
60 \\
120 \\
120 \\
240^{*} \\
240 \\
480^{*} \\
480 \\
1617^{*} \\
1616\end{array}$ & $\begin{array}{r}623.2 \\
592.4 \\
640.6 \\
695.4 \\
690.6 \\
608.0 \\
633.0 \\
789.2 \\
715.2 \\
856.2 \\
643.0 \\
700.2 \\
640.0 \\
631.8 \\
458.2 \\
944.4 \\
1126.4 \\
1128.8\end{array}$ & $\begin{array}{r}348.8 \\
479.0 \\
271.2 \\
426.6 \\
261.6 \\
367.0 \\
297.6 \\
436.4 \\
322.8 \\
398.2 \\
398.4 \\
407.6 \\
1153.8 \\
354.4 \\
3374.6 \\
456.8 \\
287.8 \\
404.4\end{array}$ & Blank & $\begin{array}{c}0 \\
0 \\
5 \\
5 \\
10 \\
10 \\
30 \\
30 \\
60 \\
60 \\
120 \\
120 \\
240 \\
240 \\
480 \\
480 \\
1547 \\
1532\end{array}$ & $\begin{array}{r}986.8 \\
516.2 \\
940.4 \\
941.6 \\
976.6 \\
909.4 \\
992.4 \\
931.4 \\
953.0 \\
1002.0 \\
1055.4 \\
1051.4 \\
1025.0 \\
1107.0 \\
1042.8 \\
984.4 \\
1118.2 \\
1195.6\end{array}$ & $\begin{array}{l}223.8 \\
187.0 \\
280.2 \\
351.4 \\
227.2 \\
391.0 \\
331.2 \\
285.4 \\
284.4 \\
297.6 \\
248.0 \\
251.2 \\
293.6 \\
275.0 \\
293.6 \\
207.6 \\
257.0 \\
263.2\end{array}$ \\
\hline $0 \mu \mathrm{g} / \mathrm{mL}$ & $\begin{array}{c}0 \\
0 \\
5 \\
5 \\
10 \\
10 \\
30 \\
30 \\
60 \\
60 \\
120 \\
120 \\
240 \\
240 \\
480 \\
480 \\
1606 \\
1588^{*}\end{array}$ & $\begin{array}{r}676.6 \\
733.8 \\
862.0 \\
613.6 \\
690.6 \\
742.6 \\
710.2 \\
691.2 \\
870.6 \\
671.8 \\
697.0 \\
740.6 \\
693.0 \\
871.6 \\
731.2 \\
932.8 \\
985.2 \\
1098.4\end{array}$ & $\begin{array}{r}283.0 \\
382.0 \\
320.8 \\
409.2 \\
401.6 \\
388.2 \\
343.0 \\
393.0 \\
370.8 \\
415.4 \\
448.0 \\
451.2 \\
312.6 \\
485.0 \\
306.0 \\
325.4 \\
318.6 \\
1527.2\end{array}$ & $0 \mu \mathrm{g} / \mathrm{mL}$ & $\begin{array}{c}0 \\
0 \\
5 \\
5 \\
10 \\
10 \\
30 \\
30 \\
60 \\
60 \\
120 \\
120 \\
240 \\
240^{*} \\
480 \\
480^{\circ} \\
1545 \\
1517\end{array}$ & $\begin{array}{r}991.0 \\
831.6 \\
932.4 \\
842.8 \\
924.4 \\
838.8 \\
883.6 \\
913.6 \\
873.8 \\
887.4 \\
969.2 \\
947.8 \\
966.6 \\
953.4 \\
992.8 \\
227.8 \\
1079.0 \\
918.6\end{array}$ & $\begin{array}{r}354.6 \\
280.6 \\
270.8 \\
306.8 \\
350.0 \\
347.0 \\
271.6 \\
271.4 \\
251.6 \\
306.4 \\
252.6 \\
351.8 \\
258.4 \\
1044.6 \\
339.4 \\
975.8 \\
284.0 \\
301.4\end{array}$ \\
\hline $\begin{array}{l}3.375 \\
\mu \mathrm{g} / \mathrm{mL}\end{array}$ & $\begin{array}{l}0 \\
0 \\
5 \\
5\end{array}$ & $\begin{array}{l}714.6 \\
666.2 \\
754.0 \\
756.4\end{array}$ & $\begin{array}{r}1259.2 \\
1398.0 \\
728.8 \\
1079.4\end{array}$ & $\begin{array}{l}3.375 \\
\mu \mathrm{g} / \mathrm{mL}\end{array}$ & $\begin{array}{l}0 \\
0 \\
5 \\
5\end{array}$ & $\begin{array}{l}978.2 \\
970.2 \\
973.8 \\
946.8\end{array}$ & $\begin{array}{l}651.0 \\
702.8 \\
806.6 \\
545.8\end{array}$ \\
\hline
\end{tabular}


Table 3: Data for Experiments 15 and 22 (continued) Experiment ${ }^{\dagger}{ }^{\dagger}$

Experiment 22**

Sample Time Supeinatant Filier Sampie Time Supernatant Fiiter

$\begin{array}{rrrrrrrr}3.375 & \frac{(\mathrm{min})}{10} & \frac{(\mathrm{cpm})}{686.2} & \frac{(\mathrm{cpm})}{571.4} & 3.375 & \frac{(\mathrm{min})}{10} & \frac{(\mathrm{cpm})}{921.2} & \frac{(\mathrm{cpm})}{479.0} \\ \mu \mathrm{g} / \mathrm{mL} & 10 & 695.4 & 708.8 & \mu \mathrm{g} / \mathrm{mL} & 10 & 909.8 & 478.4 \\ & 30 & 655.0 & 952.4 & & 30 & 924.6 & 471.8 \\ & 30 & 805.4 & 674.2 & & 30 & 1047.4 & 430.6 \\ & 60 & 885.2 & 514.2 & & 60 & 1060.8 & 527.4 \\ 60 & 1203.0 & 608.4 & & 60 & 1048.0 & 492.2 \\ 120 & 861.2 & 442.2 & & 120 & 990.2 & 465.8 \\ 120 & 824.8 & 686.6 & & 120 & 1171.8 & 417.4 \\ 240 & 762.8 & 675.0 & & 240 & 990.4 & 468.2 \\ 240 & 740.8 & 463.4 & & 240 & 982.2 & 433.8 \\ 480 & 958.4 & 561.0 & & 480 & 1040.8 & 330.6 \\ 480 & 936.0 & 446.8 & & 480 & 1066.8 & 427.4 \\ 1586 & 1158.0 & 356.6 & & 1533 & 1150.8 & 310.2 \\ 1553 & 1129.0 & 430.8 & & 1517 & 1077.2 & 368.2\end{array}$

- Data points not included in analysis due to anomalous results (i.e., low supernatant count, abnormally high filter count or other processing errors).

$\dagger$ Specific activity for Experiment 15 was $8930 \mathrm{cpm} / \mathrm{pmol}$. Total DNA used per incubation tube was $25.5 \mathrm{pmol}$.

* Specific activity for Experiment 22 was $8886 \mathrm{cpm} / \mathrm{pmol}$. Total DNA used per incubation tube was 26.0 pmol. 
This variability of the initial binding ratio means that the data from different experiments can not be simply merged, as noted in the methods and materials section.

The first step in analyzing the data collected from the dissociation experiments was the determination of the rate constant and the zero time intercept for the slow component in the ratio of bound to total label seen in the data (Figures 14 and 15). Modeling of a first order dissociation process for the blank and unsubstituted resins for one of the experiments is shown in Figure 16.

A similar analysis was used on the substituted resin data for each of the experiments, one of which is shown in Figure 17. In the case of the substituted resin data, only data points that were clearly beyond the initial rapid decrease were used to evaluate the rate constant for the slow process. For the experiments analyzed here, that translates to the last three or four replicates of the nine taken for each series $(4,8$ and 24 hours of dissociation and for some experiments, the 2 hour point). The slow rate constants and zero time intercepts for all of the experiments used to determine rate constants for the protamine substituted REACTI-GEL are shown in Table 4.

Because this slow change in the fraction of total label that bound to the filter effects all sets of data, including the blank that contained no resin at all, the process involved must be related to the experimental system itself. This process could involve some property of the labeled DNA, the residual [ $\gamma$ 33PJATP that passed through the Quick-spin column, an interaction of the labeled DNA or residual [ $\gamma$ 33P]ATP and the incubation container, or an effect of material from an earlier step (such as the T4 kinase from the labeling procedure) on the labeled DNA or residual [ $\gamma$ 33P]ATP. 


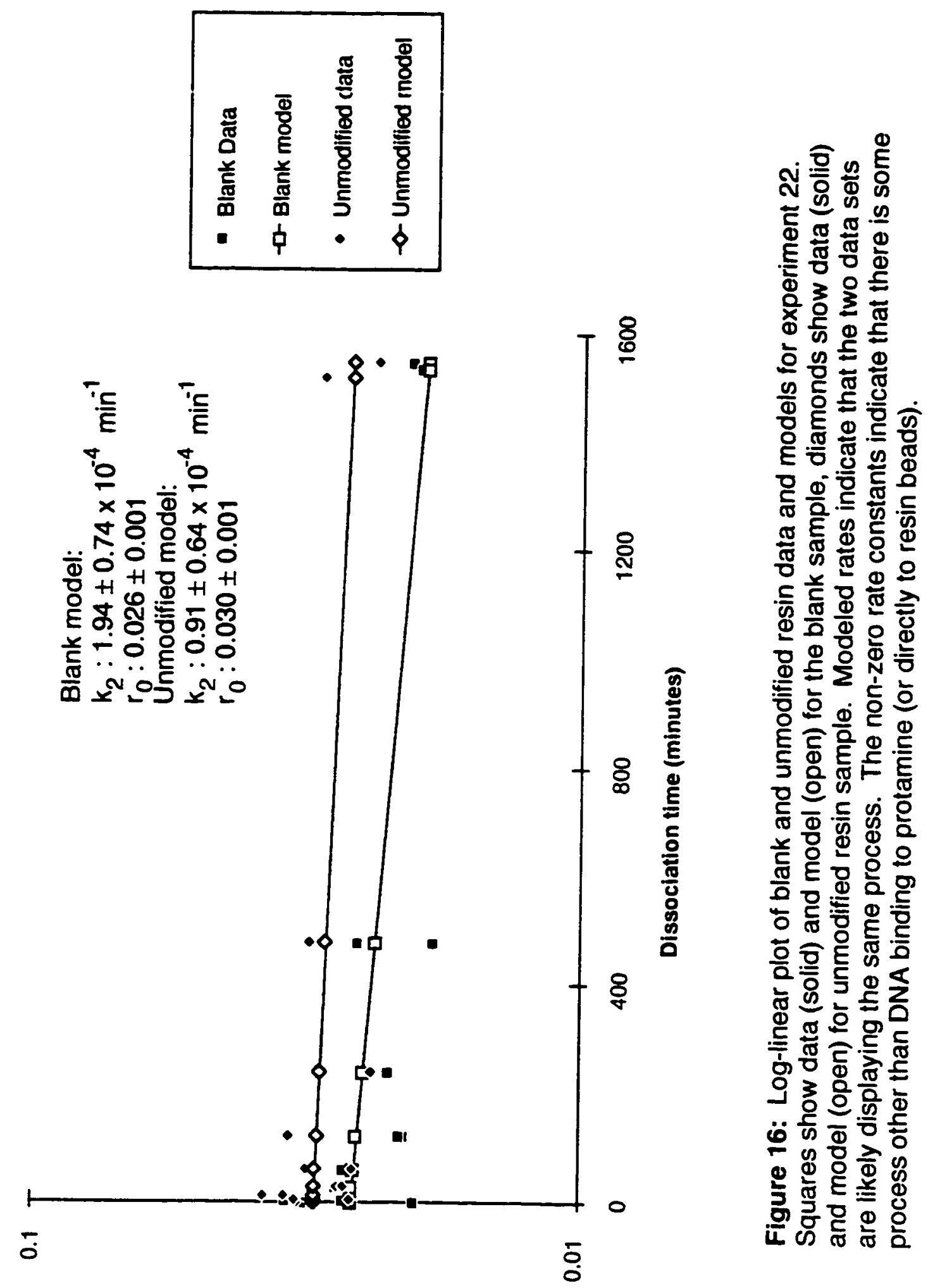

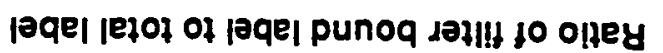




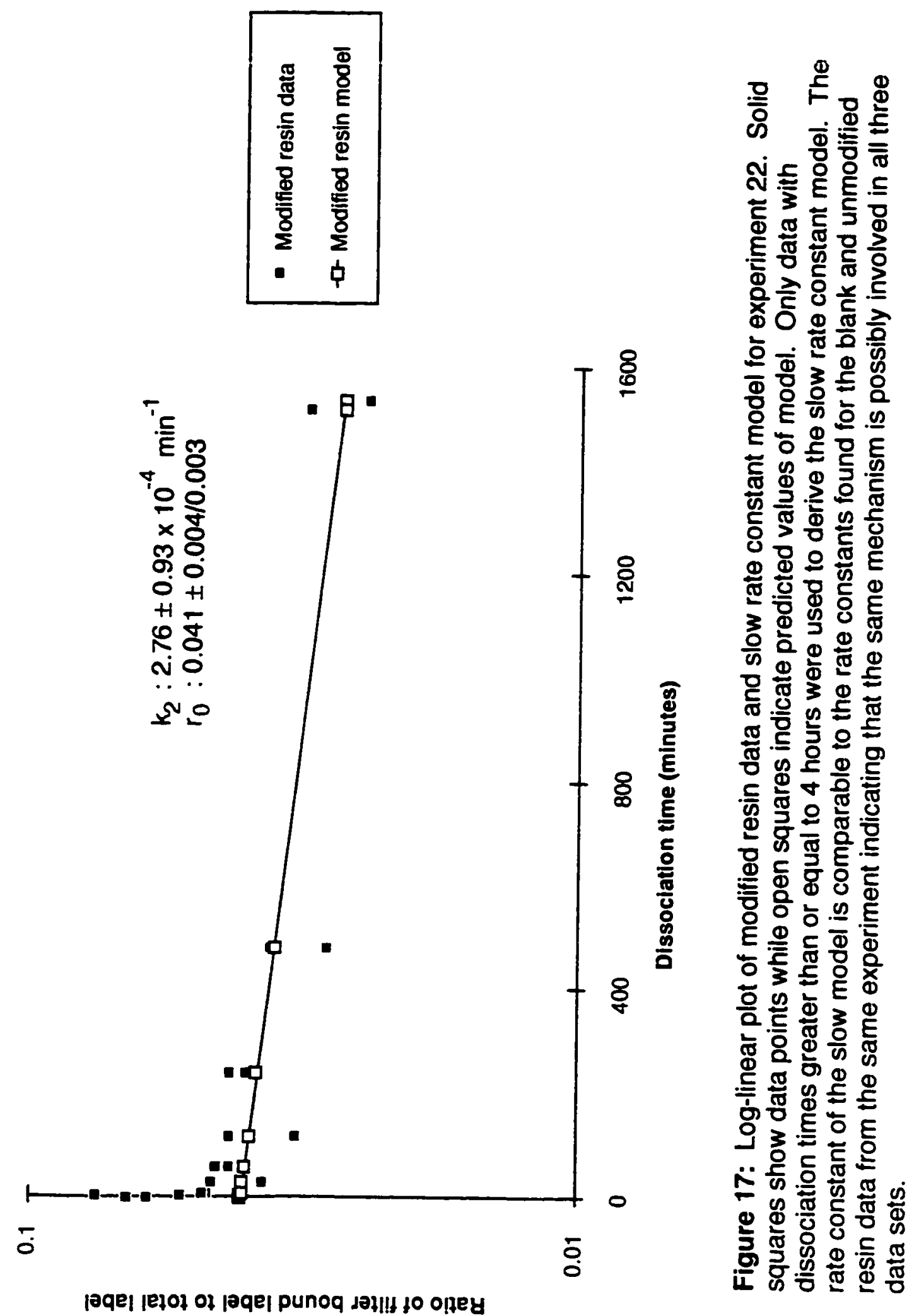


It is apparent from Table 4 that the variation of the slow rate constant between data sets, a total range of approximately a factor of 10 , is substantially larger than the standard deviation of each data set. This would seem to indicated that the slow rate constant is not closely associated with some property of the incubation container since the same type and batch of container was used in each experiment. On the other hand, the variation between data sets within an experiment is much smaller, a factor of about 3.

Experimental work to identify the source of the slow rate constant is described later in this paper.

The slow rate constants and zero time intercepts that were determined in the operation above can be used to strip the slow response from data sets that show a faster rate constant. Figures 14 and 15 show that only the data sets for the P1 substituted resins have a faster rate process involved; this is consistent with all the experiments done during this study. When this data is stripped of the slow component, the resultant graphs for the same data shown in Figures 9 and 10 produce the graphs shown in Figures 18 and 19. Due to the noise in the data, errors will be introduced into the calculated rate constant and $\left[C_{0}\right]$ values for the slow response model produced for each set of data. This will result in some of the data points falling below $0 \%$ count ratio when the slow response model is subtracted from the observed data, as can be seen in Figures 18 and 19. In extracting the fast rate constant from this stripped data, the negative values are ignored.

The fast rate constant can be extracted from the stripped data by repeating the procedure described above on the data points that clearly are dominated by the fast process. For the experiments done here, dissociation times of up to 60 minutes were used for the rate constant extraction. The 
Table 4: Slow Rate Constant Determinations, $25^{\circ} \mathrm{C}$

\begin{tabular}{|c|c|c|c|}
\hline Experiment & Data Set & Rate Const. $\left(\mathrm{min}^{-1}\right)$ & $\underline{0 \text { Time Inter. (fract) }}$ \\
\hline \multirow[t]{3}{*}{15} & Blank & $2.45 \pm 1.21 \times 10^{-4}$ & $0.049 \pm 0.003$ \\
\hline & Unmod. & $3.41 \pm 1.13 \times 10^{-4}$ & $0.047 \pm 0.002$ \\
\hline & $3.375 \mu \mathrm{g} / \mathrm{mL}$ P1 & $5.30 \pm 1.10 \times 10^{-4}$ & $0.070+0.008,-0.007$ \\
\hline \multirow[t]{4}{*}{21} & Blank & $0.70 \pm 1.00 \times 10^{-4}$ & $0.031 \pm 0.002$ \\
\hline & Unmod. & $0.57 \pm 0.75 \times 10^{-4}$ & $0.032 \pm 0.001$ \\
\hline & $1.125 \mu \mathrm{g} / \mathrm{mL} \mathrm{P}_{1}$ & $1.37 \pm 0.54 \times 10^{-4}$ & $0.041 \pm 0.002$ \\
\hline & $3.375 \mu \mathrm{g} / \mathrm{mL}$ P1 & $2.16 \pm 0.80 \times 10^{-4}$ & $0.045+0.004,-0.003$ \\
\hline \multirow[t]{3}{*}{22} & Blank & $1.94 \pm 0.74 \times 10^{-4}$ & $0.026 \pm 0.001$ \\
\hline & Unmod. & $0.91 \pm 0.64 \times 10^{-4}$ & $0.030 \pm 0.001$ \\
\hline & $3.375 \mu \mathrm{g} / \mathrm{mL} \mathrm{P}_{1}$ & $2.76 \pm 0.93 \times 10^{-4}$ & $0.041+0.004,-0.003$ \\
\hline
\end{tabular}




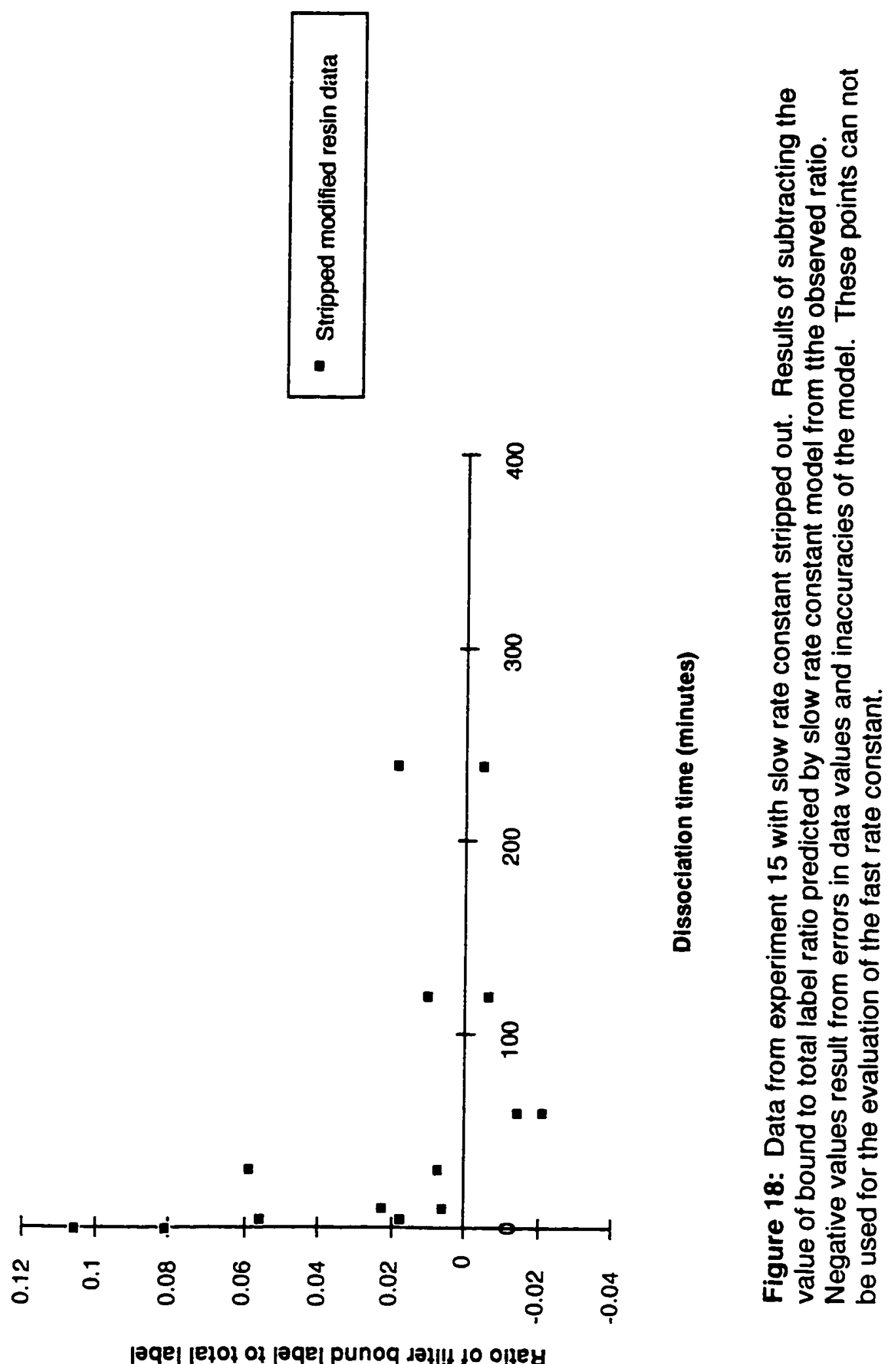




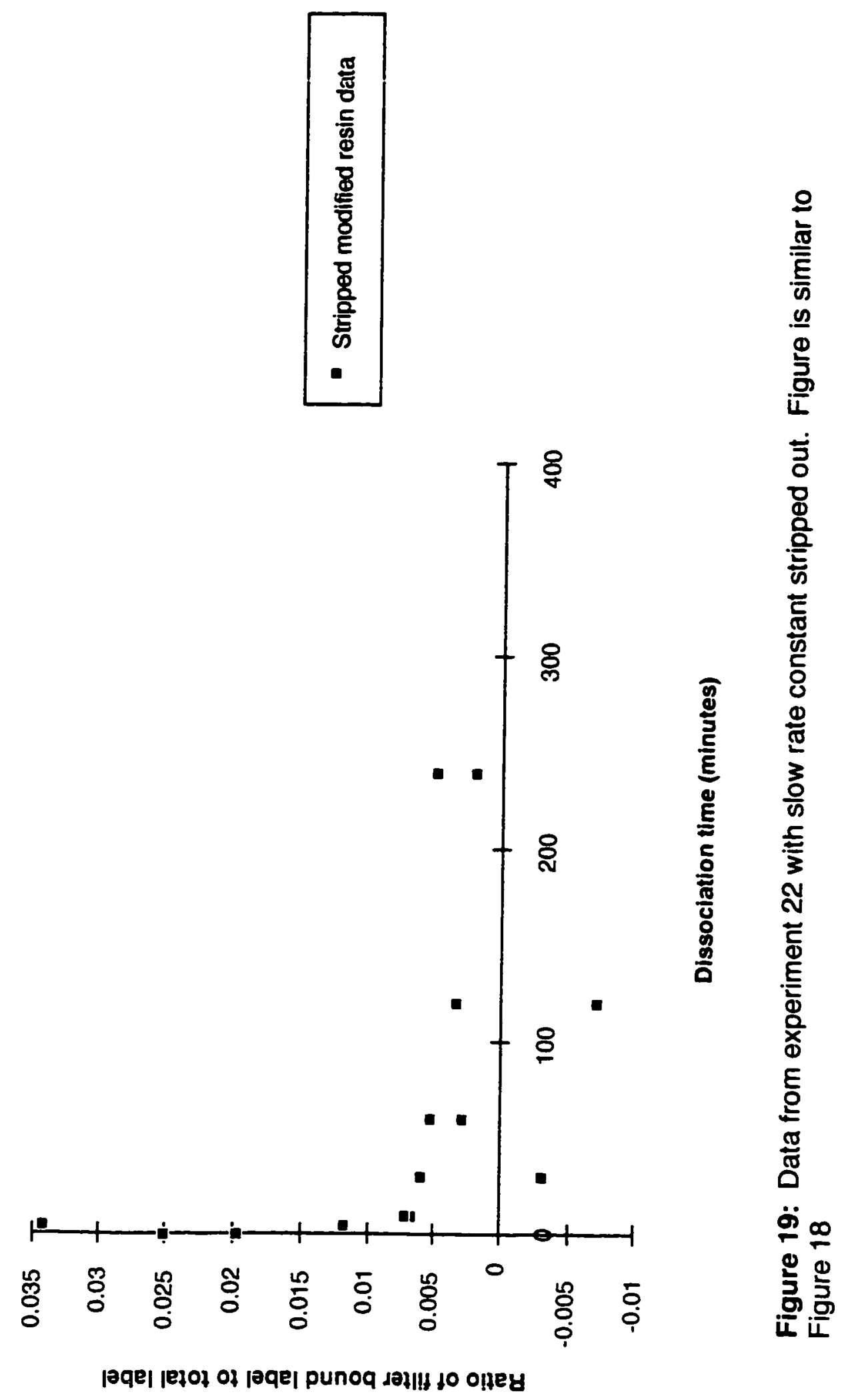


result of the procedure on the data in Figures 18 and 19 are shown in Figures 20 and 21. Table 5 gives the complete set of derived fast rate constants for P1 substituted REACTI-GEL at $25^{\circ} \mathrm{C}$.

Table 5 shows that the fast rate constant found in this data is about two orders of magnitude larger than the slow rate constant determined from the same data. However, there is a factor of greater than two between the rate constants determined in four sets of data. Combining the data from the different experiments should allow a consensus value to be determined. To meld this data together, the data must be normalized to take into account the varying amount of protamine that is available in each dissociation experiment. The easiest way to do this is to divide the count ratio value for each data point by the derived zero time count ratio (zero time intercept) for each data set. This has the effect of setting the maximum ratio of all four data sets to 1 . It should be noted that because there is uncertainty in the zero time count ratio and due to the noise in the data itself, some data points will have a normalized value greater than 1 . Once the data has been normalized and combined, (with the negative data points once again removed) the curve fitting procedure can be used to derive a rate constant value based on the combined data. The normalized data and the resulting model are shown in Figure 22. The resultant rate constant is $0.0247 \pm 0.0051 \mathrm{~min}^{-1}(4.12 \pm 0.85 \mathrm{x}$ $\left.10^{-4} \mathrm{sec}^{-1}\right)$. This value should be considered valid for conditions of $25 \pm 0.5$ ${ }^{\circ} \mathrm{C}, 7.4 \pm 0.1 \mathrm{pH}, 100 \pm 10 \mathrm{mM} \mathrm{NaCl}$ concentration and approximately neutral oxidation potential (based on the lack of chemical components that will significantly shift the oxidation potential away from neutrality, such as DTT).

In order to evaluate the validity of the derived rate constants found with the carbamate linked protamine P1 in the experiments reported above, a single 


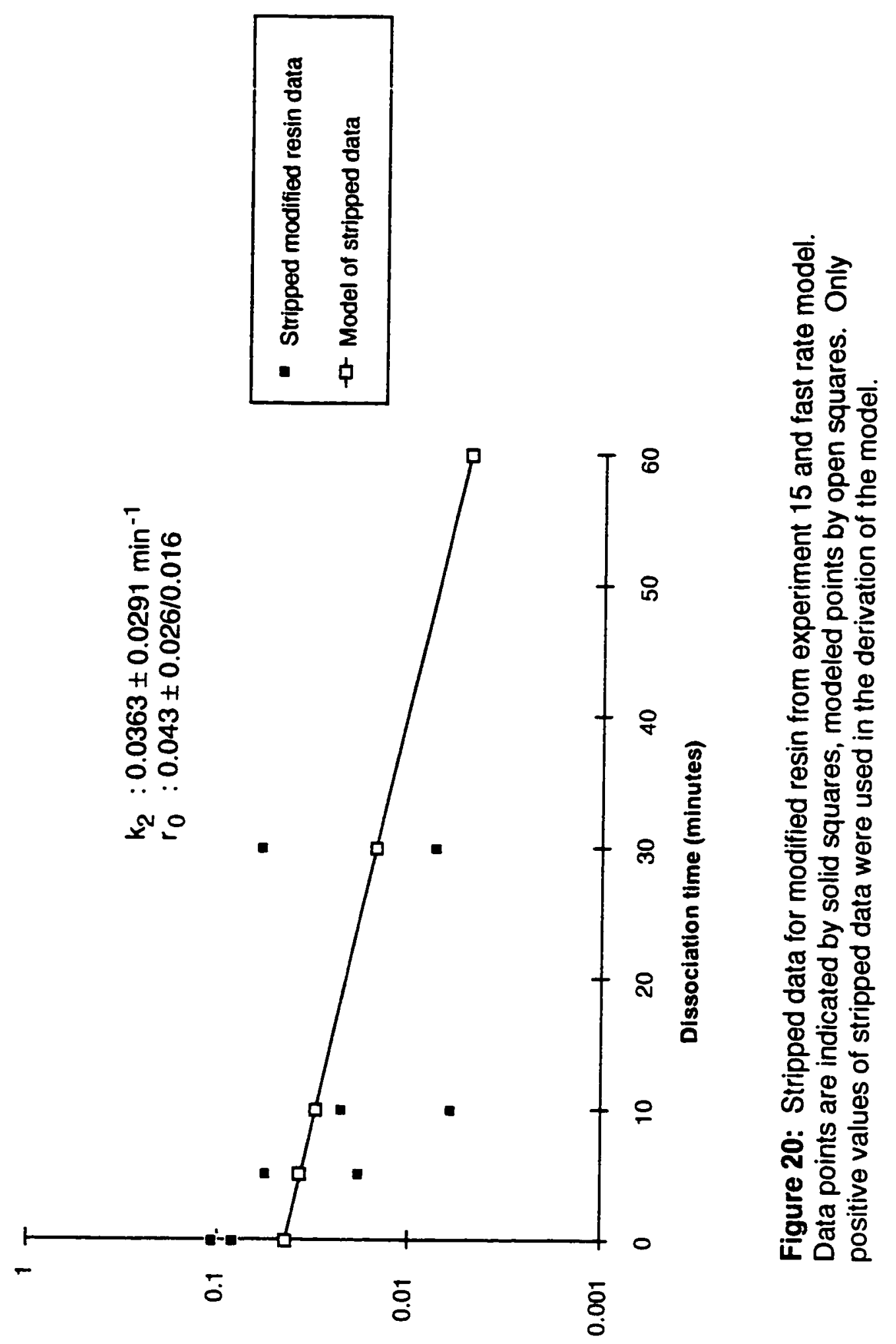

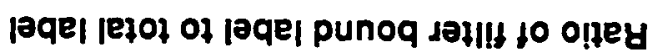




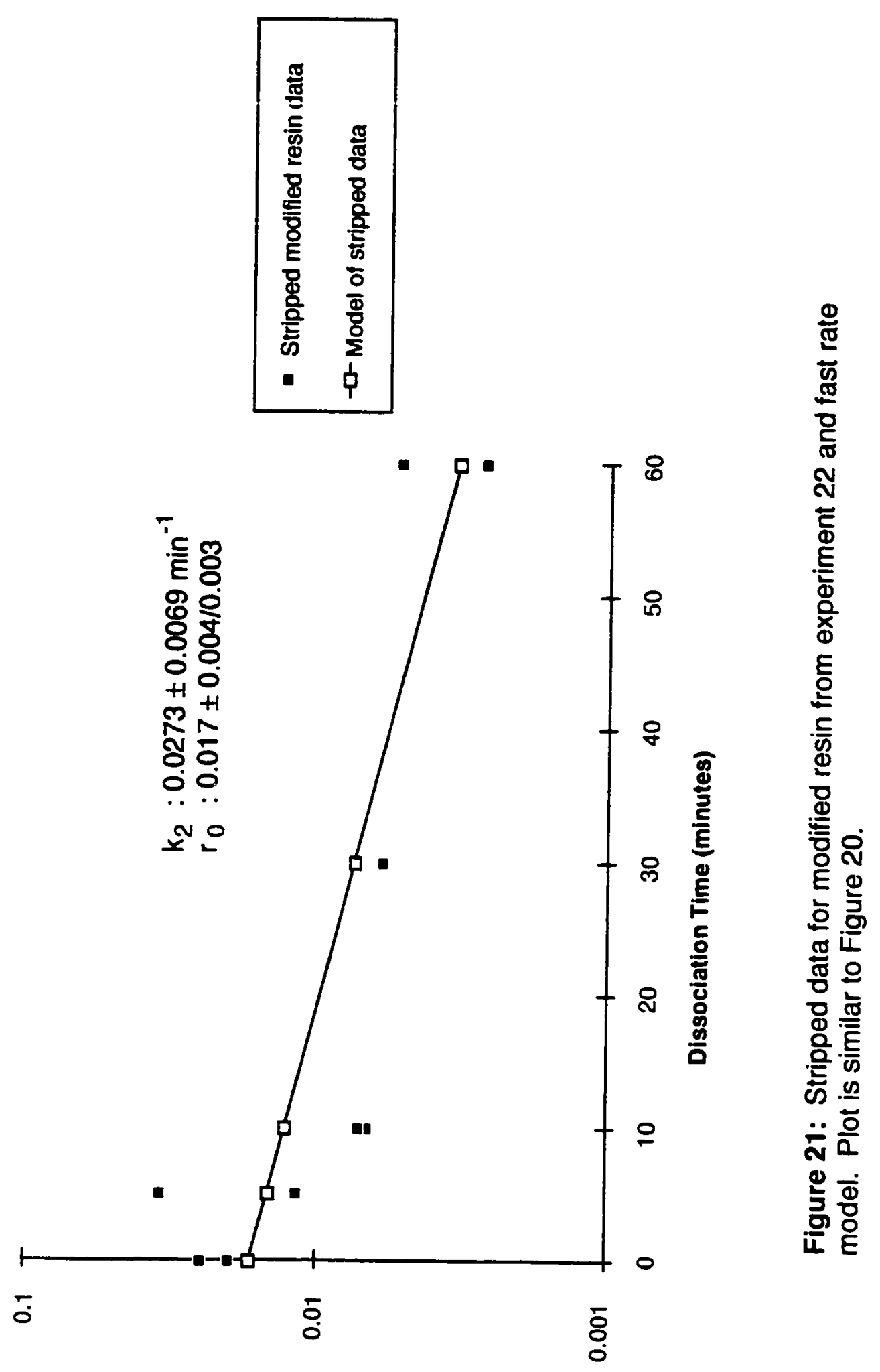

|əqe| jelol ol leqe| punoq sel|l to olfey 
Table 5: Fast Rate Constant Determinations, $25^{\circ} \mathrm{C}$

$\begin{array}{cccll}\text { Experiment } & \text { Data Set } & \text { Rate Const. }\left(\mathrm{min}^{-1} \text { ) }\right. & \text { 0 Time Inter. (fract) } \\ 15 & 3.375 \mu \mathrm{g} / \mathrm{mL} \text { P1 } & 3.62 \pm 2.91 \times 10^{-2} & 0.043+0.026,-0.016 \\ 21 & 1.125 \mu \mathrm{g} / \mathrm{mL} \text { P1 } & 3.64 \pm 0.22 \times 10^{-2} & 0.013 \pm 0.001 \\ & 3.375 \mu \mathrm{g} / \mathrm{mL} \text { P1 } & 1.53 \pm 0.33 \times 10^{-2} & 0.034+0.004,-0.003 \\ 22 & 3.375 \mu \mathrm{g} / \mathrm{mL} \mathrm{P1} & 2.73 \pm 0.93 \times 10^{-2} & 0.017+0.004,-0.003\end{array}$




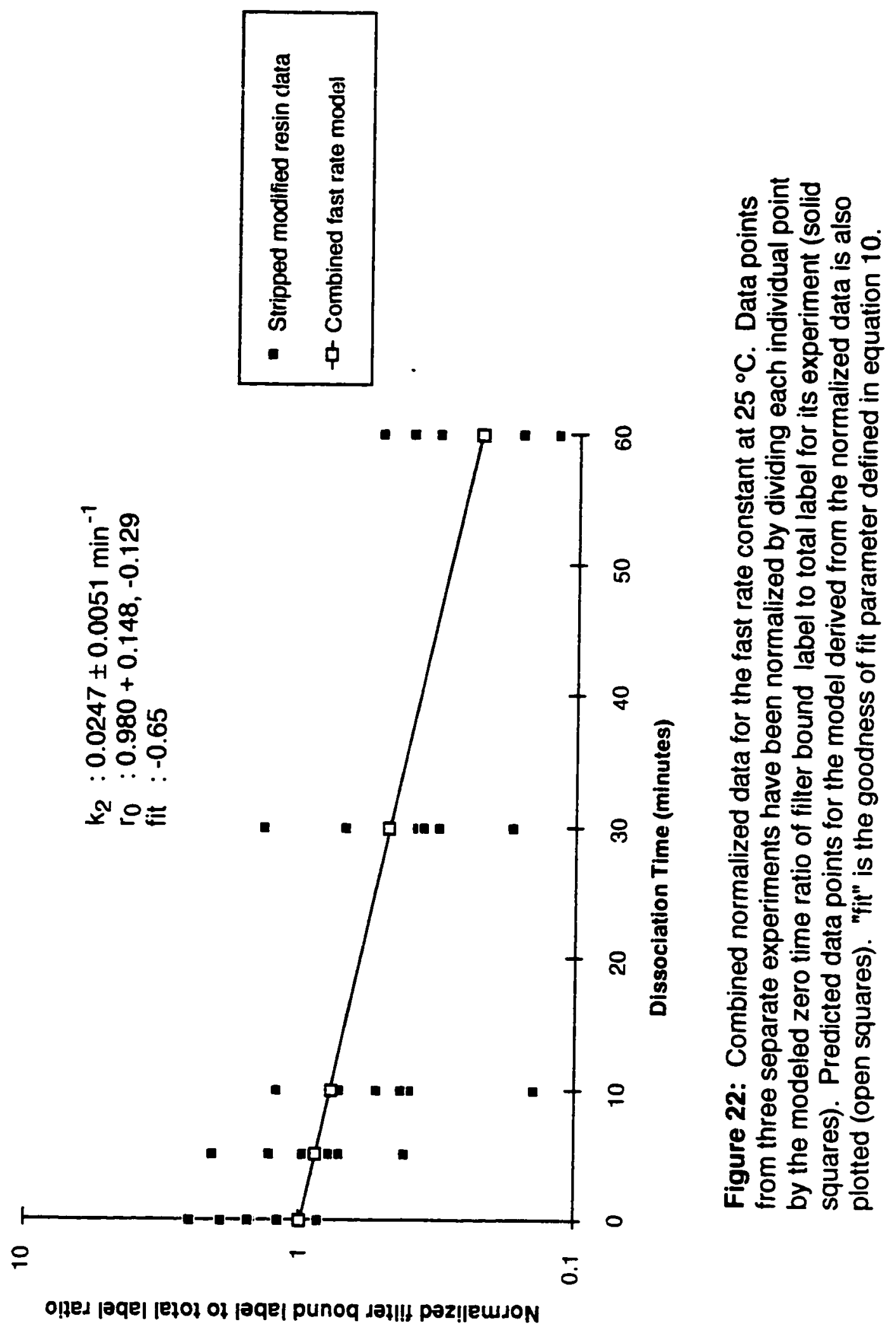


experiment was performed using protamine $\mathrm{P} 1$ linked to the thiol activated resin that has been used in previous studies in our lab. Figures 23, 24 and 25 show the data derived from that experiment. This experiment also shows the slow rate constant, Figure 24, as expected. The derived value of the fast rate constant, $0.010 \pm 0.019 \mathrm{~min}^{-1}\left(1.7 \pm 3.1 \times 10^{-4} \mathrm{sec}^{-1}\right)$ has a large variability due to the low number of data points used in its calculation. However, within that variation, it agrees with the value determined with the carbamate linked resin.

Slow Rate Constant. Because all of the experimental samples (blanks, unsubstituted resin controls and substituted resins) show a slow rate constant, examination of this phenomenon can be done with any of the sample materials. Because of the similarity between the slow rate constant values derived for the substituted resin, unsubstituted resin and the HEPES buffer blank, the assumption was made that the same process was involved for all three types of samples. Therefore, for the sake of simplicity, blank HEPES buffer samples were used in tests to identify the source of this slow rate constant.

Clearly, the presence of $33 \mathrm{P}$ is required for the slow rate constant to be examined. There are four possible forms that the radiolabel can take in these experiments: as the initial [33P- $\gamma$ ]ATP added to the DNA labeling mixture and not removed by the Quickspin gel filtration column; as 5'-33P-DNA, the intended form; as free ${ }^{33} \mathrm{PO}_{4}{ }^{3}$ - or one of the other forms of phosphate resulting from the hydrolysis of residual ATP; or finally as a 33P. phosphorylated larger molecule (such as the T4 polynucleotide kinase used in the labeling procedure). The slow rate constant, seen in all of the experiments described here, likely involves the transformation of the ${ }^{33} \mathrm{P}$ from 


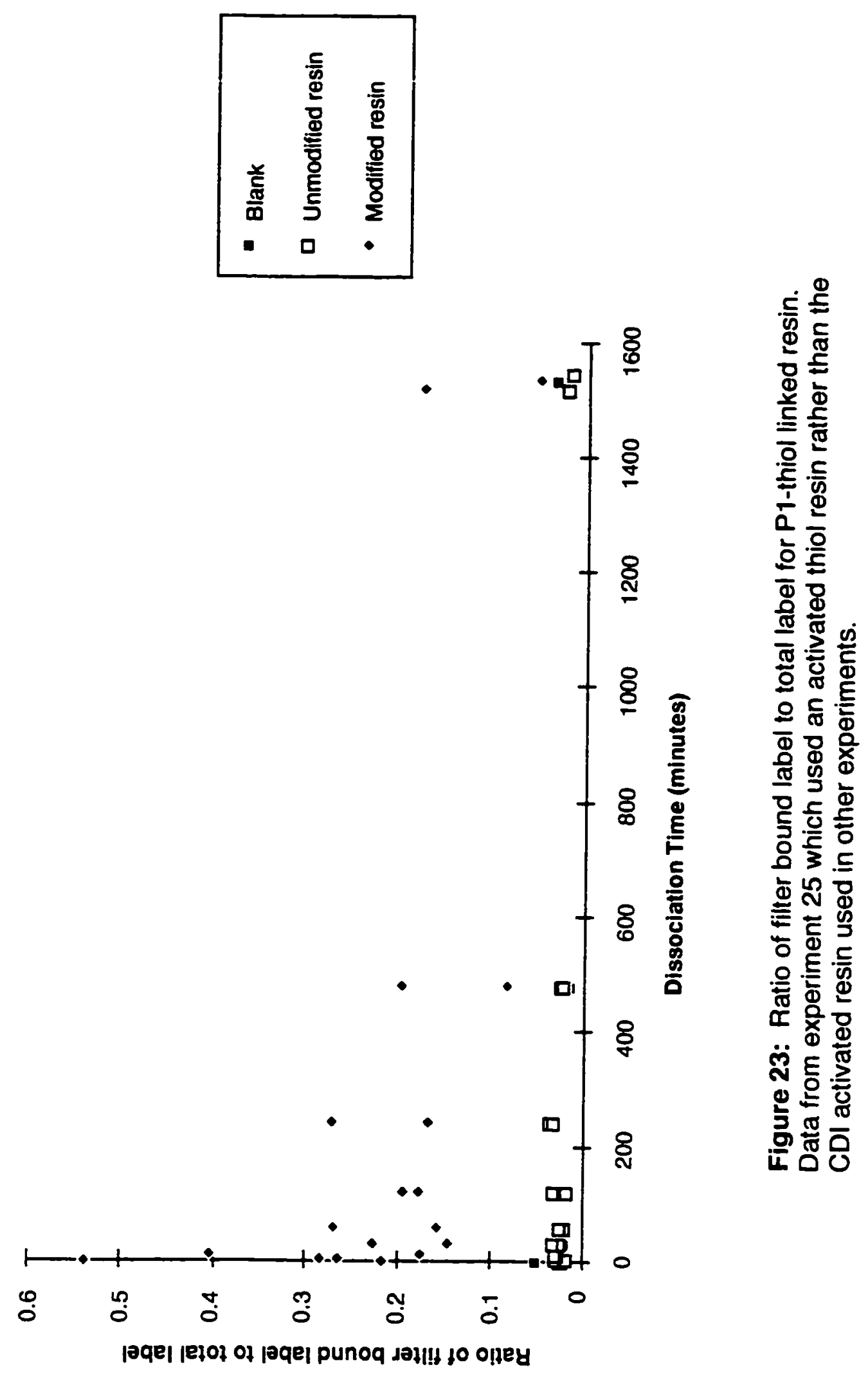




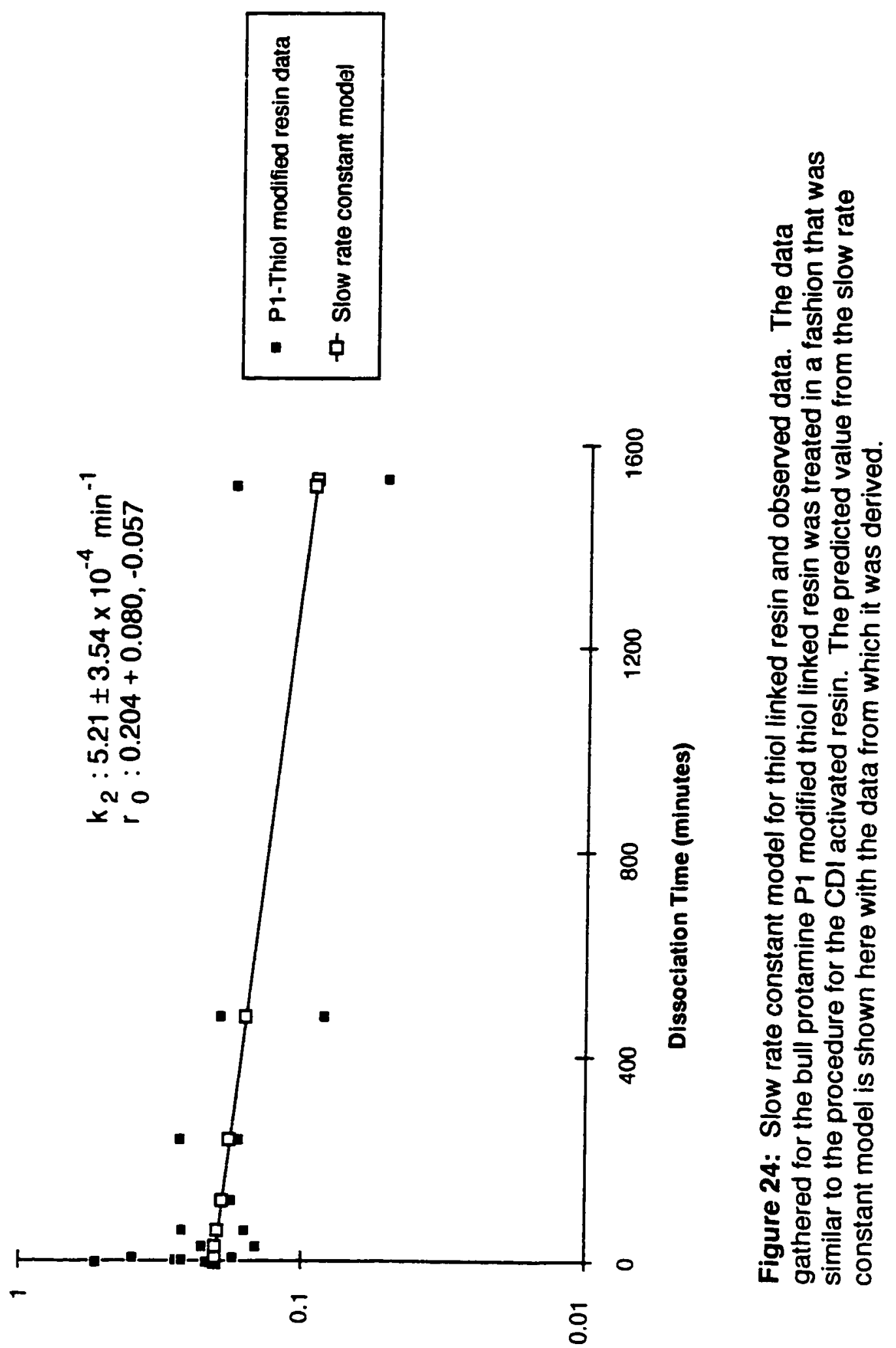

[aqe| letol of laqe| punoq dat!! to o!tey 


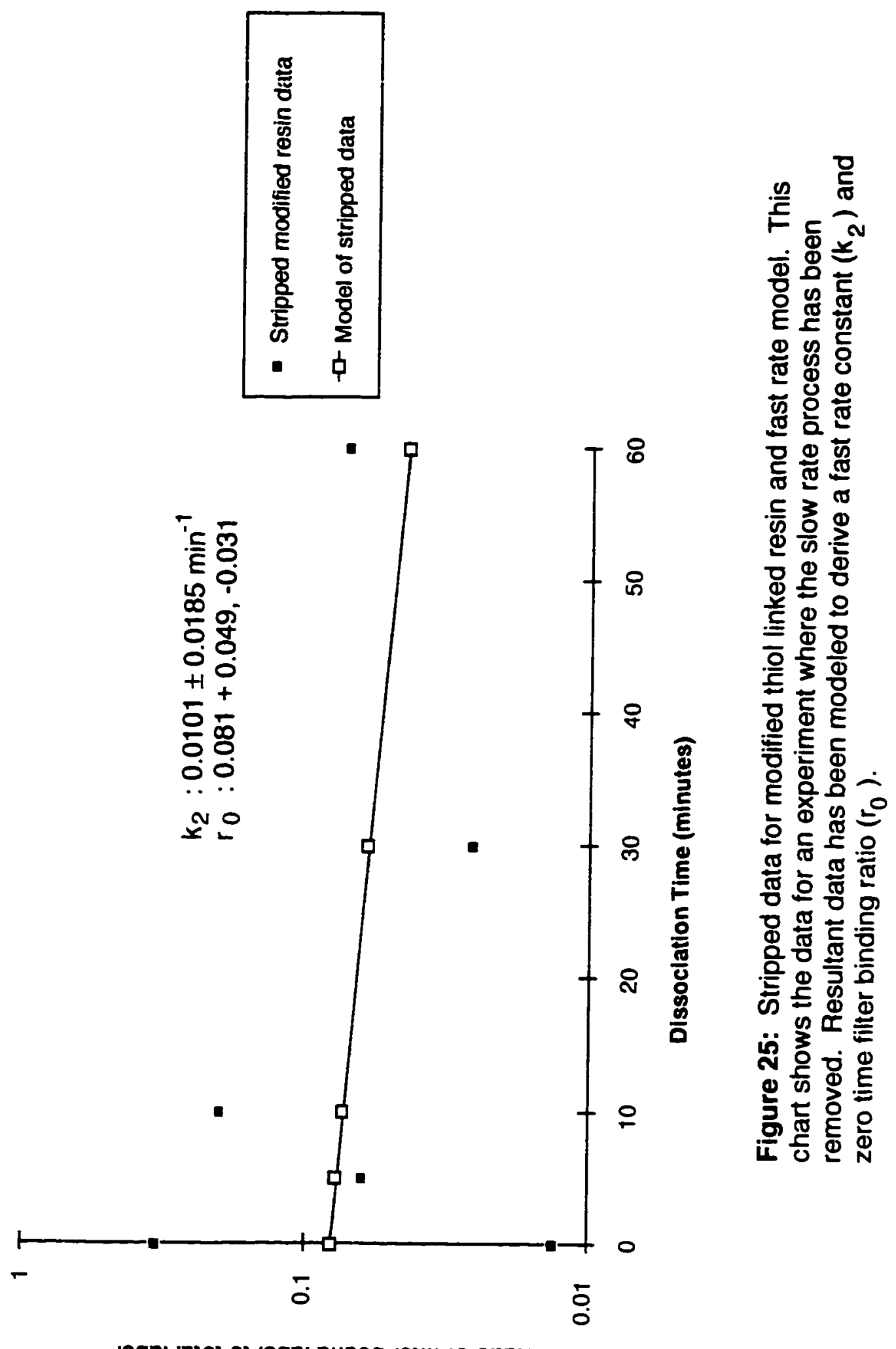

|əqe| jetol of joqe| punoq Jel|! to olfey 
one of these forms, which is retained by the nitrocellulose filter used in the dissociation experiments, to another form, which is not retained by the filter.

To try to determine which of these forms are involved in the slow rate constant, an experiment was performed which examined the role of each of the major components in the DNA labeling procedure. Four labeling mixtures were made, as shown in Table 6 . These mixtures were then individually processed in the same fashion as that described in the methods and materials section on DNA labeling with the exception that just before being passed through the Quickspin column the mixtures were diluted with HEPES buffer to $12.5 \mu \mathrm{L}$ volume rather than $50 \mu \mathrm{L}$. This change in dilution factor was made because the mixtures given in Table 6 represent a 4-fold reduction in volume for the labeling mixture (to conserve reagents) and a corresponding reduction in the dilution is needed to keep the concentration of the reactants the same as for a standard labeling sequence while they pass through the Quickspin column.

Evaluation of the properties of each of the mixtures was made by the same procedure as was used for the assay experiments described earlier. Each mixture was first diluted 1:1:3, as shown in Table 7 to simulate the dilution normally performed for an assay procedure to bring the specific activity and total DNA into the same ranges as used for dissociation experiments. One $\mu \mathrm{L}$ from each of the diluted mixtures was then individually incubated for one hour with $50 \mu$ L HEPES buffer, to simulate the normal association phase of a dissociation experiment. Once the incubation was complete, the four incubated mixtures were treated as per an assay experiment. That is, for each dissociation sample, $10 \mu \mathrm{L}$ of the appropriate solution was added to $1 \mathrm{~mL}$ HEPES-NaCl dissociation solution. Figure 26 
Table 6: Slow Rate Constant Experiment Labeling Mixtures

Solution Component

Water

Solution V (diluted 1:3 with HEPES)

[33P- $\gamma]$ ATP

12 bp DNA oligomer (diluted
\#1

2.75

1.0

1.25
\#2†

\#3

1:3 with HEPES)

0.0

0.0

2.3

HEPES buffer

$\dagger$ quantities in $\mu \mathrm{L}$

- Initial T4 Kinase solution had a concentration of between 0.8 and 1.0 units per $\mu \mathrm{L}$.
2.75

1.0

1.25

2.75

1.0

1.0

$\# 4^{\dagger}$

2.75

1.0

1.25

$0.0 \quad 1.0 \quad 1.0$

$\begin{array}{lll}1.3 & 0.0 & 1.3\end{array}$

$\begin{array}{lll}1.0 & 1.3 & 0.0\end{array}$

Table 7: Dilution Schedule for Slow Rate Constant Experiment

Dilution Component

Labeling mixture

Unlabeled DNA*

HEPES buffer
$\# 1+$

\#2†

$1.0 \quad 1.0$

0.0

0.0

4.0

4.0

+ quantities in $\mu \mathrm{L}$

\footnotetext{
Unlabeled DNA had a concentration of approximately $50 \mathrm{pmol} / \mu \mathrm{L}$
} 
shows the results of this experiment at 0 and $\sim 24$ hours dissociation time. 


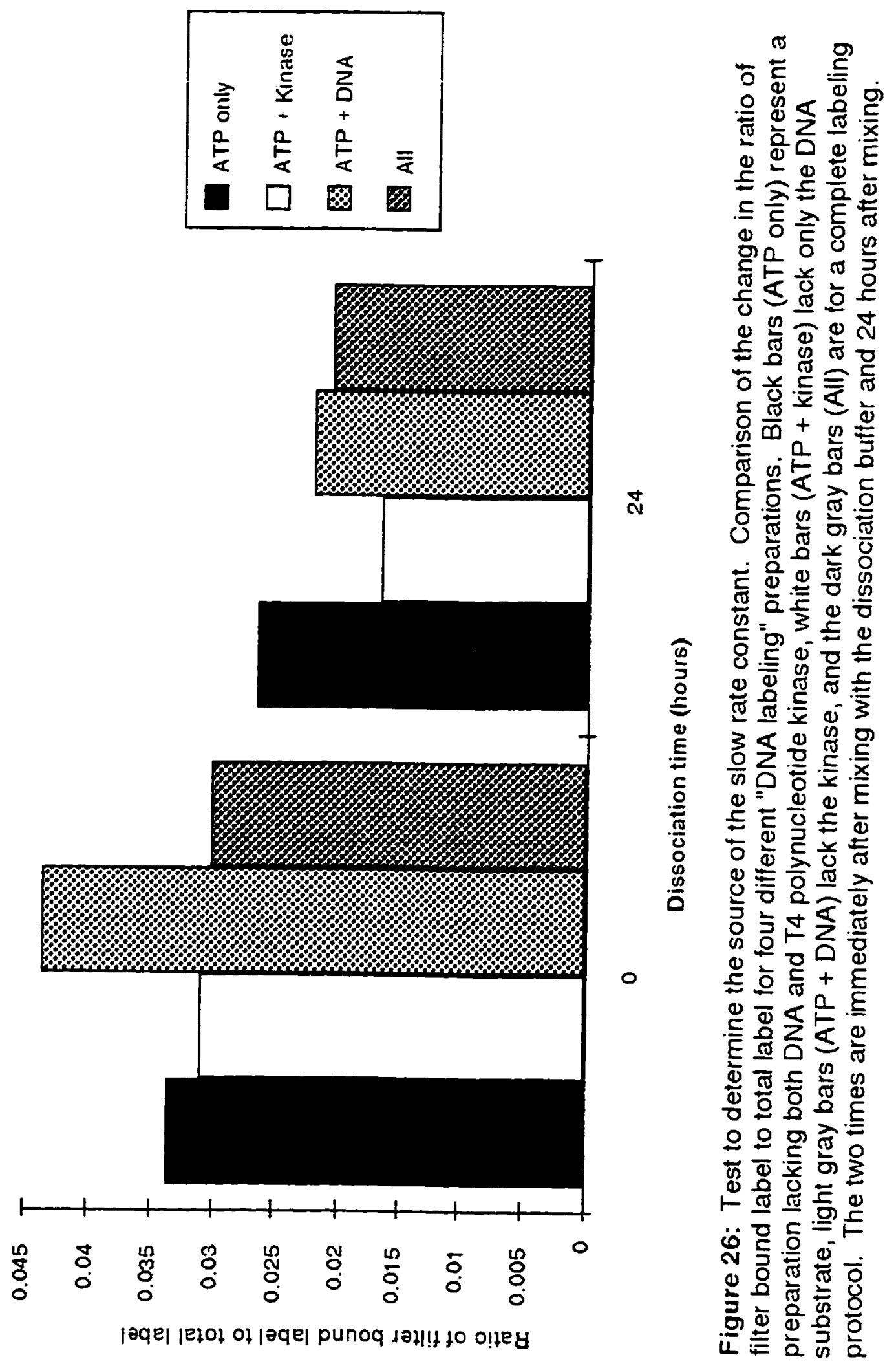




\section{Discussion}

\section{Utility of 1-1'-carbonyldiimidazole Activated Resins for Protamine}

Studies. There are five basic requirements for the solid substrate used in association or dissociation experiments. The first of these is a low background binding of both of the components (DNA and protamine in this case) of the association or dissociation experiment, with the background binding level of the free component being most important. Second, the substrate should be easily activated or, if preactivated, be stable when stored in the activated form. Third, the substrate should demonstrate controllable and repeatable substitution of the fixed component. Fourth, the resulting substituted substrate needs to be stable with a low leakage rate. Finally, the substrate must not interfere with the association or dissociation process.

Comparison of the bound to total ratios for blank (HEPES buffer only) and unsubstituted resin can be used to separate the background binding of the resin substrate and the filters used for removing the supernatant from the resin. Examination of the zero time intercept for the three experiments listed in Table $4(15,21$ and 22$)$ shows that there is a background binding ratio of roughly 3 to $5 \%$ of the total label for both the blank and unsubstituted resin samples at time 0 . Also in each of the experiments, the zero time intercept of the blank and unsubstituted resin samples track each other, generally falling within the measurement error. These results are typical of all the experiments that were performed in this work (for both the imidazolyl carbamate and thiol linked resins). This indicates that the background binding of the resin used in this study was minimal, well below the background binding associated with the filter used. (It should be noted that no wash of the resin and filter was used in this procedure so much of the background binding could be residual 
supernatant absorbed by the filter. However, the filters were pre-washed with water.)

Stability of the 1-1'-carbonyldimidazole activated resin used in this study was quite good. All of the experiments reported here, and many early experiments used to characterize the protocol (not reported here), were done with a single lot of REACTI-GEL (6X) resin. The time period involved in the work was about 18 months. During that time, there was no noticeable change in the behavior of the resin other than a slight aggregation of the material into lumps in the source bottle. In particular, there did not appear to be any reduction in the efficiency of the substitution reaction that could be attributed to the resin.

One of the most difficult aspects of this study was the controllable substitution of the bull protamine $\mathrm{P} 1$ onto the resin substrate. It was found that when the $A_{280} / A_{320}$ value of the protamine solution was above 5 (data not shown), significant binding of label was seen for the zero time data point for protamine concentrations of $3.375 \mu \mathrm{g} / \mathrm{mL}$. For cases where the $A_{280} / A_{320}$ value fell below 5, Table 1 shows that much higher concentrations of protamine are needed to obtain enough substitution on the resin to bind significant DNA.

There are two possible reasons for this behavior. If significant portions of the protamine that contributes to the $A_{230}$ absorption peak are bound up in aggregates that do not substitute onto the resin, then the available protamine in each solution is significantly lower than reported. Alternately, the protamine that is in aggregates may substitute onto the resin but may not be able to bind DNA because the DNA can not reach the binding sites in the aggregates. Note that if these aggregates were substituted onto the resin and did bind 
DNA, it would be expected that irreversible binding of the DNA would result, rather than no binding, based on previous results. .22

Once a carbamate linkage is formed between the protamine and the resin, it is quite strong. The leakage of $10 \%$ of the protein in a period of 4.6 days (under conditions of $\mathrm{pH} 7.4$ and $4^{\circ} \mathrm{C}$ ) is a factor of 10 higher than the leakage reported for glycine ${ }^{31}$ but is still a reasonable value. Additionally, the leakage rate found here may, in part, be an artifact related to a change in the background binding caused by changes in the labeled DNA preparation used for the leakage test (isee the discussion of the slow rate constant below).

Other changes in the protamine that is bound to the resin may be responsible, in part, for the observed decrease in binding. These changes could include oxidation of the sulfhydral groups by contaminating substances, self-oxidations by sulfhydral groups on the same molecule resulting in a change of the secondary structure of the protein, ester formation between the serine or threonine residues and stray organic acid, or chelating of the arginine groups by contaminating molecules with appropriate charge distributions. While these (and probably other activity loss mechanisms) are possible, other than the self-oxidation mechanism, all of them require contaminating substances. It is unlikely that contamination of this type would be consistent from preparation to preparation. On the basis of the relatively consistent results seen in the experiments reported here (and other unreported tests), it is unlikely that there is a large variability in activity loss rates, which would tend to eliminate any mechanism relying on contamination. Self-oxidation 20 is still a possibility. Tests where the resin is stored in the presence of low concentrations of DTT could be used to determine if this mechanism is present. 
Of the five requirements for a useful solid substrate that are listed above, the only one not evaluated here is the effect of the carbamate linkage on the DNA binding characteristics of protamine P1. It can be noted that the time zero binding ratio for the carbamate and thiol resins are significantly different. This could be caused by two different mechanisms; a higher binding affinity between DNA and thiol-linked protamine than for carbamate linked protamine or more efficient substitution of protamine, with the thiol linkage verses the carbamate-linkage. A difference in efficiency of substitution could result from two possible mechanisms, the first being an inherently faster reaction rate for the thiol linkage, and the second, lower accessibility for the carbamate linkage (due to the shorter linker arm for that resin preparation). Adequate evaluation of this issue will have to await the preparation of a resin substrate with an extended linker arm fitted with the imidazolyl carbamate linker group on the end. Preparations of this type will allow more separation between the protamine and the solid support, which should reduce any interaction between the two. This is particularly true if the linker arm used is flexible.

Protamine-DNA Complex Dissociation Rate. The measurement of the protamine P1-DNA complex's dissociation rate reported here is subject to an important caveat. The presence of the slow rate constant in the data means that a separation of the data related to the two rate constants must be performed. This procedure can produce negative values for the count ratio attributed to the fast rate constant (the one of interest). These negative values are the combined result of noise in the data points being used in the separation and errors in the model for the slow rate constant.

If there were no slow rate constant in this data, all the data points would be greater than zero (by definition of the scintillation count method) and data 
points close to a zero count ratio would have a one sided error (noise) $F$ distribution. The presence of the slow rate constant means that data points that would otherwise be ciose to zero ratio (and have an $F$ distribution of error) will have higher ratios and a more Gaussian error distribution.

Normally, Gaussian error distributions make data analysis easier and model fitting more likely to yield valid results (due to a simpler mathematical description of the variation of the data). ${ }^{29}$ Unfortunately, because dissociations are first order processes, a linear fit to the data must be done after taking the log of the data. The presence of negative numbers in the data is incompatible with this mathematical function, so the negative values must be discarded. The likelihood that a data point will be transformed into one with a negative value when the slow rate constant is stripped out of the data is effected by the initial value of the data point. Data points that are taken at a point in the experiment where the fast rate constant process has been nearly completed will have values that are approximately equal to the value predicted by the model for the slow rate constant process alone; noise in these data points may result in a negative value when the predicted value is subtracted from them.

Due to this effect, data points near the end of the fast rate process may be biased to higher label binding ratios (the data points that for one reason or another are low tend to become negative when the slow rate constant model is subtracted from them). For this reason it is desirable to take a larger number of data points at the beginning of the fast rate constant process (before about 30 minutes of dissociation in this case) to insure that this effect is minimized. Unfortunately due to the logistics of the experimental procedure the practical limit for data points in the first $\mathbf{3 0}$ minutes of dissociation was 
about 4. Inclusion of data points at the 60 minute dissociation point may tend to lower the estimation of the fast rate constant. For that reason the fast rate constant derived here may be somewhat iower than the actual rate constant.

Previous results for the dissociation rate constant of bull protamine $\mathrm{P} 1$ and the 12 bp oligomers used here, under the $\mathrm{NaCl}$ concentration used here (100 $\mathrm{mM}$ ) and using the thiol linked resin, were reported as $5.3 \pm 2.6 \times 10^{-3} \mathrm{~min}^{-1}$ $\left(8.9 \pm 4.4 \times 10^{-5} \mathrm{sec}^{-1}\right) .22$ When this value is compared with the value reported here for the thiol resin, $0.010 \pm 0.019 \mathrm{~min}^{-1}\left(1.7 \pm 3.1 \times 10^{-4} \mathrm{sec}^{-1}\right)$, it can be been that there is about a factor of 2 difference. Due to the large variation in the result for the thiol linked resin reported here, it is not possible to determine if this difference is significant.

When the previous result with the thiol resin is compared with the result obtained here with the CDI activated resin, $0.0247 \pm 0.0051 \mathrm{~min}^{-1}(4.12 \pm$ $0.85 \times 10^{-4} \mathrm{sec}^{-1}$ ) it is apparent that there is a significant difference between the two. Even taking the two values to the limit of their 1 sigma variance still leaves a difference of a factor of 2 between them. The larger value of the rate constant reported here may be due to either unidentified differences between the experimental conditions or to the difference between the binding mode of protamine for the two resins. If the difference is caused by the resin binding modes, then it is likely that there are significant interactions between the resin and the protein in the case of the CDI activated linkage. (The higher rate constant for this resin indicates that the protamine is not binding the DNA as tightly as it does when linked through a thiol group, indicating strain between the CDI activated resin and the protein.) Resolution of this issue may require the use of a $\mathrm{CDI}$ activated resin with a longer, flexible, linker arm. 
Origin of the Slow Rate Constant. The experiments performed to evaluate the source of the slow rate constant process that appeared in all of the dissociation and assay experiments clearly indicate that the only component needed to produce the effect is [y-33P]ATP. Although it is possible to hypothesize complex mechanisms that involve the dissociation containers or the HEPES- $\mathrm{NaCl}$ dissociation buffer, the simplest explanation of this process is the slow hydrolysis of the ATP molecules when at room temperature conditions. This explanation assumes that the nitrocellulose filters used have some finite number of binding sites for ATP and that there are significantly fewer sites that bind free phosphate. The Quickspin columns that are used for separating the labeled DNA from residual ATP are 90 to 95 $\%$ efficient at retaining the ATP, according to the manufacturer. Therefore, it is reasonable that some residual ATP exists in the stock labeled DNA. Measurements made in one experiment indicates that the Quickspin retained $89 \%$ of the ATP introduced into it (there was no DNA or T4 polynucleotide kinase mixed with the ATP). If this ATP hydrolyzes at $25^{\circ} \mathrm{C}$ much faster than at the DNA storage temperature of $4^{\circ} \mathrm{C}$, as would be expected, then the results found in the dissociation and assay experiments can be explained by this process.

Because the slow rate constant seen in all of the experiments in this study contributes significantly to the errors in deriving the dissociation rate constant, eliminating this process could improve the results of the protocol. An additional benefit would be that experiments could be run in half a day rather than a day and a half, making the process of gathering enough data for accurate rate constant determination much faster. 
Two possible methods for eliminating the slow rate constant come to mind. One possibility is passing the labeled DNA through two Quickspin columns in sequence. If each removes $90 \%$ of the residual ATP the result would aimost eliminate the this problem. However, this procedure would need to be checked as there is no guarantee that the Quickspin columns would give the same results at low ATP concentration as they do at the higher concentrations now in use.

A second possibility would be to store the labeled DNA at some elevated temperature $\left(25^{\circ} \mathrm{C}\right)$ for an extended period of time ( 2 to 4 days). The risk here is that the DNA would degrade or be transformed into free nucleotides by contaminating bacteria during this time.

Context of this Experimental System. The binding of protamine to double stranded DNA is not a simple first order reaction in most experimental systems used. This is because protamine molecules bind without sequence specificity to the DNA (that is they can bind to any position along the length of the DNA molecule, independent of the base sequence of the DNA) coupled with the property that when the protamine does bind a DNA molecule, it protects a stretch of the DNA from other protamines. Another difference between protamine binding DNA and a simple first order process is that protamine binding is highly cooperative.6,17,32

A model for binding of this type has been described by McGhee and von Hippel. ${ }^{33}$ In the model, three parameters for the characterization of binding between the polymer (DNA) and the ligand (protamine) are defined: $n$, the length of the binding site on the polymer in terms of the number of monomer units covered by the ligand; $K$, the equilibrium constant with no cooperativity; and $\omega$, the cooperativity coefficient. 
Cooperativity is modeled by $M^{c} G$ hee and von Hippel for three different cases; an isolated ligand, a ligand binding to the polymer at a site adjacent to another ligand and a ligand binding at a site between two other ligands. Binding is considered cooperative only if two ligands bind such that there are no unoccupied monomer sites between them. For cases of binding where the ligand is isolated, the basic equilibrium constant, $K$, describes the strength of binding. In cases where there is a single adjacent ligand, the effective binding constant is $\omega^{*} \mathrm{~K}$. For cases with two adjacent ligands, the equilibrium constant is $\omega^{2}{ }^{*} \mathrm{~K}$. Larger values of $\omega$ indicate that the ligands tend to bind in cooperative clusters along the length of the polymer.

Reports by Nakono et al.6, Tobita et al. ${ }^{17}$ and Watanabe and Schwarz ${ }^{32}$ give cooperativity factors, $\omega$, of 300 to 1700 . Values of $\omega$ this high indicate that in experimental systems where protamine and long DNA molecules are used, the dominate binding and dissociation activity will be of ligands on the ends of ligand clusters. This is because central ligands in a cluster are too tightly held to dissociate except under conditions of extremely low protamine concentration, where the clusters themselves are unstable due to dissociation of the ligand on the cluster ends. Under very high protamine concentrations, isolated protamine binding and dissociation would dominate except that virtually all the binding sites on the DNA would be tied up in clusters of protamine ligands. As a result of this property of the experimental system, independent determination of $\mathrm{K}$ and $\omega$ can be quite difficult.

Hopefully, use of an experimental system such as the one described here where the protamine is immobilized and cooperative binding is not possible, should allow the measurement of thermodynamic and kinetic properties without the complications inherent in other types of systems. For this type of 
system to be useful, verification is needed that the properties measured in the system are the same properties that determine the behavior of protamine and DNA in free solution.

This study was formulated to examine the kinetic properties of the protamine-DNA system, specifically the complex dissociation rate constant. Measurements of protamine-DNA complex dissociation rate constants have been rare up to this time. Watanabe and $S c h w a r 2^{32}$ have reported a $k_{2}$ value of $0.29 \mathrm{~s}^{-1}$ and an $\omega$ factor 1700 for herring protamine with calf thymus DNA in $400 \mathrm{mM} \mathrm{NaCl}$ at $20^{\circ} \mathrm{C}$ and $\mathrm{pH}$ 7.5. Direct comparison with the result reported here is virtually impossible. The $\mathrm{pH}$ and temperature differences between the two measurements are not likely to be the cause of the $21 / 2$ orders of magnitude difference between the results, but the salt, protamine and DNA concentrations in the two procedures are completely different.

There is a need to conduct a set of experiments with the system used here that duplicates, at least of the major variables, the conditions of one or more of the free solution systems that have been examined by other researchers. This would allow a direct comparison of the derived properties in the different systems. If it is verified that the system described here (or in other related work ${ }^{22}$ ) can accurately measure the non cooperative kinetic and/or thermodynamic properties of the protamine-DNA system, then use of this type of experimental system could significantly simplify characterization of protamine-DNA complexes (or other highly cooperative systems). 


\section{Conclusions}

Protamine Substitution on Imidazolyl Carbamate Activated Resin. The initial purpose of this study was to determine the usefulness of a carbamate linked resin in the study of protamine-DNA interactions. The data presented here indicates that bull protamine $P 1$ can be successfully linked to a imidazolyl carbamate activated resin, such as REACTI-GEL $6 \mathrm{X}$, with a relatively simple protocol. Additionally, the linkage, once made, is quite stable. This allows for easy usage of the modified resin without any extraordinary storage, handling or timing requirements.

On the other hand, the amount of protamine that is substituted onto the resin has been difficult to control. This could be related to the $\mathrm{pH}$ used in the protocol described here (a pH of 8 to $\mathbf{8 . 5}$ may be marginal for the carbamate linkage reaction). Alternately, it could be more related to the stability of the free protamine than to any inherent properties of the imidazolyl carbamate activated resin. If the cause of the substitution difficulty is the former mechanism, it may be possible to improve the protocol by optimizing the $\mathrm{pH}$ used in the linkage reaction. If the problem is related to the latter mechanism, this problem will probably effect all types of studies of protamines, even free solution studies.

Throughout this investigation, higher concentrations of protamine were needed during the linkage step to obtain DNA binding than was reported to be needed with the thiol activated resin.22 This could have two possible causes; either the efficiency of substitution of protamine P1 onto the imidazolyl carbamate resin is not as high as the efficiency of substitution using thiol activated resins or much of the protamine that bound to the CDI activated resin was unable to bind DNA due to structural or steric effects. If the 
efficiency of substitution is the cause of the requirement for higher protamine concentration, the effect may be related to the strongly competing hydrolysis of the imidazolyl carbamate catalyzed by the presence of hydroxide. This competing reaction would significantly lower the availability of binding sites for protamine, even though the initial number of binding sites is in great excess of the available protamine. If the second possibility, the lack of accessible P1 on the resin, is the cause, it will have to be examined in further studies with longer linker arms on the resin.

Two other factors affecting the carbamate substitution which have a lesser effect or do not affect the thiol substitution are the $\mathrm{pH}$ at which the reaction is carried out and the proportion of primary amines ( $\mathrm{N}$-terminal amines on the protamine molecules) that are ionized.

The stability problems of free protamine $\mathrm{P} 1$ preparations are apparently not confined to the formation of intra- and inter-molecular disulfide bridges. The poor substitution found in this study, when the light scattering property of the protamine solution was high, indicate that the amino terminus of the protein is either hidden or substituted during the aggregation process.

Dissociation of DNA and Bull Protamine P1. Measurement of the dissociation rate constant for double stranded DNA and bull protamine P1 was made under controlled temperature, $\mathrm{pH}$ and salt conditions. This value was determined to be $4.12 \pm 0.85 \times 10^{-4} \mathrm{~s}^{-1}$ at $25^{\circ} \mathrm{C}, \mathrm{pH}$ of 7.40 and a $\mathrm{NaCl}$ concentration of $100 \mathrm{mM}$.

The protocol used for the determination of the dissociation rate constant also produced a slower rate constant component than was evident even in preparations that contained no protamine or resin. This rate constant is apparently associated with a slow change in the background binding of label 
on the filter used to separate the solid support for the protamine from the supernatant. Experiments indicate that the most likely source of this slow change is the gradual hydrolysis of the $y$ phosphate from residual [y-33P]ATP from the DNA labeling operation. This hypothetical mechanism proposes that the nitrocellulose filters used in the procedure have a finite number of binding sites for the ATP molecule, but fewer (if any) binding sites for free phosphate.

Finally, a procedure has been developed that allows data from multiple experiments, with differing substitution levels on the resin supports and differing specific activity and DNA concentrations, to be combined. This procedure permits sufficient data to be accumulated to ensure that an accurate dissociation rate constant can be determined.

Future Directions. The simplest extension of the work reported here is variation of the temperature used for dissociation. This will allow an activation energy for the dissociation process to be determined. Obtaining the activation energy would be a significant accomplishment in that each of the possible types of bonds that could form between DNA and protamine molecules have distinctive bond energies. The activation energy of dissociation may give some indication of the type of bond that must be broken in the rate limiting step of dissociation .

Further work could be done to expand this information by varying the salt concentration and type (i.e., $\mathrm{MgCl}_{2}$ or $\mathrm{KCl}$ rather than $\mathrm{NaCl}$ ). Also, variation of the oxidation potential (which would effect the state of possible intramolecular disulfide bonds) could produce information on the importance of the protamine's configuration to DNA binding. Experiments of this type would provide further information on the environment in which the rate limiting bond(s) exist(s). 
Another extension of this work would be the variation of the length of the linker arm used to attach the protamine molecules to the carbamate substrate. The arm provided on the commercially available REACT!-GE! (6X) resin is quite short. If there is some interference between the support resin and the DNA binding site on the protamine molecules, then the dissociation rate constant and activation energy would be effected. Verification that this is not the case is important in the interpretation of the meaning of data acquired with the procedures described here.

Finally, the methods used here could be extended to protamine P1's from other species. Human protamine P1, like bull P1, lacks any lysine residues; it would therefore be a good candidate for further work with this system. Other species could also be studied by the use of site specific mutagenesis to eliminate the lysines from the molecule. However, that would require significantly more work and determination of the dissociation properties of the molecules would likely be just a small part of any project of that type. 


\section{References}

1 Adams, R. L. P.; Knowler, J. T.; Leader, D. P.The Biochemisty of Nucleic Acids, 10th edition; Chapman and Hall: Now York, 1986; Chapter 3.

2 Ingles, C. J.; Trevithick, J. R.; Smith, M.; Dixion, G. H. Biochem. Biophys. Res. Commun. 1966, 22, 627-634.

3 Louie, A.; Dixon, G. H. J. Biol. Chem. 1972, 247, 5498-5505.

4 Louie, A.; Dixon, G. H. J. Biol. Chem. 1972, 247, 7962-7968.

5 Louie, A. J.; Dixon, G. H. Can. J. Biochem. 1974, 52, 536-546.

6 Nakano, M.; Kasai, K.; Yoshida, K.; Tanimoto, T.; Tamaki, Y.; Tobita, T. J. Biochem. 1989, 105, 133-137.

7 Tobita, T.; Nomoto, M.; Nakano, M.; Ando, T. Biochim. Biophys. Acta $1982,707,252-258$.

8 Mazrimas, J. A.; Corzett, M.; Campos, C.; Balhorn, R. Biochim. Biophys. Acta 1986, 872, 11-15.

9 Winkfein, R. J.; Nishikawa, S.; Connor, W.; Dixon, G. H. Eur. J. Biochem. 1993, 215, 63-72.

10 Retief, J. D.; Winkfein, R. J.; Dixon, G. H. Eur. J. Biochem. 1993, 218 , 457-461.

11 Suau, P.; Subirana, J. A. J. Mol. Biol. 1977, 117, 909-926.

12 Balhorn, R.; Gledhill, B. L.; Wyrobek, A. J. Biochemistry 1977, 16, 4077-4083.

13 Marushige, Y.; Marushige, K. J. Biol. Chem. 1975, 250, 39-45.

14 Gatewood, J. M.; Cook, G. R.; Balhorn, R.; Schmid, C. W.; Bardbury, E. M. J. Biol. Chem. 1990, 265, 20662-20666. 
15 Gatewood, J. M.; Schroth, G. P.; Schmid, C. W.; Bradbury, E. M. J. Biol.Chem. 1990, 265, 20667-20672.

i6 Hinilica; Siein; Siein Histones and Other Basic Nuclear Proteins; CRC Press, 1989; Chapter 11.

17 Tobita, T.; Tanimoto, T.; Nakano, M. Biochem. Inter. 1988, 16, 163 173.

18 Bonner, J.; Chalkley, G.R.; Dahmus, M.; Fambrough, D.; Fujimura, F.; Huang, R. C.; Huberman, J.; Jensen, R.; Marushige, K.; Ohlenbusch, H.; Olivera, B.; Windholm, J. Methods in Enzymology; Grossman, L.; Moldave, K., Eds.; Academic Press: New York, 1968; Section V.

19 Balhorn, R.; Corzett, M.; Mazrimas, J.; Watkins, B. Biochemistry 1991, 30, 175-181.

20 Green, G. R.; Balhorn, R.; Poccia, D. L.; Hecht, N. B. Mol. Reprod. Dev. 1994, 37, 255-263.

21 Gatewood, J. M.; Cook, G. R.; Balhorn, R.; Bradbury, E. M.; Schmid, C. W. Science 1987, 236, 962-964.

22 Wren, J.P.: M.S. Thesis, DNA-Protamine Interactions, San José State University, San José, California, 1994.

23 Bethell, G. S.; Ayers, J. S.; Hancock, W. S.; Hearn, M. T. W. J. Biol. Chem. 1979, 254, 2572-2574.

24 Hearn, M. T. W.; Harris, E. L.; Bethell, G. S.; Hancock, W. S.; Ayers, J. A. J. Chromatogr. 1981, 218, 509-518.

25 Villems, R.; Toomik, P. Handbook of Affinity Chromatography; Kline, T., Ed.; Marcel Dekker: New York, 1993; Chapter 1.

26 Marushige, Y.; Marushige, K. Biochim. Biophy. Acta 1978, 518, 440449. 
27 Balhorn, R. J. Cell Bio. 1982, 93, 298-305.

28 Tabor, S. Current Protocols in Molecular Biology, Ausubel, F. M.; Brent, R.; Kingston, R. E.; Mcore, D. D.; Seidman, J. G.; Smith, J. A.; Struhl, K., Eds.; John Wiley \& Sons: New York, 1987; section 3.10.2.

29 Young, H. D.Statistical Treatment of Experimental Data, McGraw-Hill Book Company: San Francisco, 1962; Chapter 16.

30 Moore, J. W.; Pearson, R. G.Kinetics and Mechanism, 3rd ed.; John Wiley \& Sons: New York, 1981; Chapter 8.

31 Bethell, G. S.; Ayers, J. S.; Hearn, M. T. W.; Hancock, W.S. J. Chromatogr. 1981, 219, 361-372.

32 Watanabe, F.; Schwarz, G. J. Mol. Biol. 1983, 163, 485-498.

33 McGhee, J. D.; von Hippel, P. H. J. Mol. Biol. 1974, 86, 469-489. 


\section{Appendix A: Calculation of Allowable Molar Surface Concentration for Modified Affinity Resins}

A straight forward calculation can show the maximum allowable density level of protamine substitution on the surface of the resin beads that will still isolate the molecules from each other. The resin beads in use at SJSU, both the thiol and CDI activated material, have a size range of about 45 to $165 \mu \mathrm{m}$ diameter. Assuming that the average bead is $100 \mu \mathrm{m}$ in diameter, the simple surface area of the bead is:

$$
\begin{aligned}
A_{s} & =4^{*} \pi^{*}(100 \mu \mathrm{m} / 2)^{2} \\
& =31,400 \mu \mathrm{m}^{2}
\end{aligned}
$$

And the volume of the bead is:

$$
\begin{aligned}
V & =4 / 3^{*} \pi^{*}(100 \mu \mathrm{m} / 2)^{3} \\
& =524,000 \mu \mathrm{m}^{3}
\end{aligned}
$$

If we assume that these beads are made up of $1 \mu \mathrm{m}$ diameter particles of agarose (see Figure 27) and that the modification sites of interest are all on the outer half of the outside layer of these particles, then the number of particles that make up the surface of the average bead is:

$$
\begin{aligned}
n & \approx\left(A_{s} / 12\right) *(1 / 2) * 1 \mu \mathrm{m} *(1 \mu \mathrm{m} * 1 / 2) / 3 \\
& =31,400
\end{aligned}
$$

This equation assumes a close packed hexagonal arrangement of the particles on the surface of the bead. The total surface area available for binding the protamine molecules on each bead is half the surface area of each of the $1 \mu \mathrm{m}$ diameter particles that make up the surface of the bead:

$$
\begin{aligned}
A & =n * 4 * \pi *(1 \mu \mathrm{m} / 2)^{2} \\
& =98,700 \mu \mathrm{m}^{2}
\end{aligned}
$$




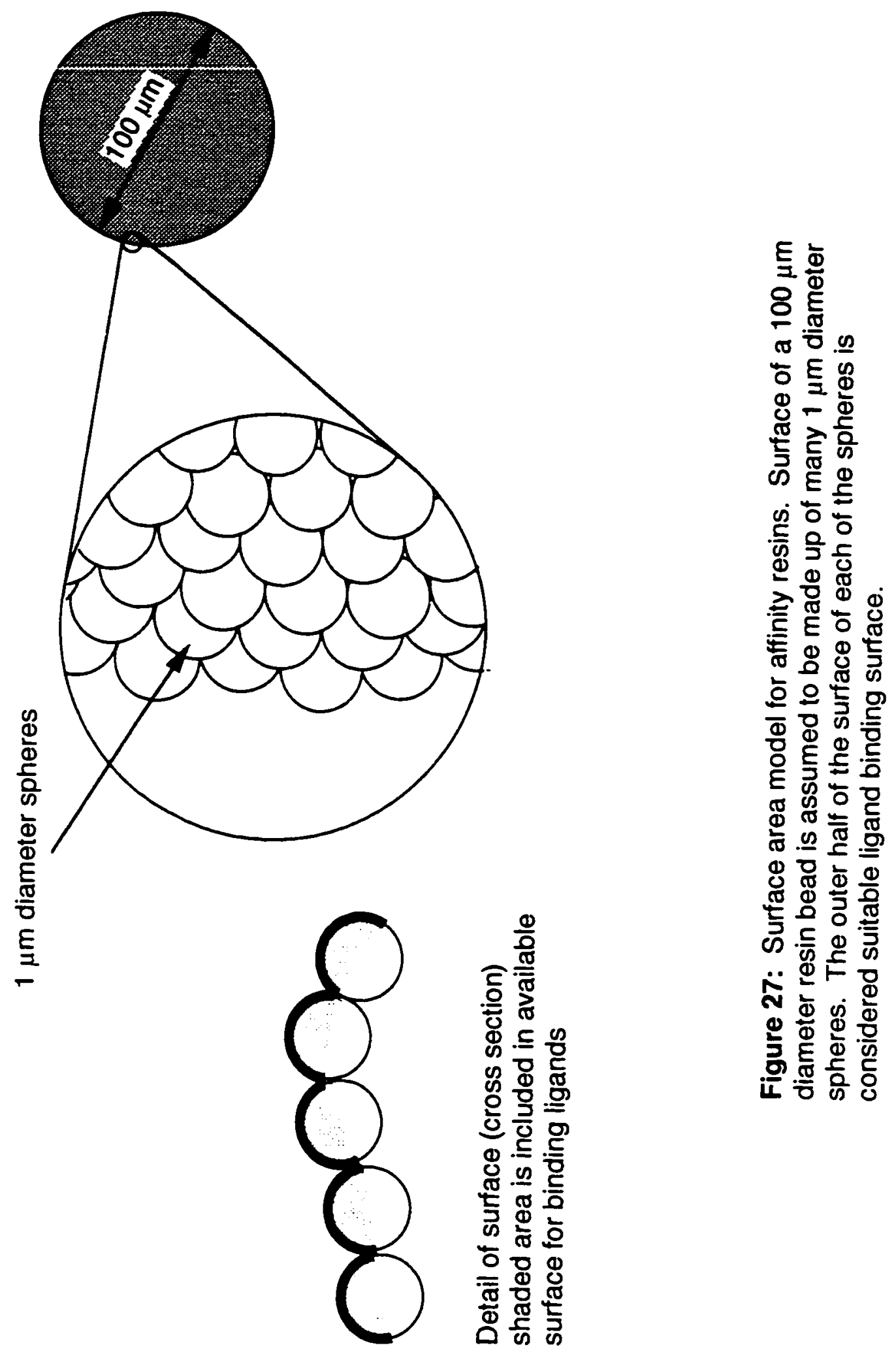


One $\mu L$ of resin contains $N$ resin beads as given by:

$$
\begin{aligned}
N & =0.740 * 10^{-3} \mathrm{~cm}^{3} / \mathrm{V} \\
& =1400
\end{aligned}
$$

This assumes a close pack arrangement of the beads. The total surface area on the beads that occupy $1 \mu \mathrm{L}$ is:

$$
\begin{aligned}
A_{1} & =A * N \\
& =139,000,000 \mu \mathrm{m}^{2}
\end{aligned}
$$

If we assume that the effect interaction range between two protamine molecules is roughly twice the length of the DNA binding site (10 to 12 nucleotides in $B$ conformation) then the average spacing between molecules needs to be at least:

$$
\begin{aligned}
S & =2 * 12 * 3.4 \mathrm{~nm} \\
& =82 \mathrm{~nm}
\end{aligned}
$$

Therefore, the area that each molecule of protamine must occupy on the surface of the bead is:

$$
\begin{aligned}
A_{p} & =\pi^{*} S^{2} \\
& =0.021 \mu \mathrm{m}^{2}
\end{aligned}
$$

To complete the calculation, the maximum number of protamine molecules that could be packed onto the resin beads that occupy $1 \mu L$ of volume is:

$$
\begin{aligned}
N_{p} & =A_{1} / A_{p} \\
& =6.62 \times 10^{9} \\
& =11 \mathrm{fmol} .
\end{aligned}
$$

This number of $11 \mathrm{fmol}$ should be taken as an order of magnitude calculation due to the number of assumptions made in the calculation. However, it does indicate that this method of studying protamine interactions with DNA (or any other interaction) involves very small amounts of material. 


\section{Appendix B: Calculation of Specific Activity for Labeled DNA}

In the DNA labeling protocol used in this study the normal ratio of ATP to DNA 5 ' ends was modified to maximize the fraction of 33p transferred to the DNA. The ratio used was $25 \mathrm{pmol}$ of ATP to $100 \mathrm{pmol}$ of DNA 5' ends. The amount of T4 polynucleotide kinase used was sufficient to transfer many times the amount of available phosphate to DNA in the time given $(13 \mathrm{nmol}$ in 30 minutes).

Under these conditions the amount of label that is transferred to the DNA is dependent on two factors. The first factor is the ratio of [ $\gamma$-33P]ATP to total ATP that is referred to as $f_{A T P}$ in equation $B 1$. This factor is important because the isotopic mass difference between phosphate groups containing 33P or ${ }^{31 P}$ is only about $2 \%$, which will produce a negligible isotope effect. Therefore, the two isotopes of phosphorus will be transferred to the DNA in the same ratio as they are present in the mixture.

The second factor is the efficiency of the transfer of phosphate groups to the DNA, $E$ in equation $B 1$. The enzyme used in the protocol has the capability of transferring $13 \mathrm{nmol}$ of phosphate to DNA $5^{\prime}$ ends during time of the reaction. However, this transfer rate is for conditions of unlimited ATP and DNA 5 ' ends and insignificant reaction products. These conditions are far different from the ones used in this procedure.

So the amount of 33P label transferred to the DNA, NDNA* in equation B1, can be expressed as shown:

$$
\text { NDNA* }=\text { NATP }^{*} \text { fATP }^{*} E
$$

In this equation NATP is the total number of ATP molecules in the mixture.

The value of $f_{A T P}$ can be calculated from either the specific activity of the ATP or from the decay count rate of a sample of the labeling mixture before it 
is placed on the separation column. To calculate $f_{A T P}$ with either method, the first step is to determine the number of ${ }^{33 P}$ atoms present in the ATP solution. This can be done with the equations below.

$$
\begin{aligned}
& r=-\ln (0.5) / t_{1 / 2} \\
& f=1-\exp \left(-r^{*} t\right)
\end{aligned}
$$

In these equations, $t_{1 / 2}$ is the half life of ${ }^{33} P, r$ is the decay rate constant, $f$ is the fraction of $33 \mathrm{P}$ atoms that decay in a given time and $\mathrm{t}$ is the time interval (in the same units as $t_{1 / 2}$. For ${ }^{33} \mathrm{P}, \mathrm{f}$ is equal to $1.96 \times 10^{-5} \mathrm{~min}^{-1}$.

Calculation of $f_{\text {ATP }}$ from an aliquot of labeling mixture is done by dividing the measured counts per minute, $C_{A T P}$, of the sample by $f$ and by the known amount of ATP in the aliquot (NATP, in molecules, not moles).

$$
f_{\text {ATP }}=C_{\text {ATP }} / f / N_{\text {ATP }}
$$

For experiment 14 , a typical DNA and resin preparation experiment, the pre-separation column count, $C_{A T P}$, was $528033 \mathrm{cpm}$, and the number of molecules containing phosphorus (ATP and phosphorus transferred to DNA 5' ends) was $3.01 \times 10^{11}(1 \mu \mathrm{L}$ of a solution containing $5 \mu \mathrm{L}$ of $5 \mu \mathrm{M}$ ATP in a total volume of $50 \mu \mathrm{L}$ ). This gives an $\mathrm{f}_{\text {ATP }}$ value of 0.090 . The specific activity of the ATP can be calculated from fATP or more directly by dividing the count rate by the number of moles in the aliquot. In this example, the specific activity of the ATP was $476000 \mathrm{Ci} / \mathrm{mol}$.

A similar calculation can be made for the DNA in the final labeled DNA preparation if the assumption is made that all of the decay count rate measured in an aliquot of the final labeled solution results from ${ }^{33 P}$ on $5^{\prime}$ ends of DNA.

$$
f_{D N A}=C_{D N A} / f / N_{D N A} *
$$


For experiment 14 the count rate of the final labeled DNA solution was $243844 \mathrm{cpm}$ and the amount of DNA in the aliquot was $1 \mathrm{pmol}(1 \mu \mathrm{L}$ aliquot of a $50 \mu \mathrm{L}$ solution containing $50 \mathrm{pmol}$ of DNA). This results in an fDNA of 0.021 and a specific activity of $110000 \mathrm{Ci} / \mathrm{mol}$.

There are two complications to this last calculation. The separation column used to remove unreacted ATP does not remove all of the ATP and it does not elute all of the DNA. The manufacturer of the separation columns states that at least $95 \%$ of the unreacted ATP will be removed from the labeling mixture and that at least $80 \%$ of the oligomer (longer than $10 \mathrm{bp}$ ) will pass through the column, when used according to specifications. These factors can be taken into account in calculating the fraction of DNA that receives a $33 \mathrm{P}$ label and to calculate the amount of ATP (both ${ }^{33 P}$ and ${ }^{31} \mathrm{P}$ ) that is present in the final DNA preparation.

We can define $C_{f}$ as the count rate of the final DNA preparation and $C_{0}$ as the count rate of the solution before it passes through the separation column. Additionally variables for the count rate of the labeled DNA at the two points in the protocol where count rates are taken can also be defined; $C_{D r}$ is the amount of $33 \mathrm{P}$ transferred to the DNA in the labeling reaction before passing through the separation column, and $C_{D f}$ the portion of the final count rate that results from labeled DNA. Similar variables for the [ $\gamma$-33P]ATP count rates can be defined; $C_{A f}$ as the portion of the final count rate that results from $[\gamma-$ 33PJATP in the final preparation and $\mathrm{C}_{\mathrm{Ar}}$ as the amount remaining after the labeling reaction has taken place but before the solution passes through the separation column. Note that $C_{A r}, C_{D r}, C_{A f}$ and $C_{D f}$ can not be measured directly. With these definitions, equations $\mathrm{B} 6$ through $\mathrm{B} 9$ can be written.

$$
C_{f}=C_{A f}+C_{D f}
$$




$$
\begin{array}{ll}
C_{0}=C_{A r}+C_{D r} & B 7 \\
C_{A f}=0.05 * C_{A r} & B 8 \\
C_{D i}=0.80 * C_{D r} & B 9
\end{array}
$$

If these equations are now solved for $C_{D f}$ in terms of $C_{F}$ and $C_{0}$, (the two values that can be measured directly), the portion of the count rate resulting from the labeled DNA can be determined:

$$
C_{D f}=0.80 *\left(C_{f} \cdot 0.05 * C_{0}\right) /(0.80-0.05) B 10
$$

Also the portion of the count rate for the final solution that results from the un-reacted [ $\gamma$-33P]ATP can be determined from equations B6 and B9:

$$
C_{A r}=C_{f}-C_{D f}
$$

For experiment 14 the value of $C_{D f}$ is 232000 and the value of $C_{A r} 12000$.

Substituting the value of $C_{D f}$ for that of $C_{D N A}$ and $0.80 * N_{A T P}$ for $N_{A T P}$ in equation B5 gives the fraction of labeled DNA in the final solution as 0.021 and a specific activity of $131000 \mathrm{Ci} / \mathrm{mol}$.

The total amount of ATP (NATP) and the amount of labeled ATP (N ATP* $^{*}$ in the $1 \mu \mathrm{L}$ aliquot of the final solution can be determined from the calculated value of $C_{A r}$ and $f_{A T P}$ using equations $B 12$ and $B 13$ :

$$
\begin{aligned}
& N_{\text {ATP* }}=C_{\text {Ar }} / f \\
& N_{\text {ATP }}=C_{\text {Ar }} / f / f_{A T P}
\end{aligned}
$$

For experiment 14 these values are $6.12 \times 10^{8}(1.05 \mathrm{fmol})$ for $\mathrm{N}_{\mathrm{ATP}}{ }^{*}$, and 6.80 $\times 10^{9}(11.3 \mathrm{fmol})$ for N ATP.

One final refinement that can be made to these calculations is the use of experimentally determined values for the proportion of DNA and ATP that passes through the separation column. As noted above, the manufacturer of the separation column guarantees these numbers when the column is used according to specifications. However, these are minimum or maximum 
numbers and could vary in actual applications. Additionally, one of the recommendations of the manufacturer is that the columns be used with a swinging bucket centrifuge, which was not the case in this application.

Fortunately, the proportion of ATP that passes through the column under the experimental conditions can be measured directly, and was in experiment 26 (see the body of this report for the procedure used in this experiment). In experiment 26, a measurement of the count rate of an initial solution containing the [ $\gamma$-33P]ATP but no T4 kinase or DNA and the same solution after it passed through a separation column was made. The values determined from that experiment were $27474.8 \mathrm{cpm}$ (before separation) and $4060.4 \mathrm{cpm}$ (after separation), with a background of $24.2 \mathrm{cpm}$. This gives a separation ratio of 0.147 , rather than 0.05 as specified by the manufacture.

Unfortunately, there is no simple method for determining how much of the DNA is trapped in the separation column. On the other hand, because the labeled DNA is typically diluted with unlabled DNA by at least 50:1 (see Niaterials and Methods section under Dissociation and Assay Procedure), knowing the total amount of labeled DNA in the final preparation can give a reasonably accurate specific activity without knowing how much unlabeled DNA there is in the preparation.

By substituting the value of 0.147 in place of 0.050 in equations B8 and B10, a more accurate measure of the amount of labeled DNA (NDNA*), total

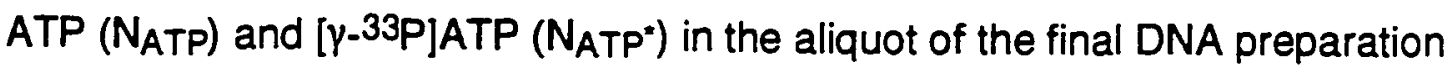
can be made. For experiment 14 the values are:

$$
\begin{aligned}
& \text { NDNA* } 1.04 \times 10^{10}(17.3 \mathrm{fmol}) \\
& N_{\text {ATP }} 2.05 \times 10^{9}(3.41 \mathrm{fmol}) \\
& \text { NATP* } 2.28 \times 10^{10}(37.9 \mathrm{fmol}) .
\end{aligned}
$$


Calculations of these three values were used in conjunction with the dates the DNA was prepared and used (to determine the amount of label that decayed in the intervening time) and the amount of dilution with unlabeled DNA for each of the experiments reported here (see table 2 in the body of this report). 